\title{
One hundred years of benzotropone chemistry
}

\author{
Arif Dastan ${ }^{* 1}$, Haydar Kilic ${ }^{2,3}$ and Nurullah Saracoglu ${ }^{* 1}$
}

\author{
Review \\ Address: \\ ${ }^{1}$ Department of Chemistry, Science Faculty, Atatürk University, \\ 25240, Erzurum, Turkey, ${ }^{2}$ Oltu Vocational Training School, Atatürk \\ University, 25400, Erzurum, Turkey and ${ }^{3}$ East Anotolia High \\ Technology Application and Research Center, Atatürk University, \\ 25240, Erzurum, Turkey \\ Email: \\ Arif Dastan* - adastan@atauni.edu.tr; Nurullah Saracoglu* - \\ nsarac@atauni.edu.tr \\ * Corresponding author \\ Keywords: \\ benzotropolone; benzotropone; dibenzotropone; halobenzotropolone; \\ halobenzotropone; tribenzotropone; tropone
}

\author{
Beilstein J. Org. Chem. 2018, 14, 1120-1180. \\ doi: $10.3762 /$ bjoc. 14.98 \\ Received: 27 December 2017 \\ Accepted: 20 April 2018 \\ Published: 23 May 2018 \\ Associate Editor: B. Stoltz \\ (c) 2018 Dastan et al.; licensee Beilstein-Institut. \\ License and terms: see end of document.
}

\section{Abstract}

This review focuses on the chemistry of benzo-annulated tropones and tropolones reported since the beginning of the 20th century, which are currently used as tools by the synthetic and biological communities.

\section{Review}

\section{Introduction}

Tropone (1) and tropolone (2) have fascinated organic chemists for well over one hundred years. The carbocycles $\mathbf{1}$ and $\mathbf{2}$ are a special variety of organic compounds and represent a nonbenzenoid type of aromatic system (Scheme 1). Their dipolar resonance structures such as tropylium oxide form $\mathbf{1 B}$ and $\mathbf{2 B}$ have been reported to provide a Hückel sextet of electrons that is necessary for aromaticity (Scheme 1) [1-9].

The tropone core is the ubiquitous structural motif in the alkaloid colchicine and in a number of other natural compounds that have shown a highly diverse range of biological activity [1-9], like the inhibitory activity of inositol monophosphatase [10,11], antitumor [12], antibiotic [12,13], and antibacterial activity [14] and lipoxygenase inhibitor activity [14-16]. Troponoids 3-10 have been reported in the literature in a number of natural forms (Figure 1) [1-8]. These compounds have a structural class spacing from the simple monocyclic tropones, such as the potent antifungal and antibiotic monoterpene $\beta$-thujaplicin (4) [17-23] (isolated from the heartwood and essential oils of trees of the family Cupressaceae), to complex macrocyclic analogues, such as harringtonolide (5) [24-26], which was found to have antineoplastic and antiviral properties, and caulersin (6) [26], which is a biologically active natural tropone fused to indole rings (Figure 1). Benzo-annulated cycloheptanones (as colchicine [8], allocolchicine), benzo[7]annulenones, or benzotropones (as purpurogallin) and their analogues are present in a great variety of pharmacologically relevant natural products [27-29]. Colchicine (7, from Colchicum autumnale) is 
<smiles>[R]c1cccccc1=O</smiles>

$1 \mathrm{R}=\mathrm{H}$

$2 \mathrm{R}=\mathrm{OH}$<smiles>O=c1cccccc1</smiles>

$1 \mathrm{~A}$
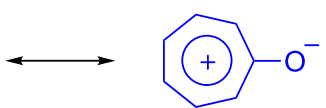

$1 B$

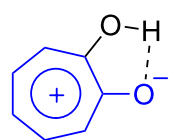

2B

Scheme 1: Tropone (1), tropolone (2) and their resonance structures.

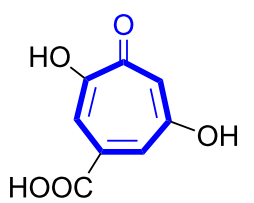

3

stipitatic acid

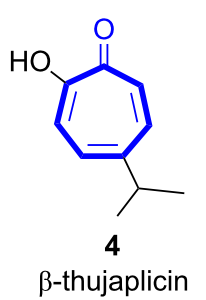

$\beta$-thujaplicin

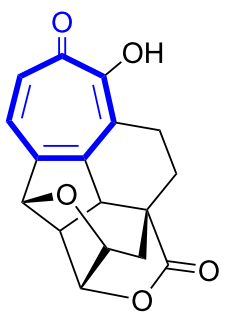

5

harringtonolide<smiles>COC(=O)c1cc2c([nH]c3ccccc32)c(=O)c2c1[nH]c1ccccc12</smiles>

caulersin<smiles>O=c1cc([C@@H]2Oc3cc(O)cc(O)c3C[C@H]2O)cc2c(O)c1C(O)=C(O)C=C2[C@@H]1Oc2cc(O)cc(O)c2C[C@H]1O</smiles>

Figure 1: Natural products containing a tropone nucleus.

a medication most commonly used to treat gout and familial Mediterranean fever (Figure 1) [30]. Colchicine and its analogues are potent microtubule-polymerizing agents and they inhibit growth of human cancer cell lines and show antimitotic activity [31-36]. Purpurogallin (8), which is biogenetically produced by oxidation of pyrogallol, and its analogues (like 9) are natural pigments (Figure 1) [37-44]. Theaflavin (10) and its derivatives, named theaflavins, are antioxidant benzotropones that are formed by the enzymatic oxidation of black tea and have been found to have numerous biological activities such as antipathogenic and anticancer activity, and they prevent heart disease, hypertension, and diabetes (Figure 1) [39,43]. Because of the pharmacological relevance of benzotropone analogues, the development of new and efficient synthetic methods is one of the major goals for future research in chemistry. Perhaps most importantly, the continued interest in troponoids systems originates from the fact that such compounds can be used as both building blocks and starting materials in the synthesis of complex natural products [1-9].

To date, the chemistry of tropone (1) and tropolones $\mathbf{2}$ has been reviewed [1-9], but there have been no surveys covering benzotropones and benzotropolenes completely. Tang's group published a recent review limited to the synthesis of naturally occurring tropones and tropolones [9]. In addition to this, chemistry of dibenzosuberenone, which is one of the dibenzotropone isomers, has already reviewed by us [45].

There are three possible benzotropone isomers: 4,5-benzotropone (11), 2,3-benzotropone (12), and 3,4-benzotropone (13, Figure 2). The present review focuses on the chemistry of parent benzotropones and their hydroxy analogues (benzotropolones) in the hundred years from the beginning to the present day, because these classes of molecules still attract noticeable attention from the synthetic and biological communities due to emerging reports of their interesting chemical struc-<smiles>O=c1ccc2ccccc2cc1</smiles>

11<smiles>O=c1ccccc2ccccc12</smiles>

12<smiles>O=c1cccc2ccccc2c1</smiles>

13
Figure 2: Possible isomers 11-13 of benzotropone. 
tures and potential biological activities. Historically, many efforts have been devoted to the chemistry of benzotropones/ benzotropolones and a plethora of benzotropone-type molecules have been produced over 100 years. Furthermore, the scope of this review includes the chemistry of halo-benzotropones, halo-benzotropolones, dibenzotropones, dibenzotropolones, tribenzotropone, and tropoquinones in addition to parent benzotropones and benzotropolones. The numerous functionalized benzotroponoids are excluded from the review.

\section{Chemistry of 4,5-benzotropone (11)}

Several research studies have been reported on the synthesis and properties of 4,5-benzotropones since they were first prepared by Thiele and Weitz nearly a century ago [46,47]. Similar approaches of this method was independently studied by Cook [48] and Föhlisch [49] groups. In 1975, the crystal and molecular structure of 4,5-benzotropone (11) was determined by Hata's group [50]. X-ray diffraction analysis showed that the molecule is approximately planar and the bond alternation in the seven-membered ring and $\mathrm{C}=\mathrm{O}$ bond length support satisfactory aromaticity.

\subsection{Synthesis of 4,5 -benzotropone (11)}

2.1.1. Oxidation of benzo[7]annulenes: 4,5 -Benzotropone (11) was synthesized for the first time via oxidation with selenium dioxide of 7H-benzo[7]annulene (14, Scheme 2) [39-45]. Furthermore, the direct oxidation of $5 H$-benzo[7]annulene to benzotropones was examined by Srivastava and Dev [37]. The selenium dioxide oxidation of $5 H$-benzo[7]annulene (15) furnished not only 4,5-benzotropone $(\mathbf{1 1} ; 27 \%)$ but also 2,3benzotropone (12; 13\%, Scheme 2).

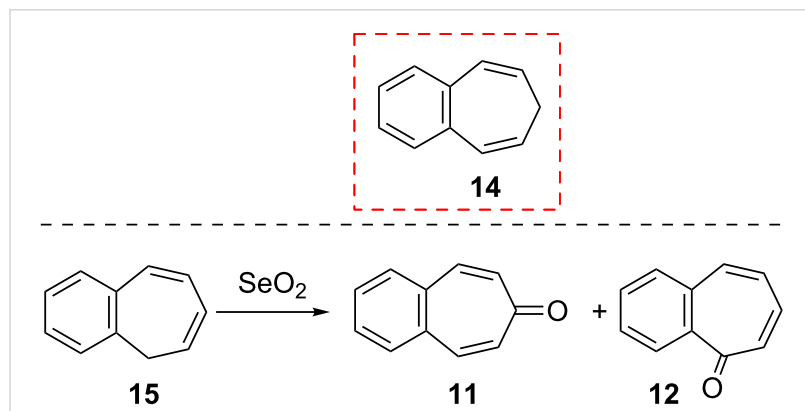

Scheme 2: Synthesis of benzotropones 11 and 12.

Pomerantz and Swei [51] investigated the oxidation of benzotropylium cation 16 with several oxidants. The oxidants used and results obtained are summarized in Table 1 and Scheme 3. Oxidation of benzotropylium fluoroborate (16) with $\mathrm{Na}_{2} \mathrm{O}_{2}$ and $\mathrm{KO}_{2}$ gives benzotropones as the major products, whereas oxidation with $m$-chloroperoxybenzoic acid ( $m$-CPBA)

Table 1: The oxidation of benzotropylium fluoroborate (16).

reagent/solvent

products/absolute yields

\begin{tabular}{|c|c|c|c|c|c|c|c|c|}
\hline & 11 & 12 & 15 & 17 & 18 & 19 & 20 & 21 \\
\hline $\mathrm{Na}_{2} \mathrm{O}_{2} / \mathrm{Me}_{2} \mathrm{SO}$ & 56 & 4 & 4 & - & trace & trace & - & - \\
\hline $\mathrm{Na}_{2} \mathrm{O}_{2} / \mathrm{CH}_{2} \mathrm{Cl}_{2}$ & 45 & 14 & 15 & - & trace & trace & - & - \\
\hline $\mathrm{KO}_{2} / \mathrm{DMF}$ & 25 & 4 & 4 & - & trace & trace & - & - \\
\hline $\mathrm{Na}_{2} \mathrm{O}_{2}(90 \%) / \mathrm{THF}$ & 3 & 13 & 0.5 & 0.9 & 2 & 3 & 5 & 13 \\
\hline $\mathrm{Na}_{2} \mathrm{O}_{2}(30 \%) / \mathrm{THF}$ & 9 & 13 & 1.2 & 2 & 9 & 13 & 2 & 4 \\
\hline$m-\mathrm{CPBA} / \mathrm{CH}_{2} \mathrm{Cl}_{2}$ & 17 & 5 & 10 & 0.7 & 3 & trace & - & - \\
\hline$t-\mathrm{BPA} / \mathrm{CH}_{2} \mathrm{Cl}_{2}$ & 6 & 0.2 & 0.4 & 1 & trace & trace & trace & 8 \\
\hline
\end{tabular}

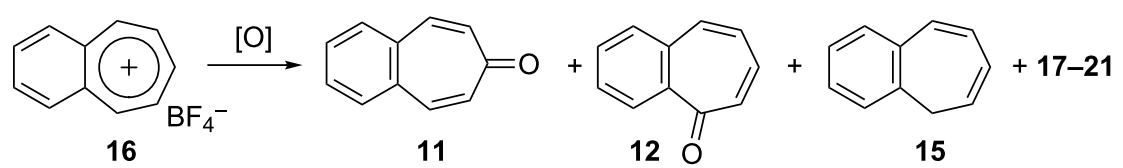<smiles>c1ccc2ccccc2c1</smiles>

17<smiles>O=Cc1cccc2ccccc12</smiles>

18<smiles>O=Cc1ccc2ccccc2c1</smiles>

19<smiles>O=C(O)c1cccc2ccccc12</smiles>

20<smiles>O=C(O)c1ccc2ccccc2c1</smiles> 
produces a small amount of ring-contracted naphthaldehydes along with benzotropones. The oxidation with $\mathrm{Na}_{2} \mathrm{O}_{2}$ gives slightly higher amounts of benzotropones than of naphthaldehydes. As shown in Table 1, the most suitable reaction conditions to obtain 4,5-benzotropone (11) with the Pomerantz and Swei procedure include $\mathrm{Na}_{2} \mathrm{O}_{2} / \mathrm{Me}_{2} \mathrm{SO}$.

Mechanistic and synthetic aspects of the reaction of 7-bromo$5 \mathrm{H}$-benzo[7] annulene (22) with $\mathrm{CrO}_{3}$ and $\mathrm{SeO}_{2}$ as oxidation reagents were studied (Scheme 4) [52]. All reactions provided 4,5-benzotropone (11) in addition to a few benzotroponoid compounds 23-26, the structures of which were determined by means of spectral data and chemical transformations. It is deemed that the dibromides $\mathbf{2 4}$ and $\mathbf{2 5}$ are the result of the addition of $\mathrm{HBr}$, which is formed under the reaction conditions.

2.1.2. Multistep synthesis of 4,5-benzotropone (11): The first multistep synthesis for 4,5-benzotropone (11) is the original procedure described by Thiele, Schneider, and Weitz, which involves the condensation of $o$-phthalaldehyde (27) with diethyl 1,3-acetonedicarboxylate (28), followed by hydrolysis and decarboxylation steps $[46,47]$ (Scheme 5). Similar syntheses were made by Cook's [48] and Föhlisch's [49] groups. Nevertheless, for performing large-scale synthesis, the cost of $\mathbf{2 7}$ make deterrent and an autoclave environment at $200-250{ }^{\circ} \mathrm{C}$ for final stage are an unattractive feature (Scheme 5).

Ranken's group reported a novel synthetic route to 4,5benzotropone (11) via an acid-catalyzed bridge cleavage reaction of 7-chloro-6,9-dihydro-5H-5,9-epoxybenzo[7]annulene (34) (Scheme 6) [53]. Transformation of adduct 31 to 11 starts with the synthesis of the stable cyclopropanoid tricyclic $\mathbf{3 2}$ from

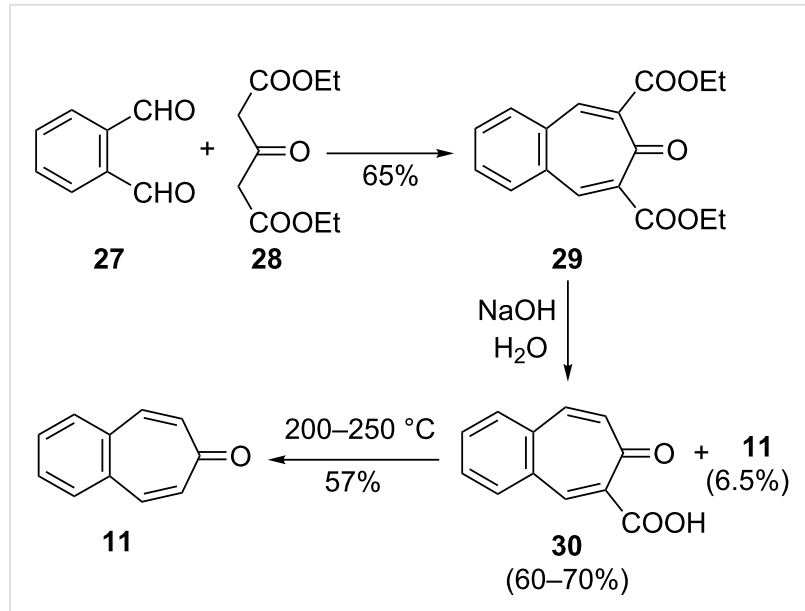

Scheme 5: Synthesis of 4,5-benzotropone (11) using o-phthalaldehyde (27).

the reaction of the 7-oxabenzonorbornadiene $\mathbf{3 1}$ with dichlorocarbene, generated by the phase-transfer method. The thermolysis of dichloride 32 in nitrobenzene at $165^{\circ} \mathrm{C}$ resulted in the formation of ring-expanded product 33. After the reduction of the allylic position with $\mathrm{LiAlH}_{4}$, the treatment of monochloride 34 with concentrated sulfuric acid in ice water afforded a quantitative yield of 4,5-benzotropone (11).

The above researchers also proposed a mechanism for the formation of $\mathbf{1 1}$ from $\mathbf{3 1}$ as shown in Scheme 7. The acid-catalyzed cleavage of the oxo-bridge of $\mathbf{3 4}$ gives benzylic carbocation 35. Consequently, after deprotonation and dehydration, chloro benzotropilium cation $\mathbf{3 7}$ undergoes hydrolysis to give 4,5-benzotropone (11) in aqueous reaction media.

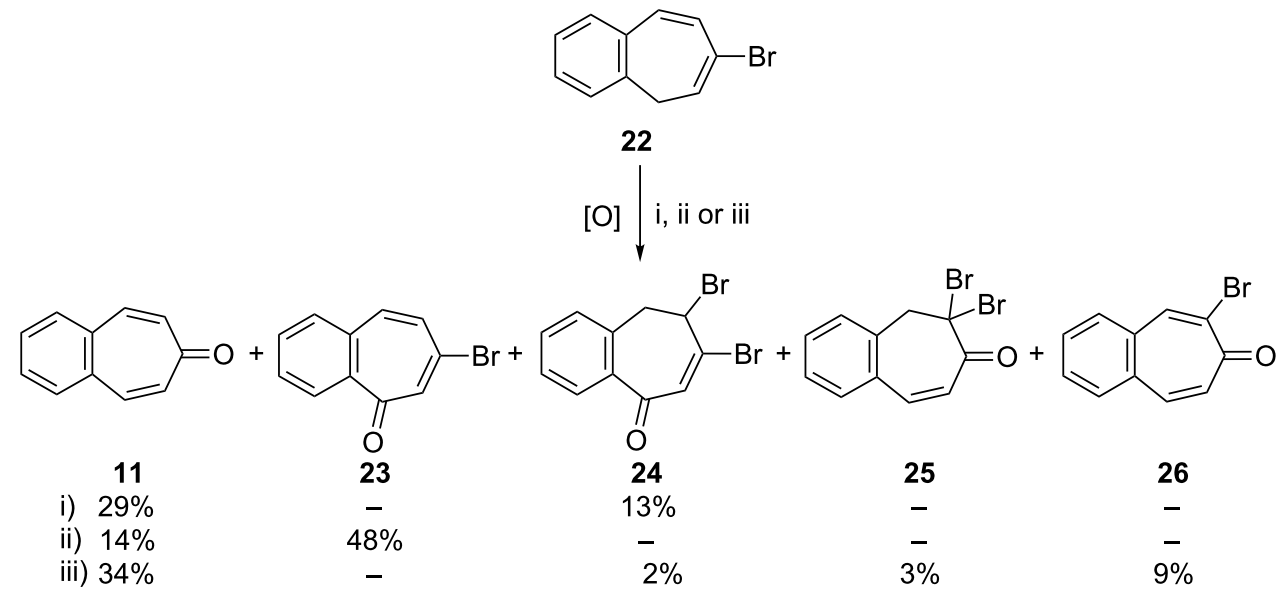

i) $\mathrm{CrO}_{3} / \mathrm{AcOH}$; ii) $\mathrm{CrO}_{3} /$ pyridine; iii) $\mathrm{SeO}_{2} / \mathrm{H}_{2} \mathrm{O}$ 

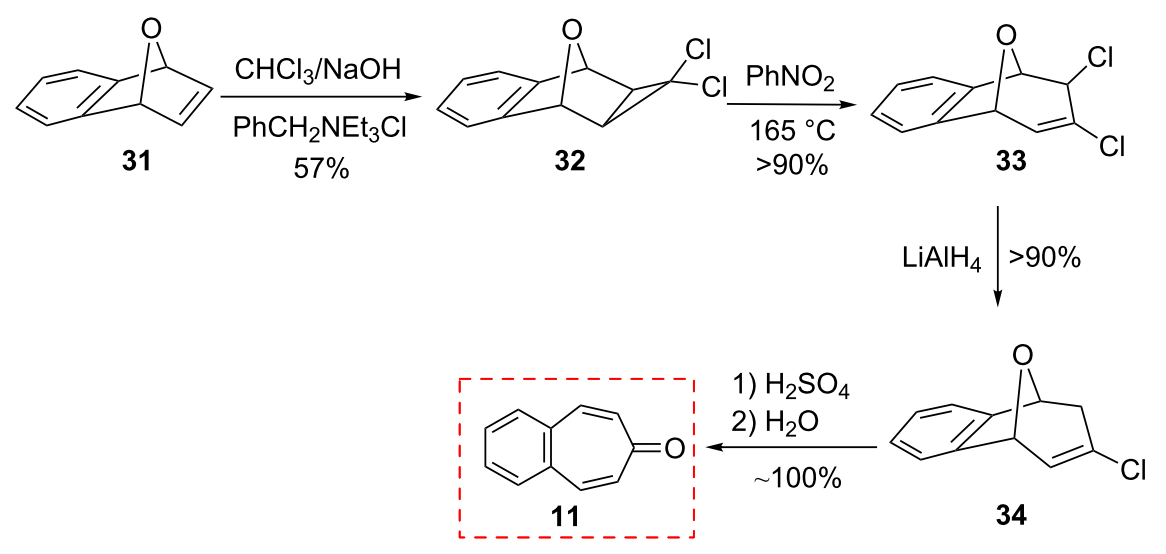

Scheme 6: Synthesis of 4,5-benzotropone (11) starting from oxobenzonorbornadiene 31.

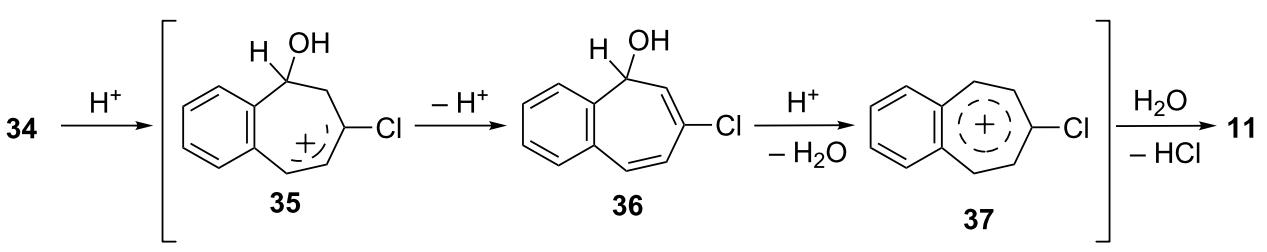

Scheme 7: Acid-catalyzed cleavage of oxo-bridge of 34 .

Using $o$-xylylene dibromide (38) as starting material, Ewing and Paquette designed and synthesized benzotropone $\mathbf{1 1}$ by an especially reliable route [54]. For this purpose, bisalkylation of $o$-xylylene dibromide (38) with tert-butyl lithioacetate (Rathke's salt) and subsequent Dieckmann cyclization provided simple access to $\mathbf{4 0}$ in $51 \%$ overall yield (Scheme 8 ). After bromination of $\mathbf{4 0}$ with molecular bromine in carbon tetrachloride, direct dehydrobromination with lithium chloride in dimethylformamide gave $\mathbf{1 1}$ in $85 \%$ isolated yield.

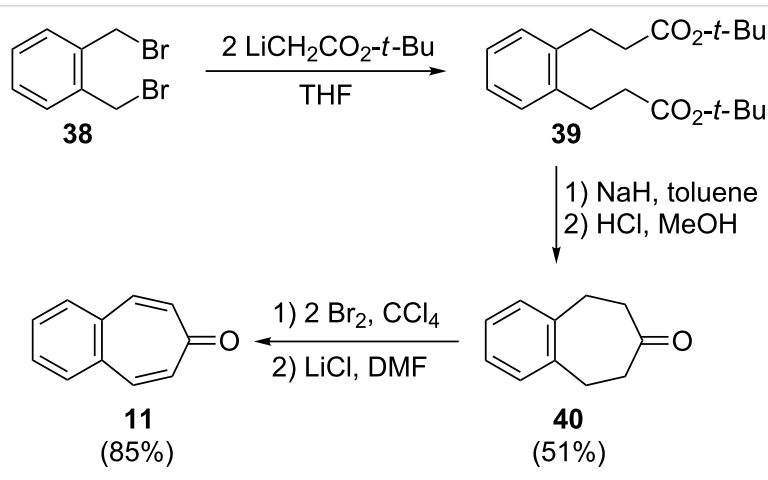

Scheme 8: Synthesis of 4,5-benzotropone (11) from o-xylylene dibromide (38).

Müller's group reported an alternative synthesis for $\mathbf{1 1}$ starting from the carbene adduct $\mathbf{4 1}$ over two or three steps [55]. Firstly, dichloride 41 was reduced with $\mathrm{LiAlH}_{4}$ in ether to give the monochloride $\mathbf{4 2}$. The reaction of $\mathbf{4 2}$ with DDQ produced 4,5 benzotropone (11) in 24\% yield together with $28 \%$ of starting material. The key step for $\mathbf{1 1}$ from $\mathbf{4 2}$ is the electrocyclic ring expansion of dehydrogenation product $\mathbf{4 4}$ to the benzotropylium ion 45. Secondly, $\mathbf{1 1}$ is obtained in $18 \%$ yield after benzylic bromination of $\mathbf{4 2}$ with NBS, followed by in situ elimination reaction of the labile bromide $\mathbf{4 3}$ mediated by $t$-BuOK (Scheme 9).

Palladium-catalyzed $\mathrm{C}-\mathrm{C}$ bond-formation reactions such as Heck and Sonogashira couplings are employed in a wide variety of areas in organic chemistry [56,57]. Recently, Shaabani's group synthesized and characterized palladium nanoparticles supported on ethylenediamine-functionalized cellulose (PdNPs@EDACs) as a novel bio-supported catalyst for Heck and Sonogashira couplings in water [58]. Shaabani's group reported the efficient synthesis of benzotropone $\mathbf{1 1}$ in a good isolated yield (83\%) via PdNPs@EDACs-catalyzed Heck coupling and intramolecular condensation of 2-bromobenzaldehyde (46) and methyl vinyl ketone (47) (Scheme 10) [58].

\subsection{Reactions of 4,5-benzotropone (11)}

2.2.1. Reactions via the carbonyl group: Fulvalenes are typical cross-conjugated carbocyclic unsaturated compounds and are of theoretical and synthetic interest [59]. Several 


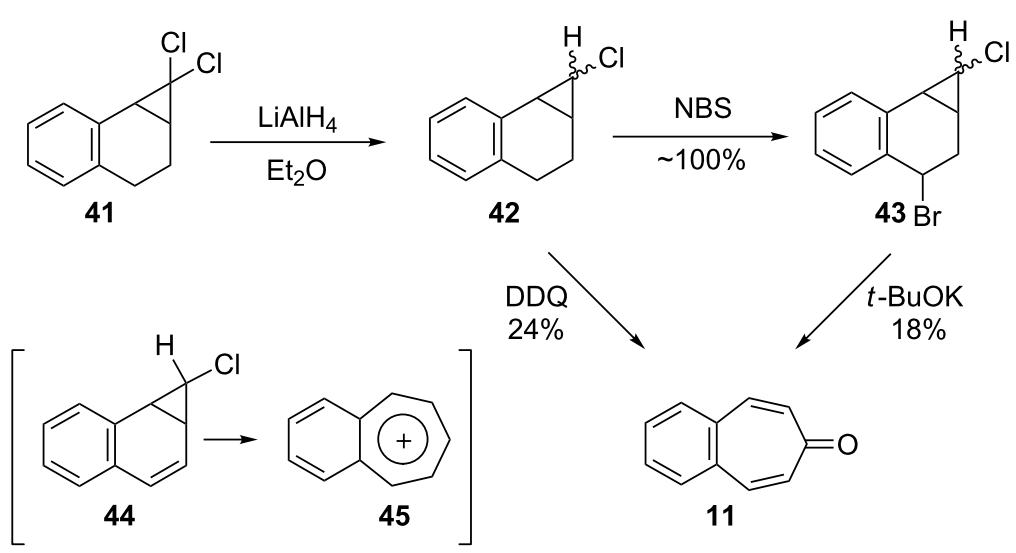

Scheme 9: Synthesis of 4,5-benzotropone (11) via the carbene adduct 41 .

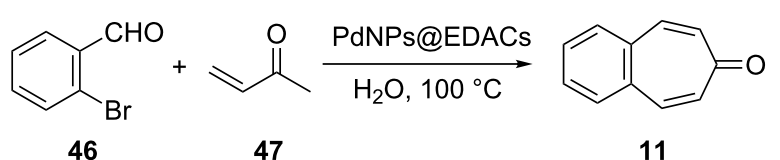

$(83 \%)$

Scheme 10: Heck coupling strategy for the synthesis of 11.

researchers have studied the synthesis of benzofulvalenes via the carbonyl group of 4,5-benzotropone (11) (Scheme 11). Halton's group applied the Peterson olefination reaction to the synthesis of benzofulvalanes $\mathbf{4 9}$ and $\mathbf{5 0}$ from the reaction of 4,5benzotropone (11) with corresponding cyclopropanes [60,61].
While the reaction of 4,5-benzotropone (11) with malononitrile afforded 8,8-dicyano-3,4-benzoheptafulvalene (51) [62], the condensation of 4,5-benzotropone (11) with dimethyl malonate and its nitro analogue gave benzoheptafulvalene derivatives $\mathbf{5 2}$ and 53 [50,63]. The condensation of 4,5-benzotropone (11) and anthrone (10H-anthracen-9-one) also afforded 4,5-benzo-tropyliden-anthron 54 in 65\% yield [63]. Kitahara reported the synthesis of 1,2,3,4-tetrachloro-7,8-benzosesquifulvalene $\mathbf{5 5}$ via condensation of 1,2,3,4-tetrachlorocyclopentadiene and 4,5benzotropone (11) [64]. The thia-heptafulvalene $\mathbf{5 6}$ was synthesized by Wittig-Horner reaction of 4,5-benzotropone (11) with 2-diethoxyphosphinyl-1,3-benzodithiole [59]. The reactants used for the synthesis of benzoheptafulvalene derivate $\mathbf{5 7}$ were

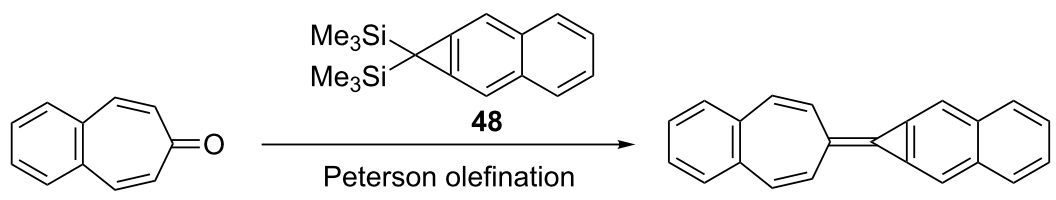

11

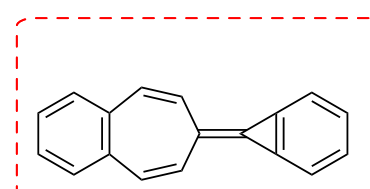

50<smiles>[R]C([R])=C1C=Cc2ccccc2C=C1</smiles>

$51 \mathrm{R}^{1}=\mathrm{R}^{2}=\mathrm{CN}$

$52 \mathrm{R}^{1}=\mathrm{NO}_{2}, \mathrm{R}^{2}=\mathrm{CO}_{2} \mathrm{Me}$

$53 \mathrm{R}^{1}=\mathrm{R}^{2}=\mathrm{CO}_{2} \mathrm{Me}$<smiles>ClC1=C(Cl)C(=C2C=Cc3ccccc3C=C2)C(Cl)=C1Cl</smiles>

55

49

Scheme 11: Synthesis of benzofulvalenes via carbonyl group of 4,5-benzotropone (11) 
$N, N$-dimethylformamide, methyl iodide, 4,5-benzotropone (11), and $\mathrm{NaClO}_{4}$ [65].

As polycyclic conjugated $\pi$ systems can endow new properties to the original $\pi$ system, conjugated systems are important in terms of both theoretical and experimental aspects. Nitta's group extensively studied the synthesis and structural and chemical properties of a new kind of cycloheptatrienylium ions using aromatic $\pi$ systems (Figure 3) [66-70]. In this context, Nitta and colleagues reported the synthesis, properties, and oxidizing ability of the novel $\mathbf{6 1}^{+} \cdot \mathrm{BF}_{4}^{-}$[71]. A condensation reaction of 4,5-benzotropone (11) with dimethyl barbituric acid (62) and subsequent oxidative cyclization reaction using DDQ$\mathrm{Sc}(\mathrm{OTf})_{3}$ or photoirradiation under aerobic conditions afforded $\mathbf{6 1}^{+} \cdot \mathrm{BF}_{4}{ }^{-}$(Scheme 12$)$. The $\mathrm{p} K_{\mathrm{R}+}$ value and reduction potential of the cation $\mathbf{6 1}$ were studied. The relative stability of a carbo- cation can be expressed by the $\mathrm{p} K_{\mathrm{R}+}$ value, which is the affinity of the carbocation toward hydroxide ions. The $\mathrm{p} K_{\mathrm{R}+}$ value for cation 61 was determined to be 4.7 spectrophotometrically. The reduction potential of the cation $\mathbf{6 1}$ was determined as -0.46 and $-1.07 \mathrm{~V}$ by cyclic voltammetry in acetonitrile. The oxidizing ability toward alcohols of $\mathbf{6 1}^{+} \cdot \mathrm{BF}_{4}{ }^{-}$in the auto-recycling process was also reported. However, to test the reactivity, the reactions of $\mathbf{6 1}^{+} \cdot \mathrm{BF}_{4}{ }^{-}$with a nucleophile such as $\mathrm{NaBH}_{4}$, diethylamine, and methanol were carried out to afford 7-adducts 64-66. Compound 64 was oxidized by DDQ to regenerate $\mathbf{6 1}^{+} \cdot \mathrm{BF}_{4}{ }^{-}$in good yield, whereas the treatment with $42 \%$ aq $\mathrm{HBF}_{4}$ of the compounds $\mathbf{6 5}$ and $\mathbf{6 6}$ regenerated $\mathbf{6 1}^{+} \cdot \mathrm{BF}_{4}{ }^{-}$in good yields.

Integrins are transmembrane $\alpha / \beta$ heterodimers that bind to extracellular matrix ligands, cell-surface ligands, and soluble

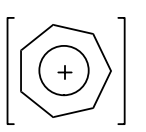

58

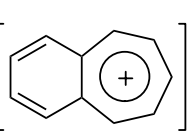

45

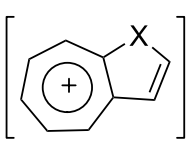

$59 X=0$

$60 X=S$

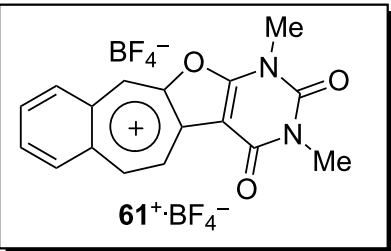

Figure 3: Some cycloheptatrienylium cations<smiles></smiles>

64

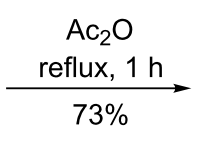

$\stackrel{\mathrm{x}, 1 \mathrm{~h}}{\longrightarrow}$

\begin{tabular}{l|l} 
i) $(20 \%)$ \\
ii) $(\sim 100 \%)$
\end{tabular}<smiles>C=c1c(=C2C=Cc3ccccc3C=C2)c(=O)n(C)c(=O)n1C</smiles>

63

i) $\mathrm{DDQ}, \mathrm{Sc}(\mathrm{OTf})_{3}$, then $\mathrm{HBF}_{4}$

ii) $h v$, aerobic, $\mathrm{HBF}_{4}$

iii) $\mathrm{NaBH}_{4}$

iv) $\mathrm{DDQ}$, then $\mathrm{HBF}_{4}$

v) $\mathrm{Et}_{2} \mathrm{NH}$ or $\mathrm{MeOH}$

vi) $\mathrm{HBF}_{4}$

$61^{+} \cdot \mathrm{BF}_{4}^{-}$

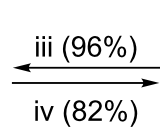<smiles>[B]c1c2ccccc2cc2c1oc1c(=O)n(C)n(C)c(=O)c12</smiles>

$v \uparrow v i$<smiles>[R16]c1ccccc1C1([R])C=Cc2c(n(C)c3c2c(=O)n(C)c(=O)n3C)O1</smiles>

$66 \mathrm{R}=\mathrm{OMe}$ 
ligands [72]. Perron-Sierra's group prepared substituted benzo[7]annulenes as a novel series of potent and specific $\alpha_{\mathrm{v}}$ integrin antagonists starting from 4,5-benzotropone (11) (Figure 4 and Scheme 13) [73].

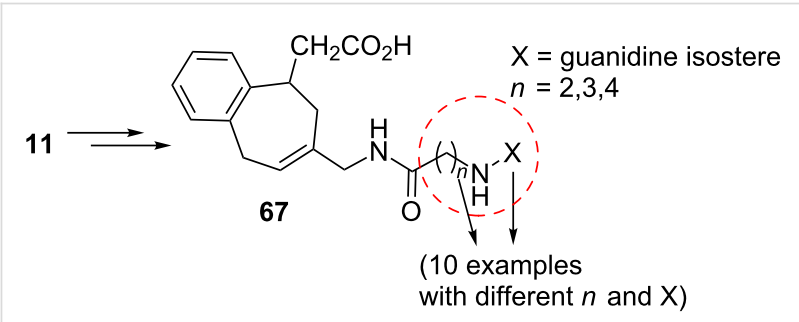

Figure 4: A novel series of benzo[7]annulenes prepared from 4,5benzotropone (11).

TBS-enol ether intermediate $\mathbf{6 8}$ was first formed by the Mukaiyama-Michael reaction of $O$-silyl ketene acetal to 4,5benzotropone (11) at low temperature in the presence of catalytic mercury iodide; it is a critical step for the formation of the compound 72. Hydrolysis of intermediate 68 led to ketone 69 in high yield containing an acetic acid residue $\beta$ to the carbonyl group. A sequence of the one-carbon homologation of ketone 69 is followed by isomerization into the $\alpha, \beta$-unsaturated aldehyde 71. A series of reductive amination and amidation reactions then led to the formation of the targeted substituted benzo[7] annulene 72 (Scheme 13). Moreover, the structure-activity study revealed that some of the compounds showed nanoto subnanomolar $\mathrm{IC}_{50}$ values on $\alpha_{\mathrm{v}} \beta_{3}$ and $\alpha_{\mathrm{v}} \beta_{5}$ integrins.

Benzo[7]annulenylidenes 73-75 and their rearrangements have attracted much interest due to their thermal and photochemical transformations (Figure 5) [74-76]. For the first time, Jones reported the chemical trapping of thermal and photochemical decomposition of the tosylhydrazone sodium salt of 4,5-benzotropone (11) and defined carbene-carbene rearrangements of 77-79 before finally it was verified by trapping of unstable intermediates 77-79 (Scheme 14) [77]. In 2002, McMahon reported obtaining the naphthylcarbene rearrangement manifold via the carbonyl groups of the isomeric benzotropones $\mathbf{1 1}$ and 12 (Scheme 14 and Scheme 33) [78]. Diazo compound 76 was prepared from 4,5-benzotropone hydrazone under oxidative conditions. Irradiation of matrix-isolated 7-diazo-7 $\mathrm{H}$ benzo[7]annulene (76) afforded a mixture of triplet<smiles>c1ccc2ccccc2c1</smiles><smiles>c1ccc2ccccc2c1</smiles><smiles>c1ccc2ccccc2c1</smiles>

Figure 5: Possible benzo[7]annulenylidenes 73-75.<smiles></smiles>

11<smiles>CCCCCC1C=C([O+]C(=O)OCC(=O)OCc2ccccc2)C=Cc2ccccc21</smiles>

68 $1 \mathrm{~N} \mathrm{HCl}, \mathrm{rt}$ $95 \%$

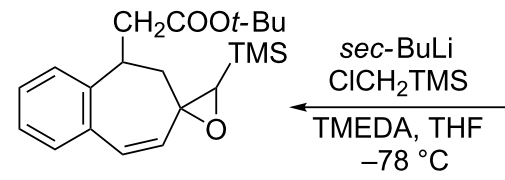

70<smiles>CCCCOC(=O)CC1CC(=O)C=Cc2ccccc21</smiles>

69

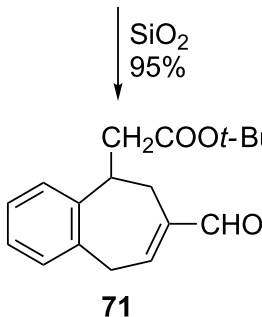<smiles>[R2]C(=O)CCNCc1ccccn1</smiles> 


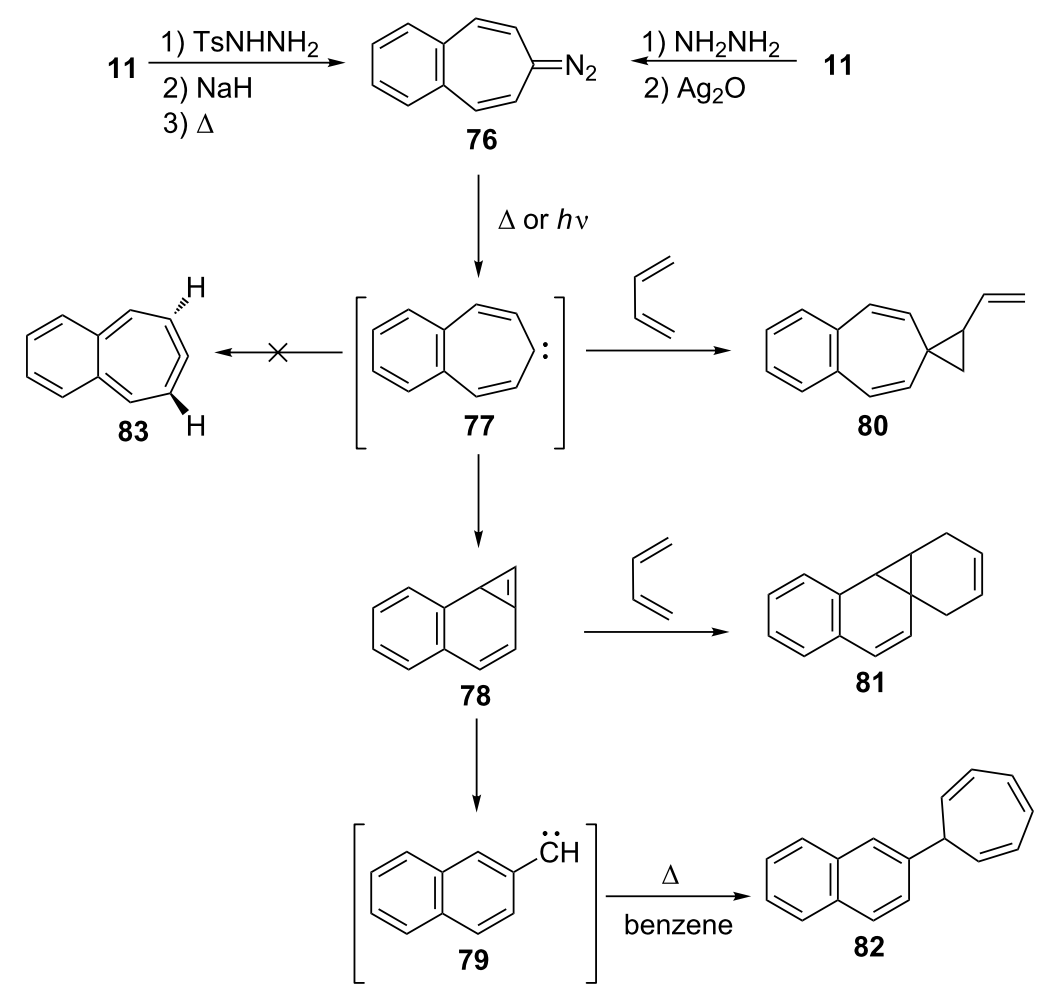

Scheme 14: Thermal and photochemical decomposition of 7-diazo-7H-benzo[7]annulene (76) and the trapping of intermediates 77-79.

7H-benzo[7]annulenylidene (77), 2,3-benzobicyclo[4.1.0]hepta2,4,6-triene (78), and triplet 2-naphthylcarbene (79). Formation of allene $\mathbf{8 3}$ as an alternative carbene rearrangement product was not detected under the studied photolysis conditions (Scheme 14).

Kitahara's group reported the one-step synthesis of heptafulvalenes and benzoheptafulvalenes from monocyclic tropones and benzotropones [79]. The reaction of 4,5-benzotropone (11) and 8-oxoheptafulvene (85), prepared in situ via the reaction of cycloheptatriene-7-carboxylic acid chloride (84) with $\mathrm{NEt}_{3}$, afforded 3,4-benzoheptafulvalene $\mathbf{8 6}$ in 50\% yield as fairly stable deep brown crystals (Scheme 15). The structure of $\mathbf{8 6}$ was confirmed by the spectroscopic data. The formation of the heptafulvalenes could be explained via an intermolecular $[2+2]$ cycloaddition product such as $\mathbf{8 7}$ between the carbonyl group of tropones and the ketene $\mathrm{C}=\mathrm{C}$ double bond of 8-oxoheptafulvene (85) followed by decarboxylation.

In a similar manner, the synthesis of 7-(diphenylmethylene)7H-benzo[7]annulene (89) was reported in two different ways (Scheme 16). First, the addition of diphenylketene $(\mathbf{8 8})$ to 11

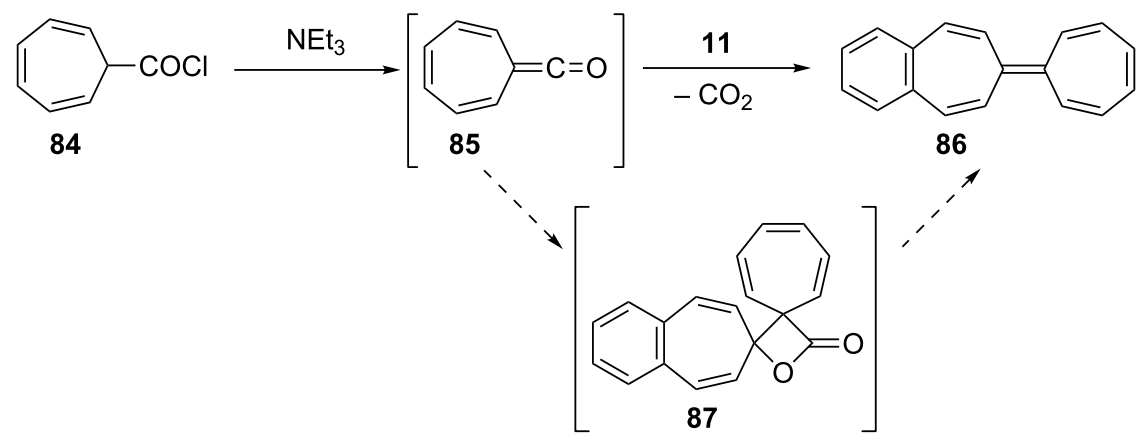



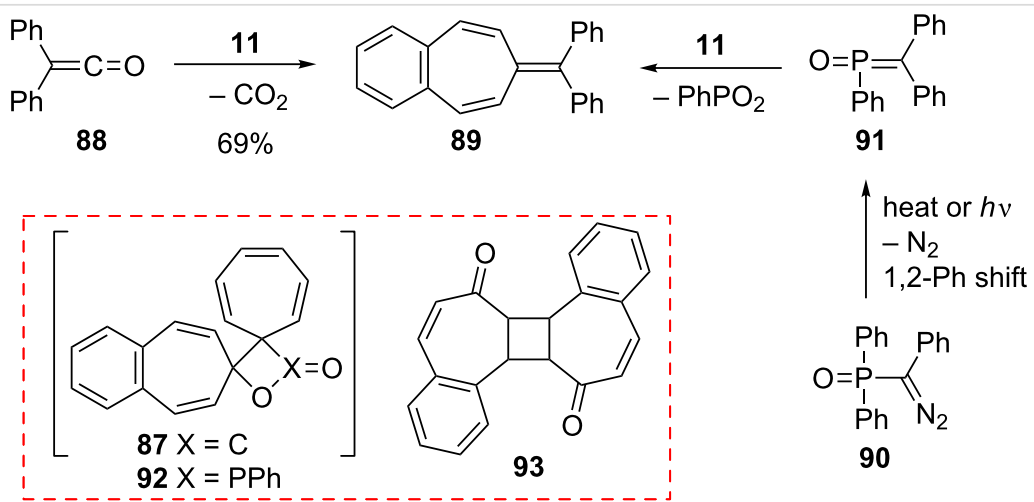

90

Scheme 16: Synthesis of 7-(diphenylmethylene)-7H-benzo[7]annulene (89).

resulted in the formation of benzoheptafulvalene $\mathbf{8 9}$ [80,81]. 7-(Diphenylmethylene)-7H-benzo[7]annulene (89) was also prepared via the oxaphosphetane 92 intermediate by treating 4,5-benzotropone (11) with (diphenylmethylene)(phenyl)phosphine oxide (91) generated thermally or photochemically from 90 [82]. Furthermore, dimeric byproduct 93 is also formed under photochemical conditions.

2.2.2. Ring expansion reactions via a tropone unit: In 1975, Franck-Neumann and Martina reported the reaction of dimethyl diazomethane with tropone and benzotropones [83]. This reaction gave benzo-4,5-dimethyl-8,8-cyclooctatrienone (94, $30 \%$ isolable yield) as an insertion product via a carbonyl group and pyrazoline $\mathbf{9 5}$ as 1,3-dipolar addition product via double bonds (Scheme 17).

Azocine derivatives, eight-membered nitrogen heterocycles, exist as the core structure in many natural and non-natural products [84]. Nevertheless, 2-methyoxyazocine (96) reduces related aromatic $10 \pi$-electron dianion 97 (Scheme 18). Paquette's group investigated benzo-annelation effects on azocine reactivity and the chemical and polarographic reduction of several methyoxy azocines [85,86]. 4,5-Benzotropone (11) was used as the logical starting material for the synthesis of benzomethoxyazocine $\mathbf{1 0 1}$ (Scheme 18). Treatment of $\mathbf{1 0 1}$ with potassium at $-40{ }^{\circ} \mathrm{C}$ in $\mathrm{NH}_{3}-\mathrm{THF}(5: 1)$, subsequent quenching by the addition of methanol, yielded dihydro derivative 103 (Scheme 18).
In 1978 , in order to examine heteroatomic influences on the possible generation of $9 \mathrm{C}-10 \pi$ homoaromatic dianions, Paquette's group described the synthesis and reducibility of benzo-fused-homo-2-methoxyazocines from benzotropones (Scheme 19) [87]. Firstly, dimethylsulfoxonium methylide addition to 4,5-benzotropone (11) provided the introduction of the cyclopropane ring required for two benzohomoazocines. Beckmann rearrangement of $\mathbf{1 0 4}$ resulted in a mixture of ring expansion products $\mathbf{1 0 5}$ and $\mathbf{1 0 6}$ in nearly equal proportions. This lactam mixture was then converted into the desired imidates and the imidates 107 and 108 were separated. Reduction of benzohomoazocine $\mathbf{1 0 7}$ proceeded without cleavage of its three-membered ring, whereas the internal cyclopropane $\sigma$ bond of $\mathbf{1 0 8}$ underwent cleavage to form 110 (Scheme 19). Paquette's group were unable to determine the formation of homoazocinyl dianion intermediates due to the added benzene ring in $\mathbf{1 0 7}$ and 108 and concluded that the presence of imino ether does not enhance the homoaromaticity of $9 \mathrm{C}-10 \pi$ dianions.

Homoaromaticity, homotropylium cations, and homotropones have been extensively studied [88-123]. Merk's group obtained with $\mathrm{H}_{2} \mathrm{SO}_{4}$ benzohomotropylium cation 111 starting from benzocyclooctatetraene and investigated its homoaromaticity (Scheme 20) [124]. Sugimura's group attempted to prepare an alternative benzohomotropylium cation 112 and reported the synthesis of 4,5-benzohomotropones 104 and 115 from 4,5benzotropones (Scheme 20). Although the conversions of 4,5-<smiles>CC(C)OC1=CC=Cc2ccccc2C=C1</smiles> 


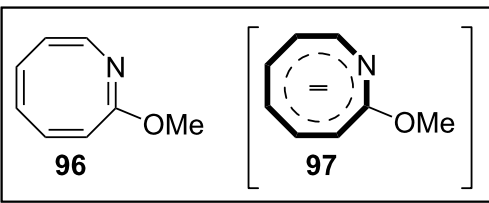<smiles>O=c1ccc2ccccc2cc1</smiles>

11

i<smiles>[13CH3]</smiles><smiles>[R]N=c1ccc2ccccc2cc1</smiles>

$98 \mathrm{R}=\mathrm{H}$

$99 \mathrm{R}=\mathrm{SO}_{2} \mathrm{C}_{6} \mathrm{H}_{5}$<smiles>COC1=N/C=C\c2ccccc2CC1</smiles>

103 OMe

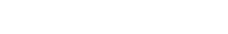

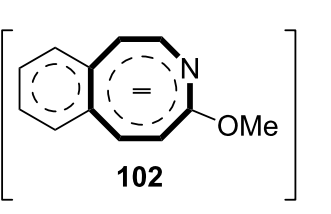<smiles>O=C1/C=C\c2ccccc2/C=C\N1</smiles>

100<smiles>COC1=N/C=C\c2ccccc2/C=C\1</smiles>

Scheme 18: Synthesis of dihydrobenzomethoxyazocine 103.

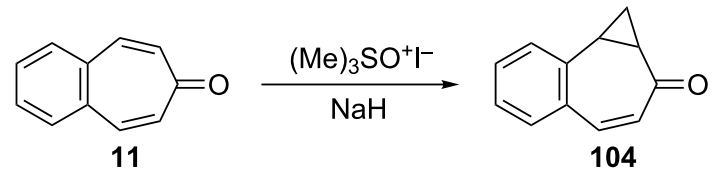

1) $\mathrm{NH}_{2} \mathrm{OH} \cdot \mathrm{HCl}$

2) $p$ - $\mathrm{TsOH}$, pyridine<smiles>O=C1C=Cc2ccccc2C2CC2NC(=O)[OH+]1</smiles>

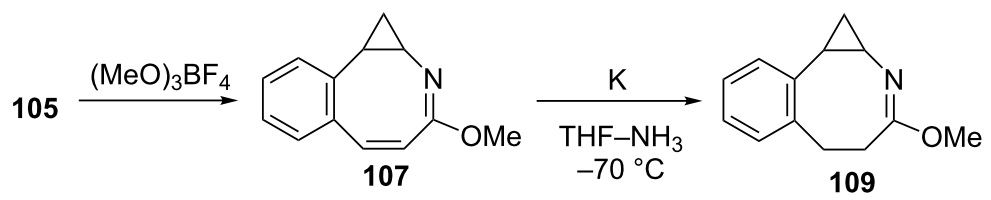<smiles>COC1=N/C=C\c2ccccc2C2CC2C(OC)=N/C=C\c2ccccc2CCC1</smiles>

Scheme 19: Synthesis and reducibility of benzo-homo-2-methoxyazocines.

benzohomotropones to hydroxytropylium ions $\mathbf{1 1 7}$ and $\mathbf{1 1 8}$ in sulfuric acid were presumed, benzohomotropylium cation 112 was not detected from the reactions of the corresponding alcohol 114 in sulfuric acid [125].
2.2.3. Reduction-based studies: To define the stereochemical, conformational, and dynamic properties of both benzo[7]annulenones (and related compounds) and monosubstituted tetrahydro-7H-benzo[7]annulenone, St-Jacques' group benefited ex- 

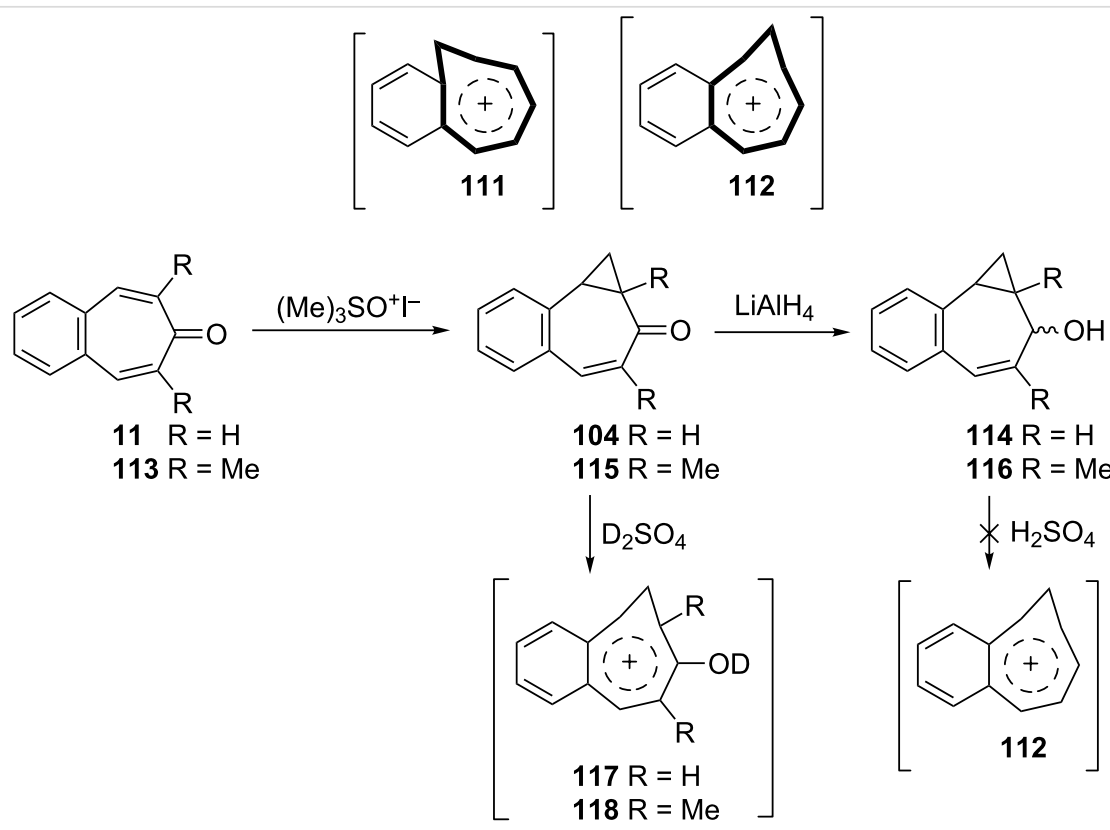

Scheme 20: Synthesis of 4,5-benzohomotropones 104 and 115 from 4,5-benzotropones 11 and 113.

tensively from the use of dynamic nuclear magnetic resonance (DNMR) techniques [126,127]. A catalytic deuterogenation of 4,5-benzotropone (11) followed by deuteration led to deuterated 5,6,8,9-tetrahydro-7H-benzo[7] annulen-7-one 119- $d_{6}$ with the presence of appreciable quantities of $d_{4}$ and $d_{5}$ species (Scheme 21). The compounds 120- $d_{6}$ and 121- $d_{6}$ were prepared from 119- $d_{6}$ as shown in Scheme 21. NMR studies for these molecules show that the chair conformation $\mathbf{1 2 2}$ is predominant over the boat. Several 5-monosubstituted benzo[7]annulenes 123-128 were prepared using 4,5-benzotropone (11) as starting material and ${ }^{1} \mathrm{H}$ and ${ }^{13} \mathrm{C}$ NMR studies in each series of compounds revealed strikingly different substituent effects (Scheme 21).

In order to perform reactions with alkyl Grignard reagents, Bertelli's group realized the synthesis of 7-methoxy-7 $\mathrm{H}$ benzo[7]annulene (129) (Scheme 22) [128]. Reduction of 4,5benzotropone (11) with $\mathrm{LiAlH}_{4}$ followed by etherification gave

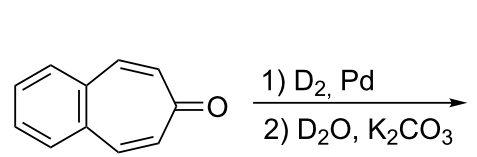<smiles>O=C1CCc2ccccc2CC1</smiles>

40<smiles>[3H][V]</smiles><smiles>[R]C1Cc2ccccc2CC([2H])([2H])C1[X]</smiles>

$123 \mathrm{X}=\mathrm{OH}$

$124 \mathrm{X}=\mathrm{OMe}$

$125 X=O A C$

$126 \mathrm{X}=\mathrm{OCOCF}_{3}$

$127 \mathrm{X}=\mathrm{Cl}$

$128 \mathrm{X}=\mathrm{Me}$

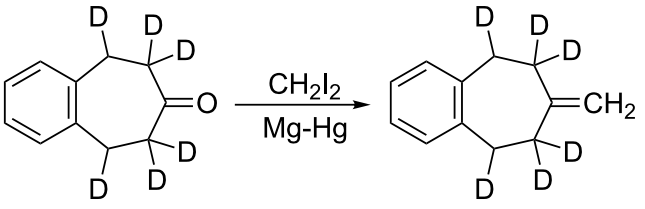

120- $d_{6}$<smiles>[2H]C1c2ccccc2C([2H])C([2H])([2H])C(=C=C2CCCCC2)C1([2H])[2H]</smiles>

121-d 6 
<smiles>CN(C)OC(=O)C=Cc1ccccc1</smiles>

11<smiles>COC1C=Cc2ccccc2C=C1</smiles>

129

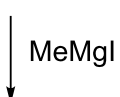

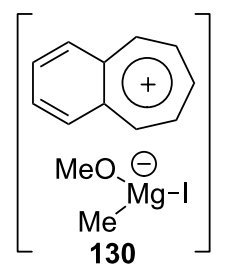

$+$<smiles>C=CC(=C)/C=C\CCCCCC</smiles><smiles>COI</smiles><smiles>CC1C=CC=Cc2ccccc21</smiles>

$131(52 \%)$

$132(48 \%)$

Scheme 22: Synthesis of methyl benzo[7]annulenes 131 and 132

the corresponding ether 129. Treatment of the ether 129 with $\mathrm{MeMgI}$ afforded an approximately equal mixture of two methyl benzo[7] annulenes, 131 and 132. An intermediate, 130, formed via the coordination of the Grignard reagent with ether was proposed to be operative in the reaction (Scheme 22).

\subsubsection{Miscellaneous reactions: a. Halogenated benzo[7]-} annulenes and their synthetic potentials: In 1978, Föhlisch's group reported the synthesis and ambident reactivity of benzo[7]annulenylium cations 133a and 133b (Scheme 23) [49]. While the reaction of $\mathbf{1 1}$ with oxalyl bromide yielded bromobenzo[7] annulenenylium bromide 134a as a stable carbenium salt, the reaction of oxalyl chloride or phosgene with $\mathbf{1 1}$ afforded 7,7-dichloro-7H-benzo[7] annulene (135b) as a covalent compound that ionizes in liquid $\mathrm{SO}_{2}$ to the cation $\mathbf{1 3 4 b}$ Treatment of cations with nucleophiles that are preferably added to the benzylic position (C-5 or C-9) yielded chloro- and bromo-5H-benzo[7]annulenes 136-143. According to Hückel molecular orbital (HMO) calculations, this observed regiochemistry is attributed to the highest positive charge density at the benzylic position, which is the favored process under kinetic conditions. During the attempted preparation of 4,5-benzotropone diaziridine 144, the synthesis of 7,7-dichloro- $7 \mathrm{H}$ benzo[7] annulene (135b) was also carried out from the reaction of 4,5-benzotropone (11) with $\mathrm{SOCl}_{2}$ in a quantitative yield (Scheme 23) [77,78]. However, all attempts to synthesize 144 from 135 have failed.

7-Bromo-5H-benzo[7]annulene (22) was also used as a key molecule in the synthesis of benzo[7] annulenylidene-iron complexes 147 and 148 (Scheme 24) [129]. The monobromide $\mathbf{2 2}$ obtained from the reaction of oxalyl bromide with $\mathbf{1 1}$ fol-

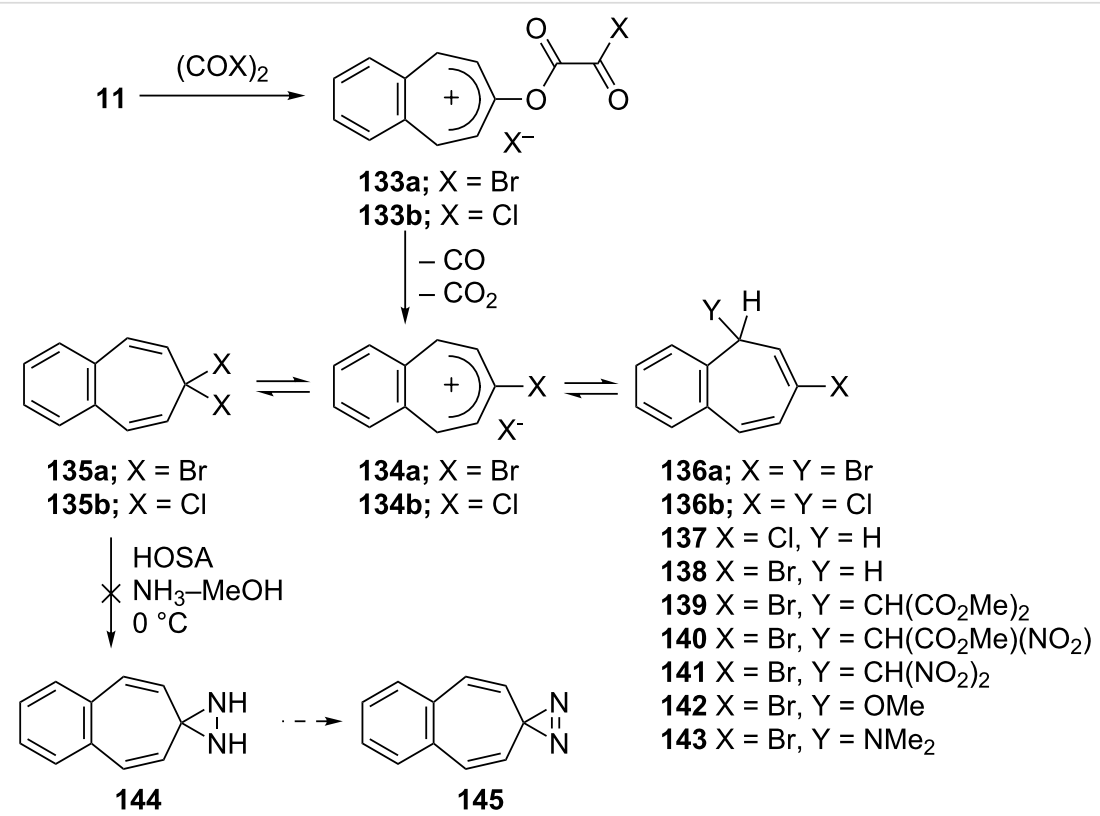

Scheme 23: Ambident reactivity of halobenzo[7]annulenylium cations 133a/b. 


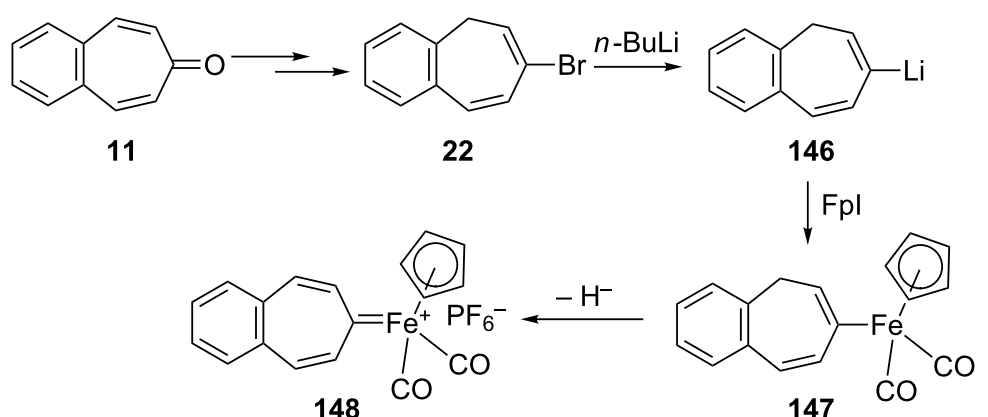

Scheme 24: Preparation of benzo[7]annulenylidene-iron complexes 147.

lowed by $n$-BuLi-reduction converted into 146 and then into yellow-brown complex 147 by treatment with a cold solution of $\left(\eta^{5}-\mathrm{C}_{5} \mathrm{H}_{5}\right)(\mathrm{CO})_{2} \mathrm{FeI}(\mathrm{FpI})$. After chromatography of 147 over alumina with a pentane-benzene mixture, the complex 147 oxidized to $\mathbf{1 4 8}$ as a fairly air-stable red-brown solid.

b. Nucleophilic addition to 4,5-benzotropone (11): Ried's group realized the reaction of 4,5-benzotropone (11) and its derivatives with lithium acetylide as a nucleophile between -50 and $-32{ }^{\circ} \mathrm{C}$ [130]. While the possible 1,4-conjugate addition product 149 was oxidized to 1-ethynylbenzotropone 150 in situ, the etheric compound $\mathbf{1 5 2}$ was obtained from the reaction of 1,2-addition product $\mathbf{1 5 1}$ with $\mathrm{HCl}$ (Scheme 25).

c. Decarbonylation of 4,5-benzotropone (11): The mechanism for the neutral and radical-cationic decarbonylation of tropone and benzannulated tropones was compared by both experimental techniques and by means of MNDO calculations (Scheme 26) [131]. While the key steps for the thermal decomposition of tropones are electrocyclic ring closure and cheletropic $\mathrm{CO}$ extrusion to give an aromatic system, the cationic reactions occur with ring closure followed by the opening to a benzoyl-type ion, which is the actual precursor of the CO loss (Scheme 26).

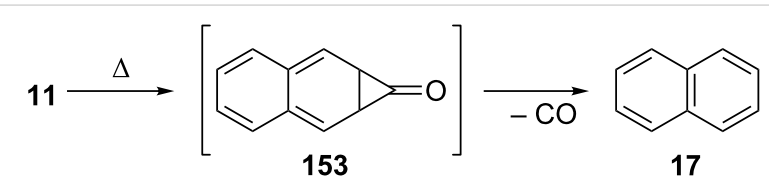

Scheme 26: Thermal decomposition of 4,5-benzotropone (11).

d. Ketalization of 4,5-benzotropone (11): Cavazza's group reported their unsuccessful attempts to obtain tropone dithioketals such as 155 [132]. The treatment of 4,5-benzotropone (11) with 1,2-ethanedithiol and $\mathrm{BF}_{3} \cdot \mathrm{Et}_{2} \mathrm{O}$ in $\mathrm{MeOH}$ gave the expected dithioketal 154, whereas the reaction of tropone under similar conditions presented complications from rapid [1,7] sigmatropic shifts of unhindered alkylthio groups to give bicyclic 1,7-disubstituted cycloheptatrienes like $\mathbf{1 5 6}$ (Scheme 27). Leitich's group reported the synthesis and cycloaddition of tropone ethylene acetal and benzotropone ethylene acetal 157 (Scheme 27) [133]. The ketal 157 was prepared from the reaction of 4,5-benzotropone (11) with ethylene glycol in the presence of triethyloxonium tetrafluoroborate. The cycload-

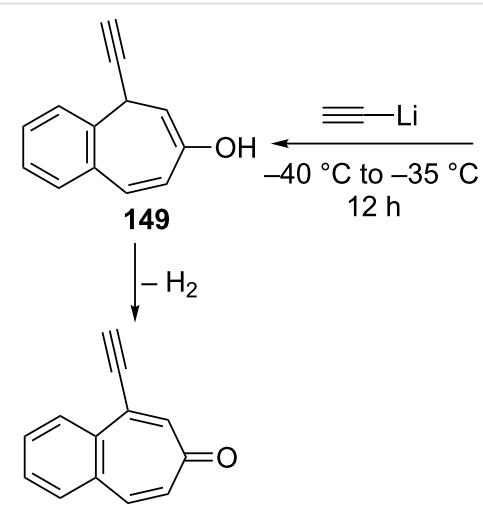

150

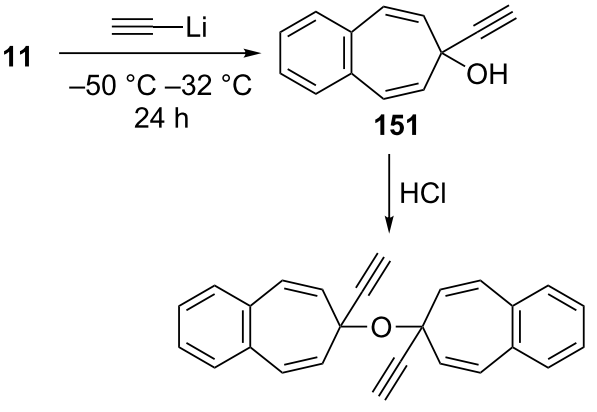

152

Scheme 25: Synthesis of 1-ethynylbenzotropone (150) and the etheric compound 152 from 4,5-benzotropone (11) with lithium acetylide 


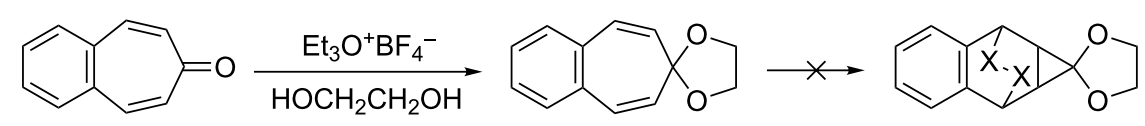

11

161<smiles>O=C(Br)CSC1(Br)C=Cc2ccccc2C=C1</smiles>

154
157

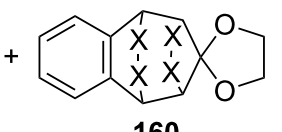

160

159

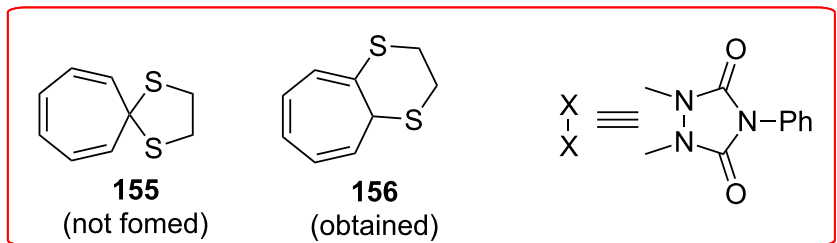

Scheme 27: Reaction of 4,5-benzotropone (11) with 1,2-ethanediol and 1,2-ethanedithiol.

dition of 157 with 4-phenyl-1,2,4-triazoline-3,5-dione (158) gave the cycloadducts $\mathbf{1 5 9}$ and $\mathbf{1 6 0}$ via the cycloheptatriene form. However, usually the norcaradiene type product $161 \mathrm{ob}-$ served with cycloheptatrienes was not formed (Scheme 27).

\section{Chemistry of 2,3-benzotropone (12)}

\subsection{Synthesis of 2,3-benzotropone (12)}

Several procedures relating to the synthesis of 2,3-benzotropone (12) were reported. The vast majority of these procedures utilize commercially available 1 -benzosuberone $(6,7,8,9$-tetrahydro-5H-benzo[7] annulen-5-one, 162) (Scheme 28).<smiles>O=C(CCCCc1ccccc1)c1ccccc1</smiles><smiles>CC#CC</smiles><smiles>O=c1ccccc2ccccc12</smiles>

Scheme 28: Conversions of 1-benzosuberone (162) to 2,3-benzotropone (12).

3.1.1. Synthesis using 1-benzosuberone (162): In 1959, Buchanan's group realized a nontedious method for the synthesis of 2,3-benzotropone (12) starting with 1-benzosuberone (162) (Scheme 29) [134]. First, the unsaturated ketone 163, which is called Julia's ketone, was prepared by NBS-bromination in the presence of a trace of benzoyl peroxide (BPO) and followed by dehydrobromination. Another synthesis of Julia's ketone was achieved by dehydration of the known keto-alcohol $\mathbf{1 6 4}$ by boric acid. Oxidation of Julia's ketone with selenium dioxide gave 2,3-benzotropone (12). An alternative synthesis for 12, which represents a feasible route to avoid the disadvantage of selenium dioxide, is also bromination of Julia's ketone $\mathbf{1 6 3}$ followed by spontaneous elimination of hydrogen bromide at the temperature of the reaction.

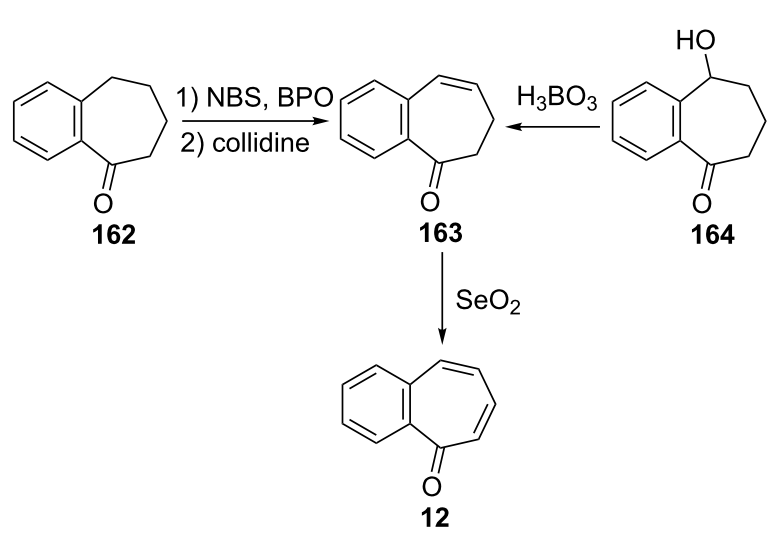

Scheme 29: Synthesis strategies for 2,3-bezotropone (12) using 1-benzosuberones.

2,3-Benzotropone (12) was also prepared by bromination of 1-benzosuberone (162) using both NBS and molecular bromine followed by dehydrobromination (using lithium chloride in dimethylformamide) of the resulting dibromo derivatives (Scheme 30) [135,136]. Moreover, the formation mechanism of the elimination of $\mathrm{HBr}$ from the germinal dibromide was investigated by Jones' group [135]. Jones' group also investigated the mechanism of the elimination of $\mathrm{HBr}$ from geminal-dibro- 


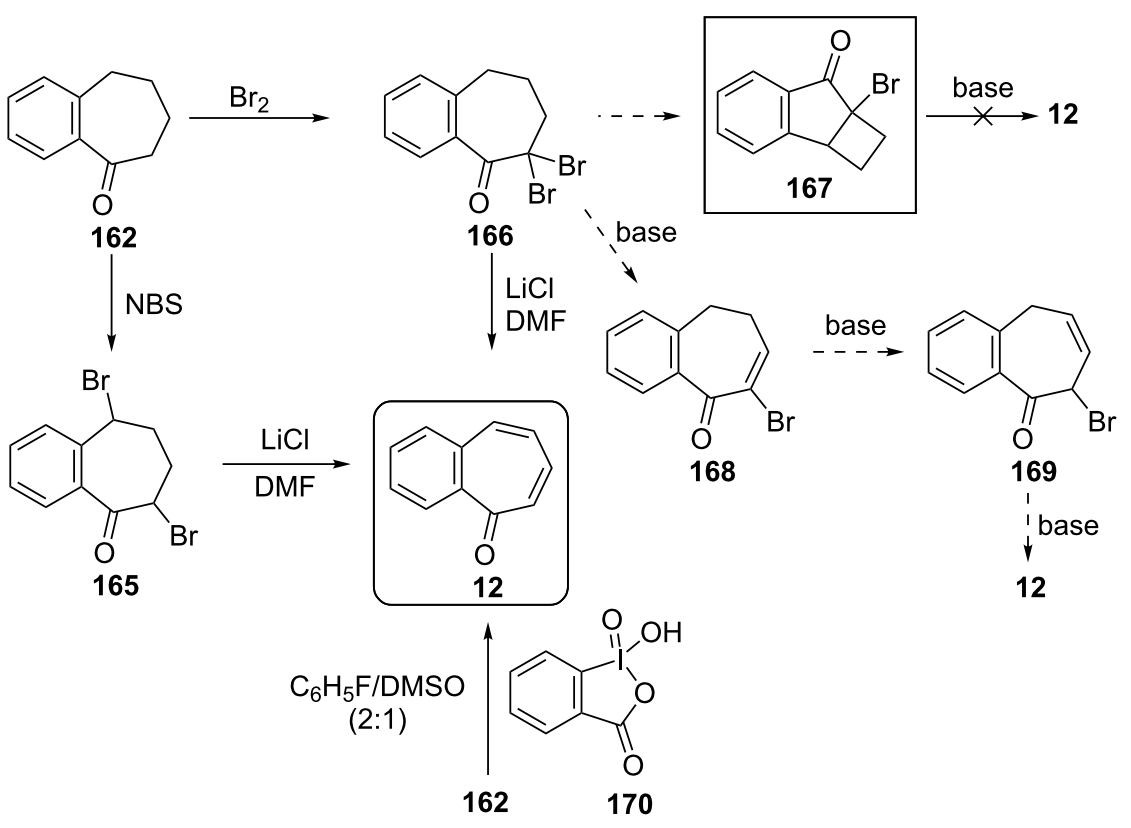

Scheme 30: Oxidation-based synthesis of 2,3-benzotropone (12) via 1-benzosuberone (162).

mide 166 with the preparation of possible intermediate bromotetrahydrocyclobuta[a]inden-7-one 167 [136]. As the reaction of $\mathbf{1 6 7}$ does not work under basic conditions, it is supposed that the reaction takes place via an acid-catalyzed double bond isomerization followed by an elimination reaction. Moreover, Ghosh's group repeated the synthesis of $\mathbf{1 2}$ through a molecular bromination-dehydrobromination sequence starting with 162 [137].

Hypervalent iodine(V)-based reagents such as IBX (or 2-iodoxybenzoic acid) and Dess-Martin periodinane (DMP) are commonly used in organic synthesis as oxidizing agent to form both unsaturated carbonyl compounds and conjugated aromatic carbonyl systems. Nicolaou's group reported a general method for the mild, swift, and highly efficient oxidation of alcohols, ketones, and aldehydes to unsaturated compounds in one pot (Scheme 30) [138,139]. Accordingly, an IBX-controlled dehydrogenation through single-electron-transfer-based oxidation processes of $\mathbf{1 6 2}$ gave $\mathbf{1 2}$ in $60 \%$ yield.

3.1.2. Other synthetic approaches: A convenient synthesis of 2,3-benzotropone (12) from $\alpha$-tetralone (171) by ring expansion was performed by Sato's group (Scheme 31) [140]. First, 1-ethoxy-3,4-dihydronaphthalene (172) was prepared by reacting $\alpha$-tetralone (171) with ethyl orthoformate in the presence of an acid catalyst. Subsequent successive reactions are dihalocarbene addition to enolether 172, ring expansion of the adduct 173 to halocycloheptadienone 168, and dehydrohalo-<smiles>O=C1CCCc2ccccc21</smiles><smiles>CCOC1=CCCc2ccc([18OH])cc21</smiles>

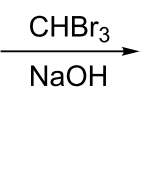<smiles>CCOC12c3ccccc3CCC1C2(Br)Br</smiles><smiles>O=c1ccccc2ccccc12</smiles>

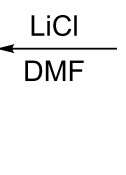<smiles>O=C1C(Br)=CCCc2ccccc21</smiles>

Scheme 31: Synthesis of 2,3-benzotropone (12) from a-tetralone (171) via ring-expansion. 
genation of 168 with lithium chloride. Later, McMahon's group reiterated the same protocol in their work on achieving the rearrangement of naphthylcarbene [78].

Rennhard's group reported the formation of 2,3-benzotropone (12) from benzotropolone 176 (Scheme 32) [141,142]. After the etherification of benzotropolone $\mathbf{1 7 4}$ using isobutanol in the presence of $p$-toluenesulfonic acid ( $p$-TsOH), the reduction of 175 with lithium aluminum hydride afforded the intermediate 176, which was converted to 2,3-benzotropone (12) under acidic conditions.

\subsection{Reactions of 2,3-benzotropone (12)}

3.2.1. Reactions via a carbonyl group: Among the most common reactions for 2,3-benzotropone (12) are condensation reactions with active methylenic compounds, resulting in the formation of benzoheptafulvenoids (Figure 6). For example,
Machiguchi reported that the condensation reaction of deuterium tracer 2,3-benzotropone 177 with malononitrile to yield 8,8-dicyano-2,3-benzoheptafulvene $\mathbf{1 7 8}$ via reaction paths including the choice of a Michael-type attack of the nucleophile at the $\mathrm{C}-4$ position to Knoevenagel-type attack at the $\mathrm{C}-1$ position [143]. Benzannulated quinotropylidene $\mathbf{1 8 0}$ was produced by the condensation reaction of 2,3-benzotropone (12) and $10 H$-anthracen-9-one [63]. 2,3-Benzotropone (12) was transformed into the corresponding benzoheptafulvalene $\mathbf{1 8 1}$ using the ketene addition protocol illustrated in Scheme 15 and Figure 6 .

The thermal decomposition of the obtained tosylhydrazone salt 182 from 2,3-benzotropone (12) afforded a trapping product of 1-naphthylcarbene (185) [128], while the allenic rearrangement product $\mathbf{1 8 3}$ for the carbene $\mathbf{7 5}$ was not detected in the photolysis of a diazo compound (Scheme 33) [78]. 2,3-Benzotropone

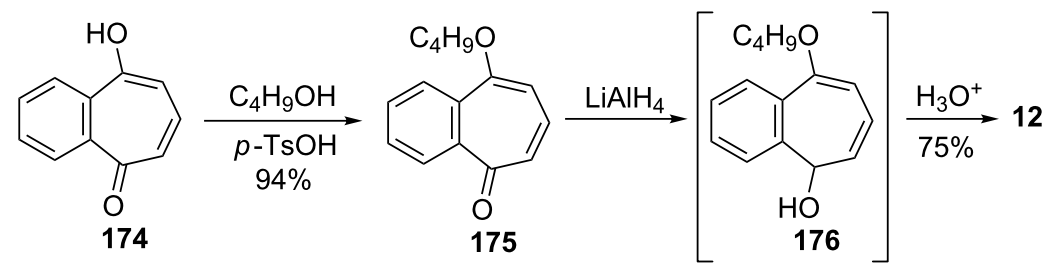

Scheme 32: Preparation of 2,3-benzotropone (12) by using of benzotropolone 174.<smiles></smiles><smiles>O=C1c2ccccc2C(=C2C=CCC3=CC=CC=C2C3)c2ccccc21</smiles><smiles>BrC1=CC=CC(=C2C=CC=Cc3ccccc32)C=C1</smiles>

Figure 6: Benzoheptafulvenes as condensation products of 2,3-benzotropone (12)

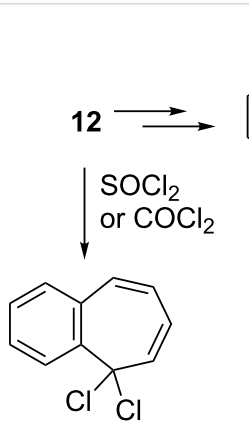

187<smiles>[Nb]=c1ccccc2ccccc12</smiles>

182<smiles>C1=CC2C=C2c2ccccc21</smiles>

184<smiles>[Y]C1(C)C=CC=Cc2ccccc2C1</smiles>

75<smiles>C1=CC=Cc2ccccc2C=1</smiles>

183<smiles>Cc1cccc2ccccc12</smiles>

185<smiles>C1=CC=CC(c2cccc3ccccc23)C=C1</smiles>

186

Scheme 33: Conversion of 2,3-benzotropone (12) to tosylhydrazone salt 182 and gem-dichloride 187 
(12) was converted to gem-dichloride $\mathbf{1 8 7}$ to achieve diazirine as carbene precursor (Scheme 33) [77,144].

3.2.2. Ring-expansion reactions via a tropone unit: The ringexpansion product $\mathbf{1 8 8}$, which is a net insertion of a diazomethane unit into the tropone, was prepared from the reaction of 2,3-benzotropone (12) with dimethyl diazomethane (Figure 7) [83]. Benzohomoazocines 191-193 and benzomethoxyazocines 195-197 were prepared using a similar protocol illustrated in Scheme 18 and Scheme 19 (Figure 7) [84-87,145]. The cyclopropane ring in 192 was reduced to the corresponding dihydroazonine $\mathbf{1 9 3}$.

Additionally, Ogliaruso's group prepared 2,3-benzo-6,7-monohomotropone (189) and trans-2,3-benzo-4,5:6,7-bishomotropone (190) from the nonselective reaction of 2,3-benzotropone (12) with dimethyloxosulfonium methylide in yields of $35 \%$ and $28 \%$ and investigated the structural characterization of these compounds by extensive NMR analysis (Figure 7 and Scheme 34) [146]. In addition, carbonium ions 198-201, prepared via the protonation of 2,3-benzotropone (12), homotropone 189, and bishomotropone 190, and their deuterated analogues using fluorosulfuric acid-antimony pentafluoride were investigated using NMR spectroscopy (Scheme 34) [147]. NMR investigation of the carbonium ion formed from 189 indicated the formation of the carbonium ion $\mathbf{1 9 9}$ with complete electron delocalization, whereas the carbonium ion 200 (and 201) formed from 190 indicated considerably less electron delocalization (Scheme 34).

3.2.3. Cycloaddition reactions: $2,3-$ Benzotropone (12) possesses a high functional tolerance towards both the diene and

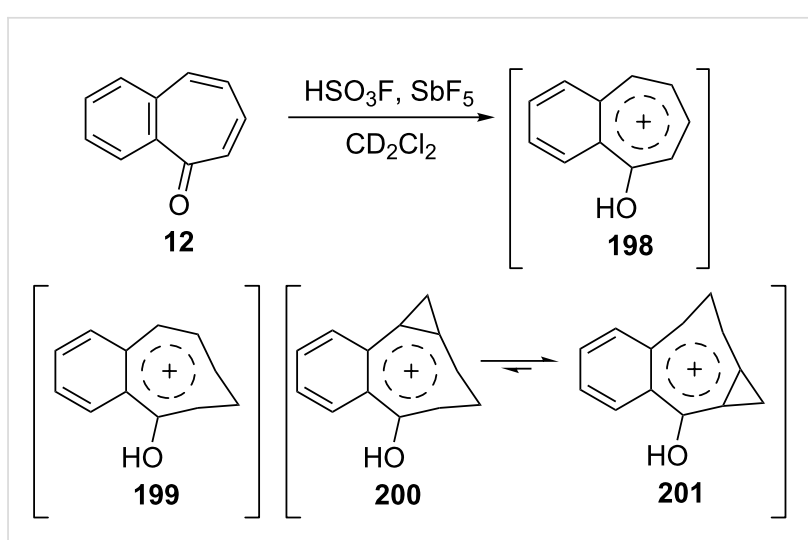

Scheme 34: From 2,3-benzotropone (12) to carbonium ions 198-201.

dienophile and undergoes the Diels-Alder reaction. Ghosh's group reported an exclusive peri-, regio-, and stereoselective cycloaddition reaction of $5 H$-benzo[7]annulen-5-one (Scheme 35) [137]. The intermolecular [4 +2] cycloaddition of 2,3-benzotropone (12) with cyclopentadiene (202) in the presence of boron trifluoride occurred totally periselectively, regioselectively, and exo-diaselectively to afford the adduct $\mathbf{2 0 3}$ in $75 \%$ yield. The Diels-Alder reaction of 2,3-benzotropone (12) with various dienophiles has also been reported. In the first example, Rennhard's group realized the cycloaddition of benzotropone 12 with maleic anhydride (204) to give a tricyclic adduct 207 (in 90\% yield) (Scheme 35) [141,142]. Later, Middlemiss' group also used dienophiles such as maleic anhydride (204), $N$-methylmaleimide (205), and $N$-phenylmaleimide (206) to give endo-adducts 207-209 [148]. Furthermore, these ethenobenzocycloheptenones 207-209 underwent di- $\pi$-methane photo-rearrangement to 210-212 exclusively<smiles>CC1(C)/C=C\C=C/c2ccccc2C1=O</smiles>

188<smiles>O=C1Nc2ccccc2C=CC2CC12</smiles>

191<smiles>O=C1c2ccccc2C=CC2CC12</smiles>

189<smiles>COC1=Nc2ccccc2C=CC2CC12</smiles>

192<smiles></smiles><smiles>COC1=Nc2ccccc2C/C=C\CC1</smiles><smiles>O=C1/C=C\C=C/c2ccccc2N1</smiles>

194<smiles>COC1=CC=CC=c2ccccc2=N1</smiles>

195<smiles></smiles>

196<smiles>COC1=Nc2ccccc2CC=CC1</smiles>

197

Figure 7: Benzohomoazocines 191-193 and benzoazocines 194-197. 


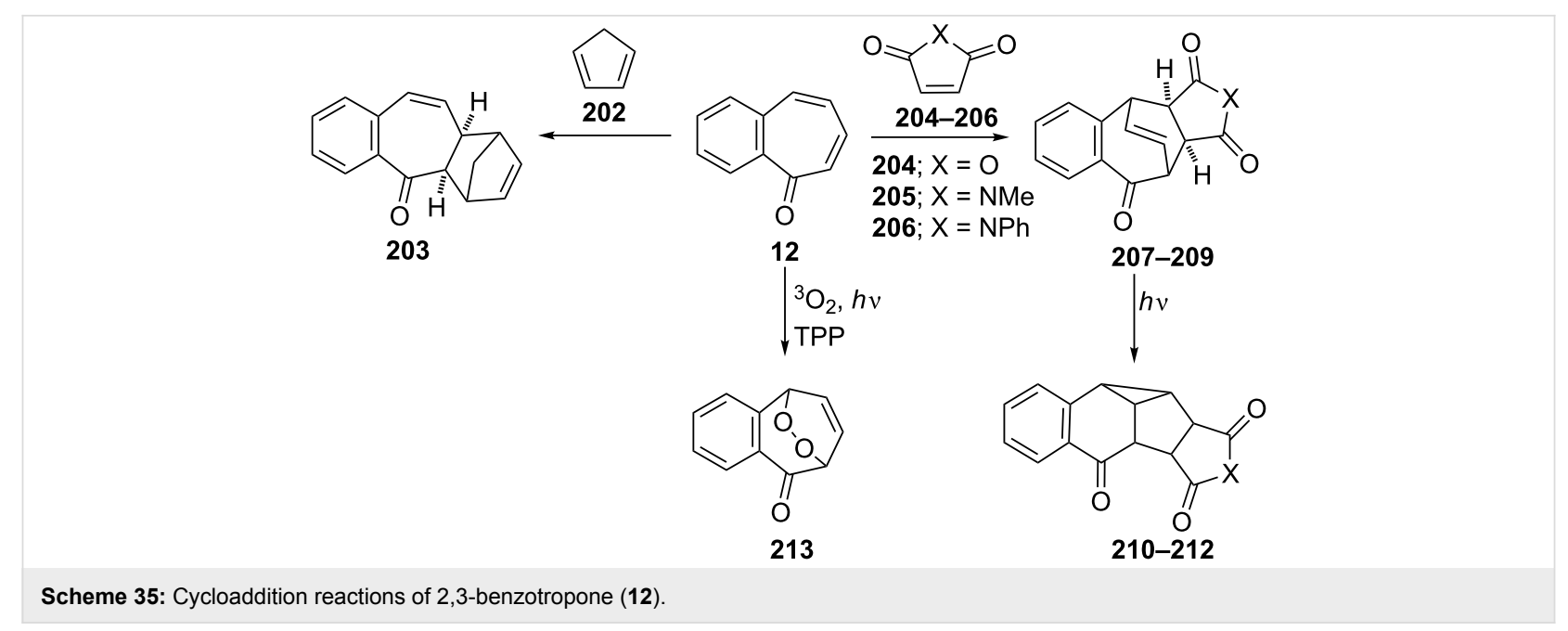

(Scheme 35). Moreover, Dastan's group prepared bicyclic endoperoxide $\mathbf{2 1 3}$ in 74\% yield from 2,3-benzotropone (12) via tetraphenylporphyrine (TPP)-sensitized photo-oxygenation (Scheme 35) [149].

3.2.4. Miscellaneous transformations: Machiguchi reported that the oxidative amination of 2,3-benzotropone (12) with methylcopperamine sulfate in aqueous methylamine at room temperature afforded 4-methylamino-1-naphthalene carbaldehyde (215) with a trace amount of 4-methylamino-2,3-benzotropone (214) via reaction paths including the dishing of Michaeltype attack of the nucleophile at the $\mathrm{C}-4$ position to a normal attack at the C-1 position. (Scheme 36) [143]. Preparation of benzotropylium cations 216-218 was reported by Rennhard's group [142]. The corresponding cations 216-218 were produced by reduction of $\mathbf{1 2}$ with $\mathrm{LiAlH}_{4}$ followed by treatment with Brønsted acids (Scheme 36) [142]. Bauld and Brown reported the ready generation of the first detectable dianion radicals as outlined in Scheme 36 [150]. Benzo[7] annulenide (benzotropenide) dianion radical $\mathbf{2 2 0}$ was generated in two steps from 12 via benzotropyl methyl ether 219. Holzmann's group described the thermal and electron impact-induced decarbonylation reaction of 12 (Scheme 36) [131]. Tajiri's group reported the resolution and determination of the kinetic parameters of the optically active 2,3-benzotropone(tricarbonyl)iron complex 221 using high-performance liquid chromatography (HPLC) and circular dichroism (CD) measurements, respectively (Scheme 36) [151]. In conjunction with the efficient preparation of $5 H$-benzo[7]annulen[1,2-b]naphthalenes as key intermediates to the naturally occurring red pigment radermachol (226), condensation of the anion of the isobenzofuranone 222 with 2,3benzotropone (12) was also performed (Scheme 36). This condensation followed by incipient oxidation gave the quinone $\mathbf{2 2 3}$ (15\%), the bridged bicyclic product 224 (7\%), and 225 (28\%) [152].

\section{Chemistry of 3,4-benzotropone (13)}

\subsection{Generation, characterization, and reaction}

3,4-Benzotropone (13) is of considerable interest for both theoretical and preparative reasons. The aromaticity of 3,4benzotropone (13A) is considered to depend on the contribution of electronically polarized form 13B such as tropone 1A (Figure 8) $[153,154]$. Kurihara's group reported the calculated resonance energies and bond currents for benzotropones and troponoid compounds [155]. Although benzotropones $\mathbf{1 1}$ and $\mathbf{1 2}$ have been isolated, 3,4-benzotropone (13) is rather unstable and has not been isolated. This instability is attributed to the $o$-quinoidal structure of $\mathbf{1 3}$ because it has no sextet electron system in the benzene ring and there are limited reports on the o-quinoidal 3,4-benzotropones 13.

Considering the known reactivity of benzocyclobutenes, i.e., their isomerisation to $o$-quinodimethanes, Tsuji's group used 6,7-benzobicyclo[3.2.0]hepta-3,6-dien-2-one (230) as a precursor to produce 13. They reported the first generation and spectroscopic characterization of this elusive molecule obtained by electrocyclic ring-opening reaction of $\mathbf{2 3 0}$ through irradiation in a rigid medium at low temperature or by thermolysis at high temperature [153]. As shown in Scheme 37, compound 230 was synthesized through the addition of benzyne to 2-cyclopentenone acetal (228) followed by hydrolysis and subsequent oxidation of the resultant ketone $\mathbf{2 2 9}$ with DDQ. Irradiation (>300 nm) of 230 in EPA (a 5:5:2 mixture of ether, isopentane, and ethanol) at $-196{ }^{\circ} \mathrm{C}$ led to the formation of 13 , which exhibited the development of characteristic UV-vis absorption in the range $300-550 \mathrm{~nm}$. In addition to product 13 , two [ $\pi 8+\pi 10]$ dimers 231 and 232 at $-78{ }^{\circ} \mathrm{C}$ were also isolated (Figure 9) [153]. In a subsequent study, Tsuji’s group described details of the spectral and chemical properties of 13 [154]. The IR spectroscopic results showed a substantial contribution of 13B to $13 \mathrm{~A}$ in the ground state. Moreover, it was found that the 

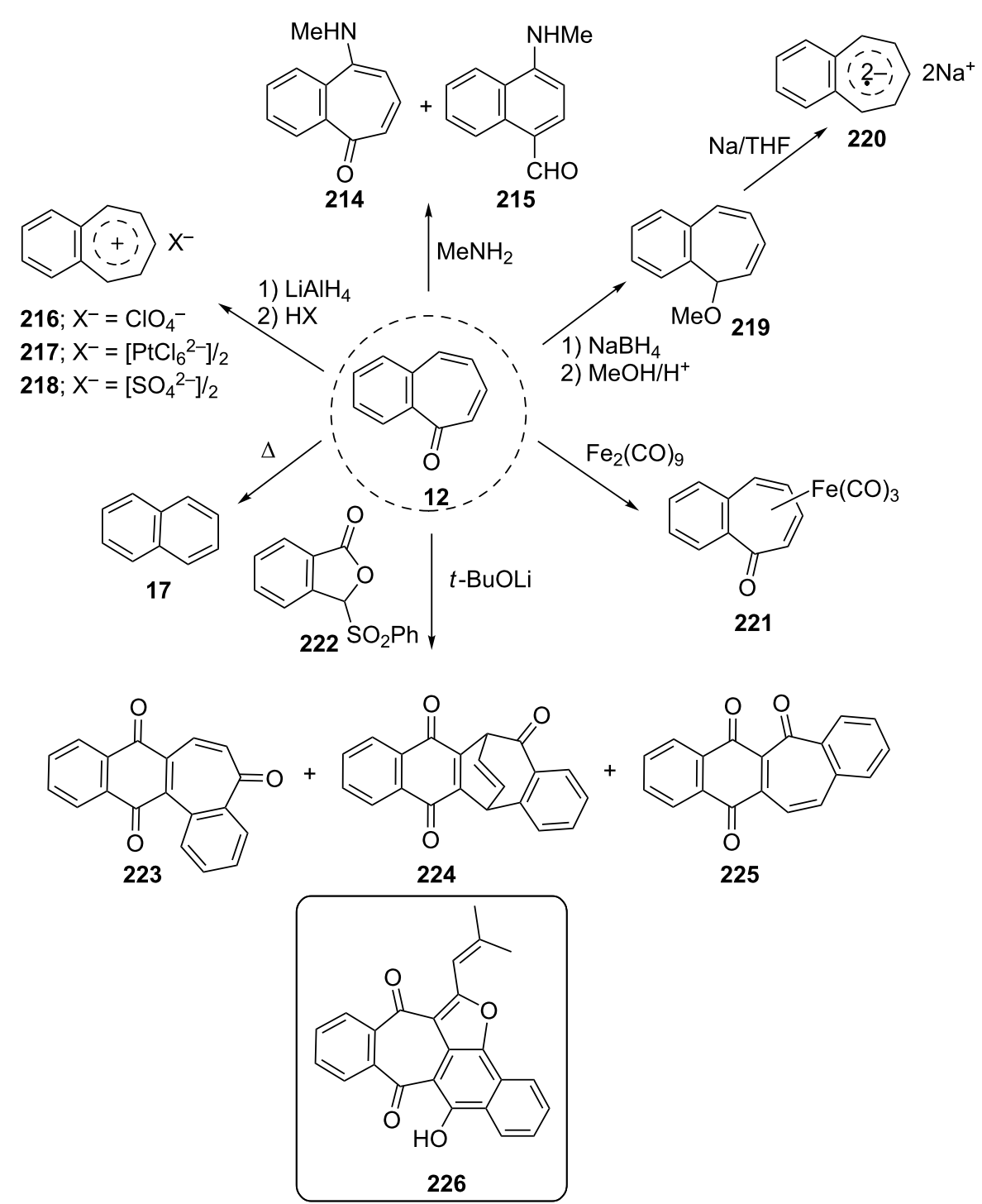

Scheme 36: Reaction of 2,3-benzotropone (12) with various reagents and compounds.

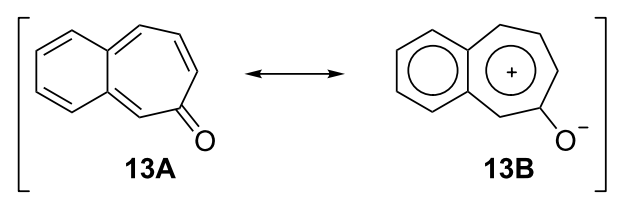

Figure 8: 3,4-Benzotropone (13) and its resonance structure.

photochemical behavior of $\mathbf{2 3 0}$ depended on the state of the irradiation medium. For example, the smooth $[\pi 10+\pi 10]$ dimerization of $\mathbf{1 3}$ to give dimeric product $\mathbf{2 3 3}$ was realized with the irradiation $(>420 \mathrm{~nm})$ of $\mathbf{1 3}$ in a fluid EPA solution below $-100{ }^{\circ} \mathrm{C}$ [154]. Furthermore, the IR spectra of 3,4-benzotropone (13) generated in matrices at $13 \mathrm{~K}$ by the photoisomerization of $\mathbf{2 3 0}$ were directly observed [156]. In addition, the ther- mal generation of $\mathbf{1 3}$ from $\mathbf{2 3 0}$ was investigated [153,154]. When 230 with 10 equiv of maleic anhydride in benzene at $220{ }^{\circ} \mathrm{C}$ was reacted, $[\pi 2+\pi 8]$ cyclo-adduct 234 as a single product was isolated in $52 \%$ yield (Figure 9) $[153,154]$. The thermolysis of $\mathbf{2 3 0}$ in the presence of ethyl vinyl ether gave three volatile products $\mathbf{2 3 5}-\mathbf{2 3 7}$ in GLC yields of 10\%, 7\%, and $15 \%$, respectively (Figure 9) [154].

\section{Benzotropolones}

Benzannulation to the tropolone scaffold can give numerous tautomeric hydroxybenzotropones or benzotropolenes. Figure 10 shows $238 \mathrm{~A}$ (or $\mathbf{2 4 1} \mathrm{A}-\mathbf{2 4 0}$ ) as single tautomers, whereas $\mathbf{2 3 9}$ and $\mathbf{1 7 4}$ are depicted as a mixture of tautomers. Moreover, benzenoid structures as $\mathbf{2 3 8 \mathbf { A }}$ are more stable than $o$-quinoidal structures as $\mathbf{2 3 8 B}$ due to Clar's $\pi$-sextet rule. 

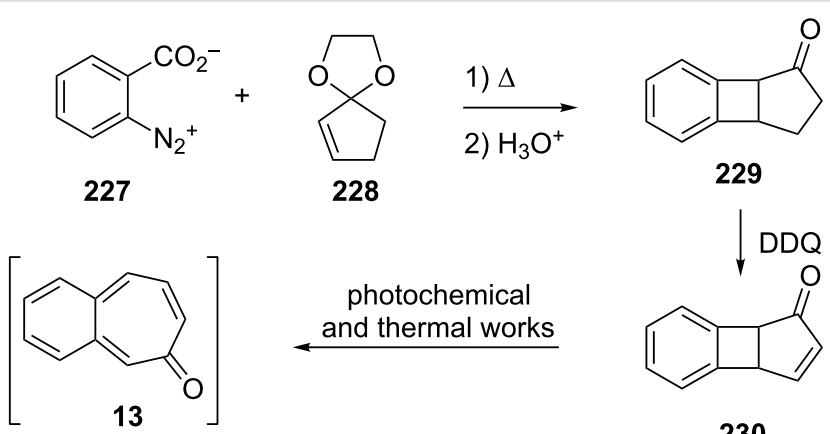

229

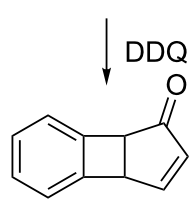

230

Scheme 37: Synthesis of 6,7-benzobicyclo[3.2.0]hepta-3,6-dien-2-one (230)
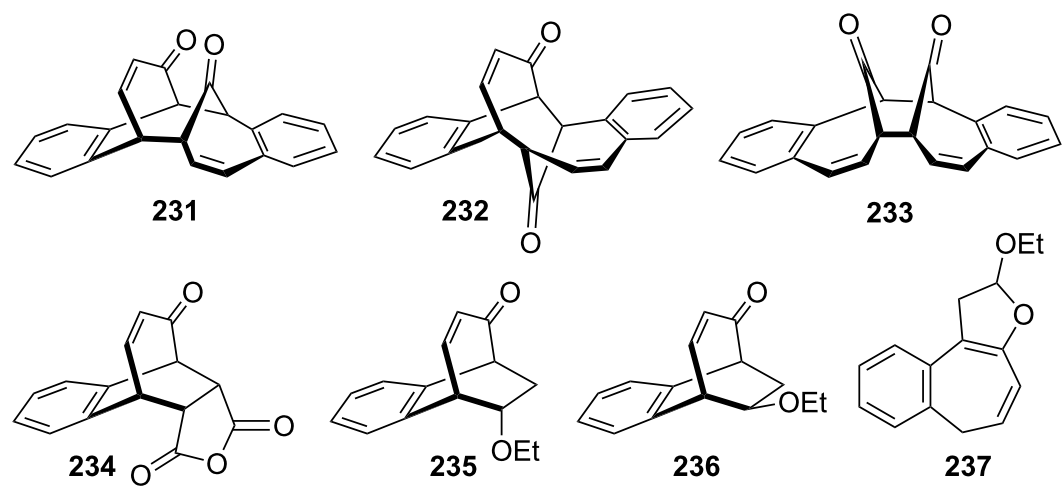

Figure 9: Photolysis and thermolysis products of $\mathbf{2 3 0}$

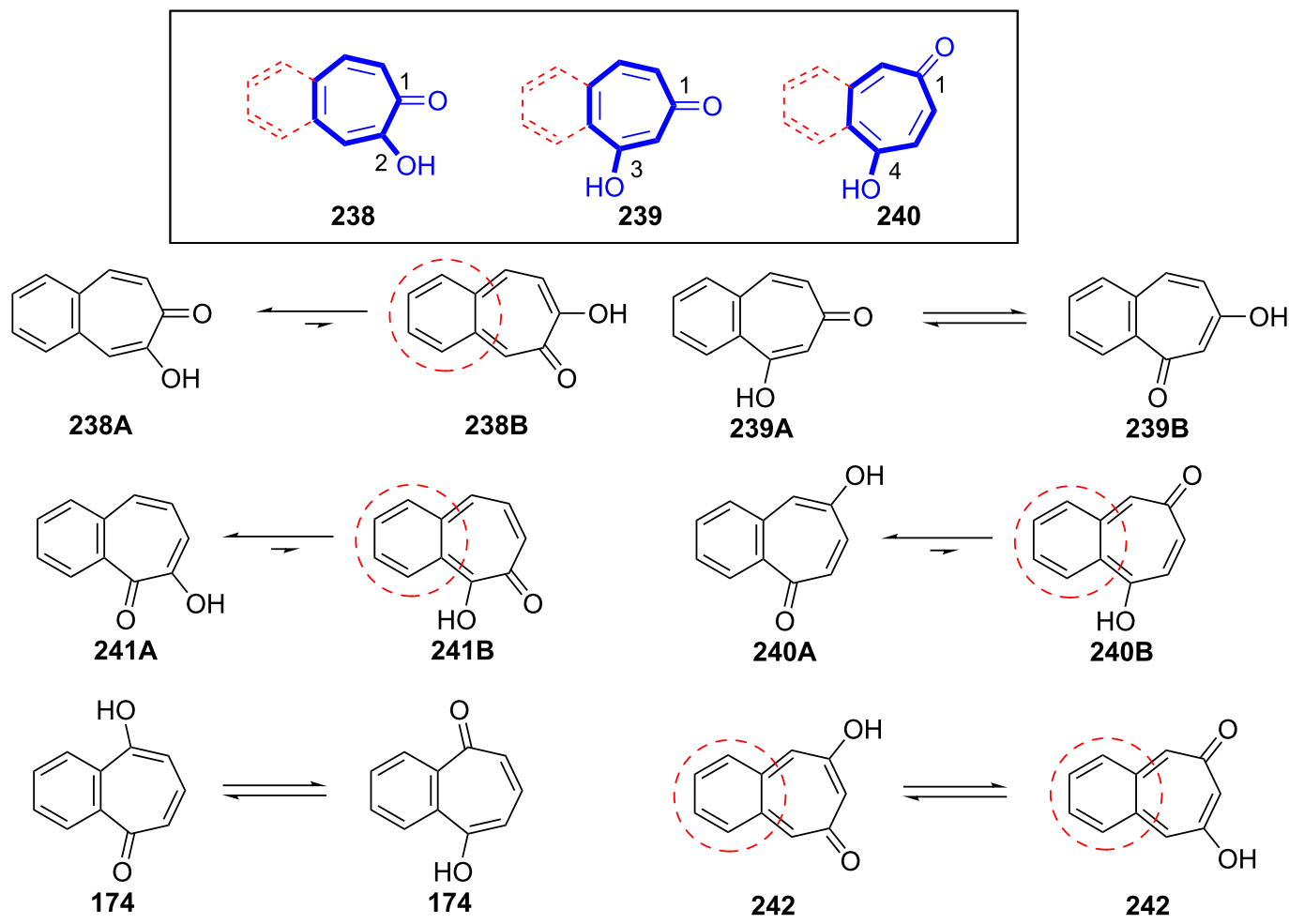

Figure 10: Benzotropolones and their tautomeric structures. 


\subsection{2-Hydroxy-4,5-benzotropone (238)}

5.1.1. Synthesis of 2 -hydroxy-4,5-benzotropone (238): Tarbell's group reported the first synthesis of 2-hydroxy-4,5benzotropone (238) starting from phthalaldehyde (27) in two steps (Scheme 38) [157]. Condensation of 27 with methoxyacetone in the presence of $\mathrm{NaOH}$ and then cleavage of the methyl ether $\mathbf{2 4 3}$ by strong acid afforded 2-hydroxy-4,5-benzotropone (238). Turner's group reported a new method for the synthesis of 4,5-benzotropolone (238) via the cycloaddition of dichloroketene (generated in situ from trichloroacetyl chloride) with indene followed by hydrolysis of the adduct $\mathbf{2 4 4}$ with sodium acetate in aqueous acetic acid (Scheme 38) [158]. In addition, Stevens' group reported a method for the synthesis of $\mathbf{2 3 8}$ using a strategy similar to that of Turner's group (Scheme 38) [159]. One-step synthesis for $\mathbf{2 3 8}$ was described by Christol's group through the oxidation of benzocyclopheptene $\mathbf{2 4 5}$ with $\mathrm{SeO}_{2}$ in $35 \%$ yield (Scheme 38) [160].

Galantay's group described a novel synthetic protocol for benzotropolones using the oxazole-benzo[7]annulenes 247 and
248, which may be easily obtained from the reaction of $\alpha$-oximino-benzosuberone $\mathbf{2 4 6}$ with $\mathrm{Ac}_{2} \mathrm{O} / \mathrm{AcOH} / \mathrm{HCl}$ (Scheme 39) [161]. The olefin 249, derived from reduction, chlorination, and elimination of $\mathbf{2 4 7}$, was converted by $\mathrm{SeO}_{2}$ in refluxing dioxane or xylene to the acetamido-benzotropone $\mathbf{2 5 0}$, which in turn can be hydrolyzed to 2-hydroxy-4,5-benzotropone (238).

5.1.2. Reactions of 2-hydroxy-4,5-benzotropone (238): Some quinoxaline and pyrazine derivatives 254-256 were synthesized from 1,2-phenylenediamine (251), 1,2-diaminocyclohexane (252), and ethylenediamine (253) with 4,5-benzotropolone 238 (Figure 11) [162]. Compound 256 can be converted to methylated 257.

Tarbell's group also reported 4,5-benzotropolone $\mathbf{2 3 8}$ and its methyl ether do not give the characteristic aromatization reactions as colchicine and monocyclic tropolones, and explained that $\mathbf{2 3 8}$ is a weaker acid than colchicine or tropolone [157]. However, the conversion of $\mathbf{2 3 8}$ to 1-nitro-2-naphthoic acid

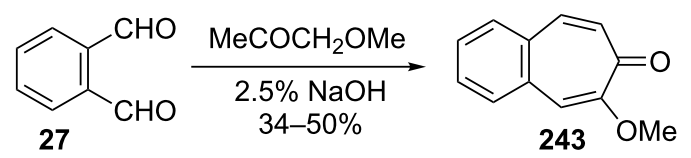

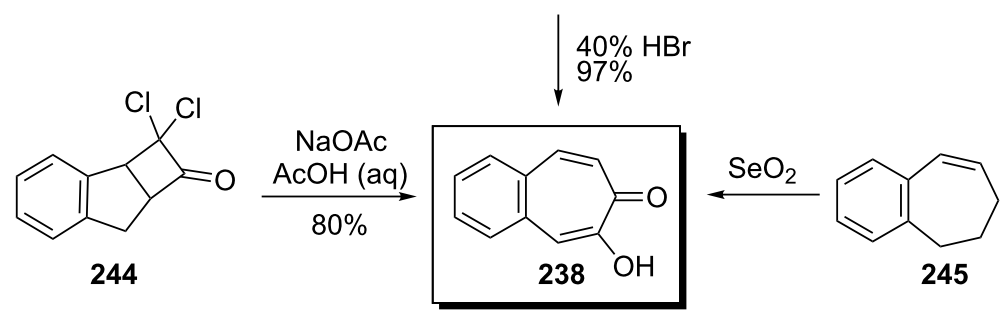
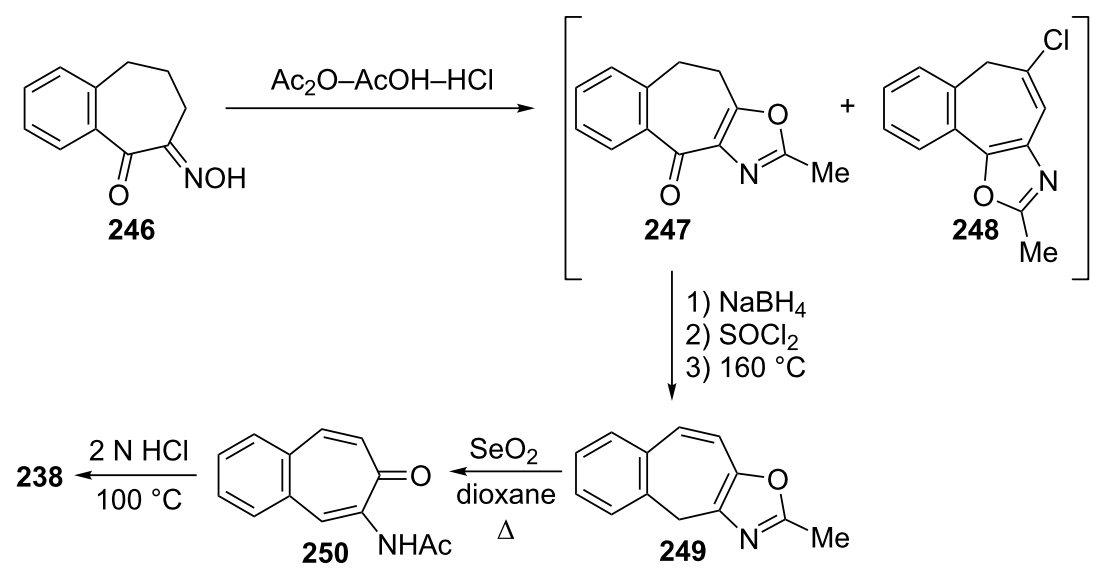


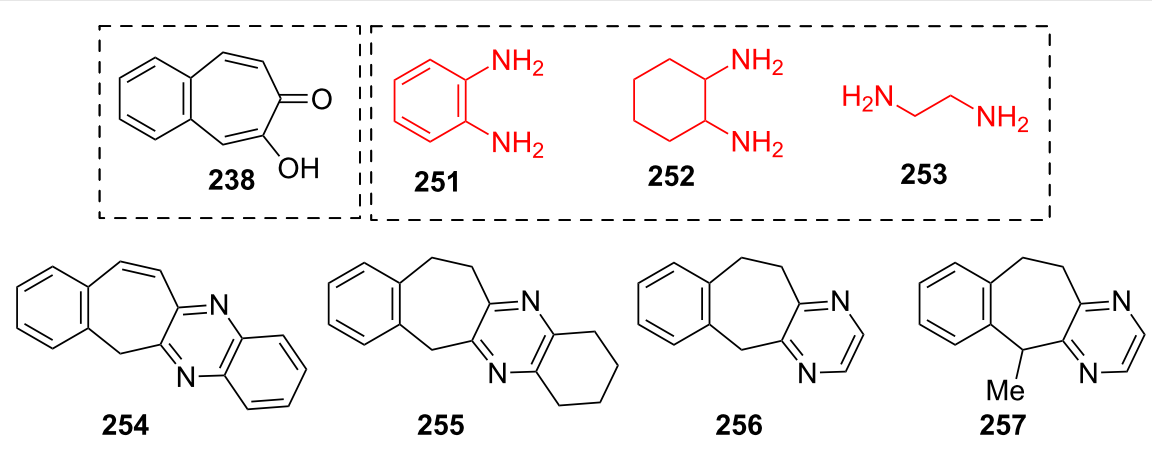

Figure 11: Some quinoxaline and pyrazine derivatives 254-256 prepared from 4,5-benzotropolone (238).

(259) was reported in two steps including the treatment of $\mathbf{2 3 8}$ with concentrated nitric acid in glacial acetic acid, followed by the reaction of $10 \%$ aqueous alkali at room temperature (Scheme 40) [157].

\subsection{6-Hydroxy-2,3-benzotropone (239)}

5.2.1. Synthesis of 6-hydroxy-2,3-benzotropone (239): Takahashi and co-workers described a route for 6-hydroxy-2,3benzotropone (239) starting from benzosuberone (162) [163] Firstly, a mixture of isomeric dibromides $\mathbf{2 6 1}$ was prepared with excessive bromination of $\mathbf{1 6 2}$ followed by subsequent dehydrobromination. By treatment of dibromides 261 with hydroxylamine in pyridine, 5- and 4-bromo-6-hydroxylamino-2,3benzotropone oximes $\mathbf{2 6 2}$ were obtained. Hydrolysis of these oximes 262 with sulfuric acid gave 5-bromo-6-hydroxy-2,3benzotropone and the 4-bromo isomer $\mathbf{2 6 3}$, which were debrominated with catalytic hydrogenation to give 239 (Scheme 41). Although $\mathbf{2 3 9}$ is capable of existing as two tautomeric mixture tautomers, 239A and 239B, which predominates is not clear, and the formation of a single methyl ether,<smiles>O=C(O)c1ccc2ccc([SeH])cc2c1[N+](=O)[O-]</smiles>

Scheme 40: Nitration product of 4,5-benzotropolone (238) and its isomerization to 1-nitro-naphthoic acid (259).

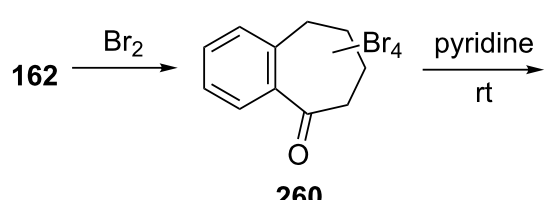

260<smiles>[X]c1c(N)cc(Br)c(=O)c2ccccc12</smiles>

261A; $X=\mathrm{H}, Y=\mathrm{Br}$ 261B; $\mathrm{X}=\mathrm{Br}, \mathrm{Y}=\mathrm{H}$<smiles>O=c1ccc2ccccc2c(O)c1</smiles>

239A<smiles>O=c1cc(O)ccc2ccccc12</smiles>

239B<smiles></smiles>

262A; $X=\mathrm{H}, \mathrm{Y}=\mathrm{Br}$ 262B; $X=B r, Y=H$<smiles>CCS(=O)(=O)O</smiles><smiles>[X]c1c(O)cc(=O)c2ccccc2c1[X]</smiles>

263A; $X=\mathrm{H}, Y=B r$ 263B; $X=B r, Y=H$ 
acetate, and 2,4-dinitrophenylhydrazone has been reported [163].

\subsubsection{Reactions of 6-hydroxy-2,3-benzotropone (239):} Hoshino's group reported the synthesis and chemical transformations of azo, nitro, and amino derivatives of 6-hydroxy-2,3benzotropone (239) (Scheme 42) [164]. While 7-amino derivative 264 was prepared via diazo coupling of 239 with diazotized $p$-toluidine in a pyridine solution followed by hydrogenation, the nitration of $\mathbf{2 3 9}$ in acetic acid solution afforded nitro compound 267. Nitro compound 267 was also hydrogenated to produce 7-amino derivative 264 . Diazoketone 265 was prepared from 264 with sodium nitrite in fluoroboric acid $\left(\mathrm{HBF}_{4}\right)$ and its Wolff rearrangement under reflux conditions in water gave 1-hydroxy-2-naphthoic acid (266). Acetylation of 264 with sodium acetate in acetic anhydride at $100{ }^{\circ} \mathrm{C}$ for $30 \mathrm{~min}$ afforded an unusual product, $\mathbf{2 6 9}$ or $\mathbf{2 7 0}$ via intermediate $\mathbf{2 6 8}$. The hydrolysis of $\mathbf{2 6 9}$ (or 270) provided a compound that is assumed to be an oxazolobenzotropone based on its infrared absorption spectrum. In fact, the authors reported that the correct structures for both pairs (271 or 272) are not clear. However, the oxidation of both $\mathbf{2 3 9}$ and $\mathbf{2 6 4}$ to $o$-carboxycinnamic acid (273) was also reported under alkaline hydrogen peroxide conditions (Scheme 42) [163,164]. Furthermore, bromination of 6-hydroxy-2,3-benzotropone (239) and corresponding transformations will be covered in the next sections.

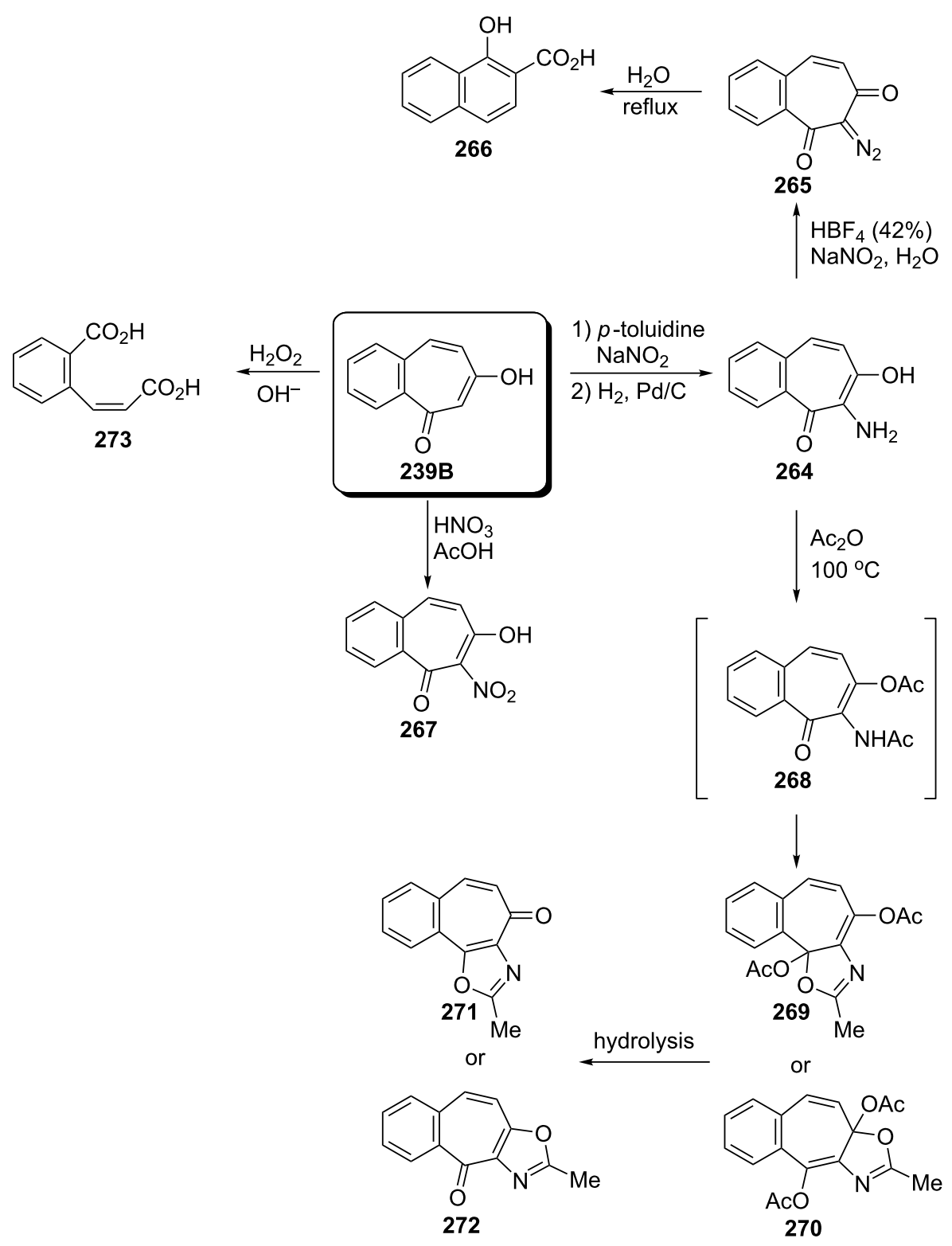

Scheme 42: Various reactions via 6-hydroxy-2,3-benzotropone (239). 
Photoreaction of 6-hydroxy-2,3-benzotropone (239) was reported by Yoshioka and Hoshino (Scheme 43) [165]. The irradiation of 239 in methanol with Pyrex-filtered light gave the products 274 and 275 in $25 \%$ and $2 \%$ yields, respectively, accompanied by undefined materials.

\subsection{7-Hydroxy-2,3-benzotropone (241)}

5.3.1. Synthesis of 7-hydroxy-2,3-benzotropone (241): The first synthesis of 7-hydroxy-2,3-benzotropone (241) was described by Cook's group (Scheme 44) [166,167]. 7-Hydroxy2,3-benzotropone (241) was prepared from benzosuberone (162) by oxidation with selenium dioxide in boiling ethanol, followed by dehydrogenation with bromine in acetic acid at $100{ }^{\circ} \mathrm{C}$. Another method for the synthesis of 7-hydroxy-2,3benzotropone (241) starting from the reaction of diketone $\mathbf{2 7 6}$ with boiling acetic anhydride was achieved by Maignan (Scheme 44) [168]. The reaction of enol-acetate with NBS led to 277 , which was heated in water-dioxane at $100{ }^{\circ} \mathrm{C}$ to give 7-hydroxy-2,3-benzotropone (241) by an elimination process. Galantay's group also reported the synthesis of 7-hydroxy-2,3benzotropone (241), which was similar to the synthesis of 2-hydroxy-4,5-benzotropone (238) as depicted in Scheme 38 (Scheme 45) [161].

Sato's group reported the synthesis of 7-hydroxy-2,3-benzotropone (241) via the ring expansion pathway of $\beta$-naphthoquinone (280) with diazomethane under various conditions and hydrolysis steps (Scheme 46) [169]. The boron trifluoride etherate-promoted ring expansion reactions were carried out at various quinone/ $\mathrm{BF}_{3} \cdot \mathrm{OEt}_{2} / \mathrm{CH}_{2} \mathrm{~N}_{2}$ molar ratios in a different solvent under an atmosphere of nitrogen and with cooling in an ice bath and 3,4-benzotropolonoboron difluoride $\mathbf{2 8 1}$ was obtained in $2-25.5 \%$ yield. The hydrolysis of chelate compound $\mathbf{2 8 1}$ was performed with dilute sulfuric acid to afford $\mathbf{2 4 1}$ in almost quantitative yield.

Bicyclic endoperoxides generated from the cycloaddition of singlet oxygen to 1,3-dienes serve as excellent synthetic precursors and have led to developments in tropone chemistry [170-172]. Taking advantage of the endoperoxide transformation, the synthesis of 7-hydroxy-2,3-benzotropone (241) was

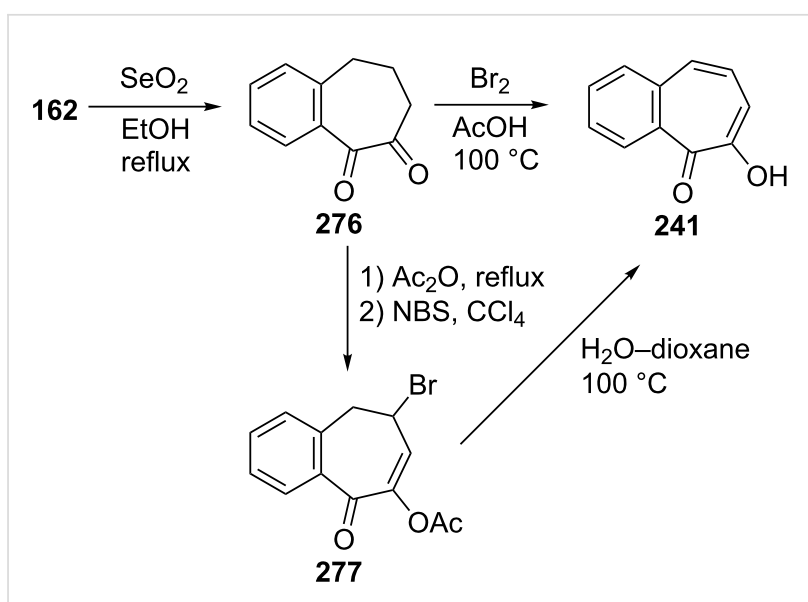

Scheme 44: Synthesis of 7-hydroxy-2,3-benzotropone (241) from benzosuberone (162).

successfully realized by Dastan's group (Scheme 47) [149]. Thiourea reduction of the peroxide linkage of 213 to the diol $\mathbf{2 8 2}$ and then simultaneously dehydration in situ gave the corresponding benzotropolone $\mathbf{2 4 1}$ in nearly quantitative yield.

Recently, Arican and Brückner reported the synthesis of 7-hydroxy-2,3-benzotropones by ring-closing metathesis (Scheme 48) [173]. 7-Hydroxy-2,3-benzotropone (241) was synthesized in four steps starting from a $\mathrm{Br} / \mathrm{Li}$ exchange reaction of $o$-bromostyrene (283) followed by the addition of aldehyde 284 to give the benzylic alcohol $\mathbf{2 8 5}$. Oxidation with Dess-Martin periodinane of the alcohol $\mathbf{2 8 5}$ followed by ringclosing metatheses in the presence of $1 \mathrm{~mol} \%$ of the second generation Grubbs catalyst (287) gave the 5H-benzo[7]annulene-5,6(7H)-dione monoketal $\mathbf{2 8 8}$ in nearly quantitative yield. The hydrolysis of $\mathbf{2 8 8}$ with excess $p$-Ts $\mathrm{OH}$ in aqueous acetonitrile at $75{ }^{\circ} \mathrm{C}$ for $4 \mathrm{~h}$ afforded the benzotropolone 241 .

5.3.2. Reaction of 7-hydroxy-2,3-benzotropone (241): Various monosubstitution products 289-291 of 7-hydroxy-2,3benzotropone (241) were readily prepared by Nozoe's group (Figure 12) [174]. The synthesis of bromo-derivative 290 from 241 was also reported by Cook's group [166]. The coupling of 241 with aryldiazonium chlorides resulted mainly in the forma-

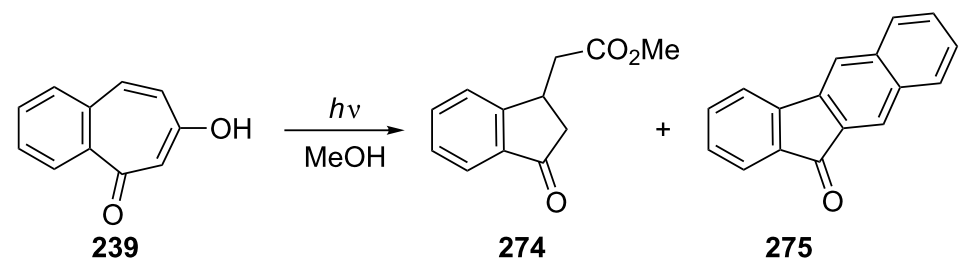

Scheme 43: Photoreaction of 6-hydroxy-2,3-benzotropone (239). 


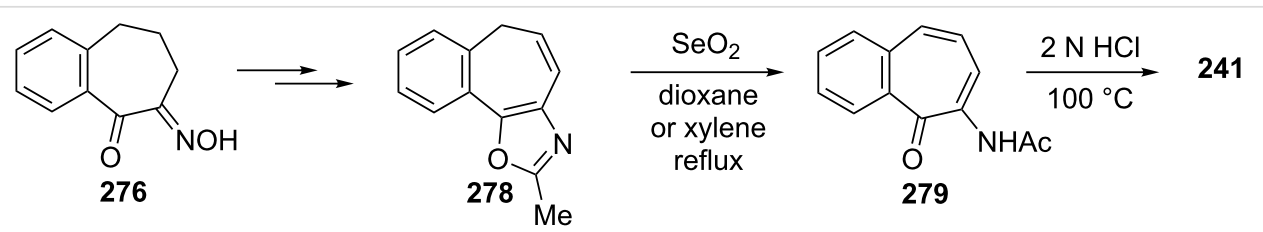

Scheme 45: Synthesis strategy for 7-hydroxy-2,3-benzotropone (241) from ketone 276.

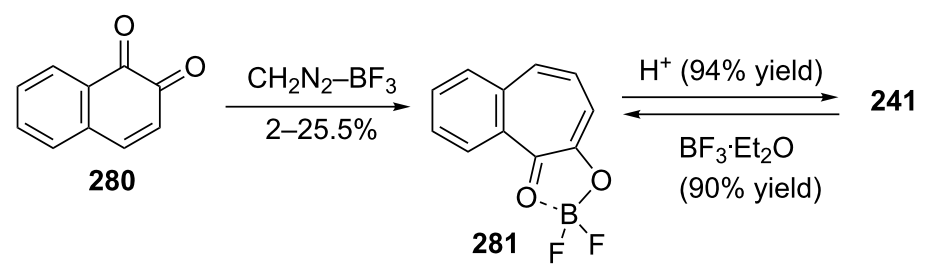

Scheme 46: Synthesis of 7-hydroxy-2,3-benzotropone (241) from $\beta$-naphthoquinone (280).

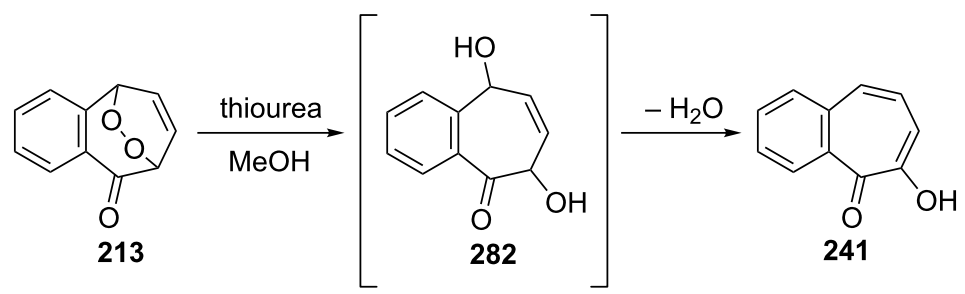

Scheme 47: Synthesis of 7-hydroxy-2,3-benzotropone (241) from bicyclic endoperoxide 213.
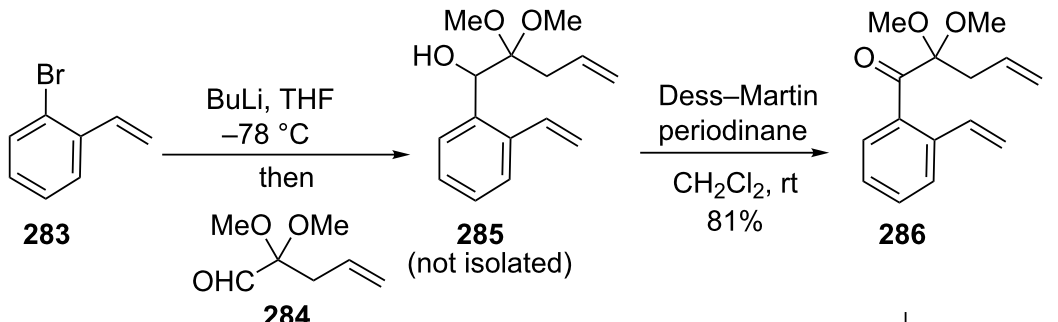

284
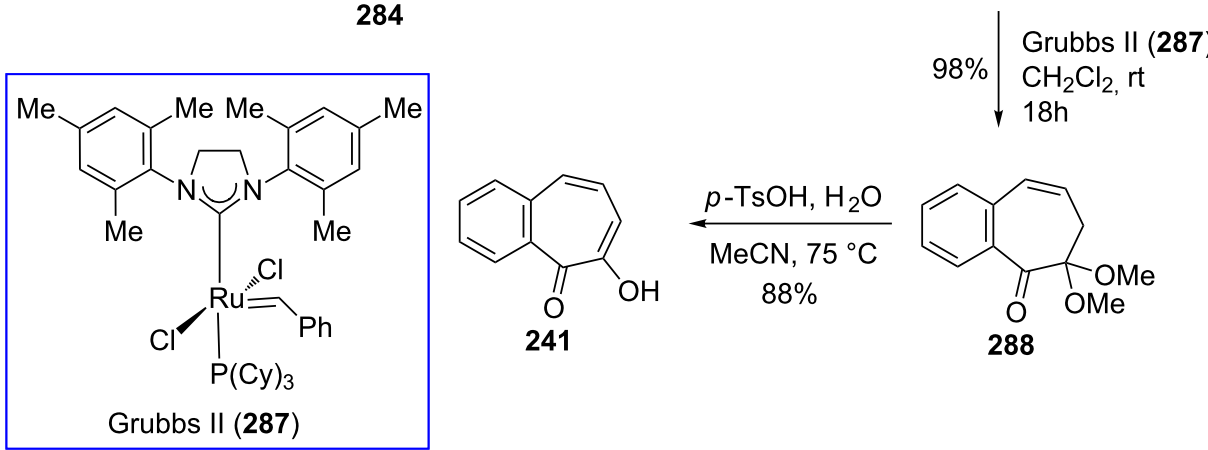

Grubbs II (287)

Scheme 48: Synthesis of 7-hydroxy-2,3-benzotropone (241) by ring-closing metathesis.

tion of 5-phenyl- and $p$-tolylazo-coupling products 292 [175] and 293 [174] (Figure 12). The reaction of 241 with diazomethane afforded methoxy-benzotropone 294 (Figure 12) [174].
Catalytic hydrogenation of 241 over Adams's catalyst $\left(\mathrm{PtO}_{2} \cdot \mathrm{H}_{2}\right)$ gave the diol 295 (Scheme 49) [162,165,174]. Treatment of 241 with alkaline hydrogen peroxide caused degradative fission to give $o$-carboxycinnamic acid (296) [165], while nitration of 241 
<smiles>[X]c1ccc2ccccc2c(=O)c1O</smiles>

289; $\mathrm{X}=\mathrm{Cl}$

290; $\mathrm{X}=\mathrm{Br}$

291; $\mathrm{X}=\mathrm{SO}_{3} \mathrm{H}$
292; $\mathrm{Ar}=\mathrm{Ph}$ 293; $\mathrm{Ar}=p$-tolyl<smiles>O=c1c(O)ccc(N=N[AlH2])c2ccccc12</smiles>

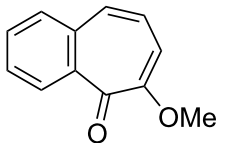

294
Figure 12: Various monosubstitution products 289-291 of 7-hydroxy2,3-benzotropone (241)

with nitric acid in an acetic acid solution afforded 2,4-dinitro-1naphthol (297) [175] (Scheme 49). Yoshioka's group studied the photochemical behavior of benzotropolone 241 (Scheme 49) [176]. Irradiation of a dilute solution of $241 \mathrm{~A}$ in methanol with Pyrex-filtered light led to the formation of 1-hydroxy-6,7-benzobicyclo[3.2.0]hepta-3,6-dien-2-one (299) in good yield as a major product. The formation of this product has been described either by the initial formation of $\mathbf{2 9 8}$ followed by rearrangement or by a mechanism with $241 \mathrm{~B}$ as an intermediate. Also, Aihara's group reported excited-state intramolecular proton transfer (ESIPT) and aromaticity studies for 241A and 241B [177].

\subsection{4-Hydroxy-2,3-benzotropone (174)}

\subsubsection{Synthesis of 4-hydroxy-2,3-benzotropone (174):} Benzotropolone 174 was prepared through intermediate bis-enol acetate obtained from reaction between benzo[7]annulene-3,7dione (300) and isopropenyl acetate followed by dehydrogenation using $\mathrm{N}$-bromosuccinimide, and its properties were compared with those of benzotropolone 241A (Scheme 50) [178]. The benzotropolone $\mathbf{1 7 4}$ could also be prepared from diester 301 in a similar way (Scheme 50) [179]. The simultaneous hydrolysis and decarboxylation of benzotropolone-diester 304 to $\mathbf{1 7 4}$ were catalyzed by $\mathrm{NaOH}$.

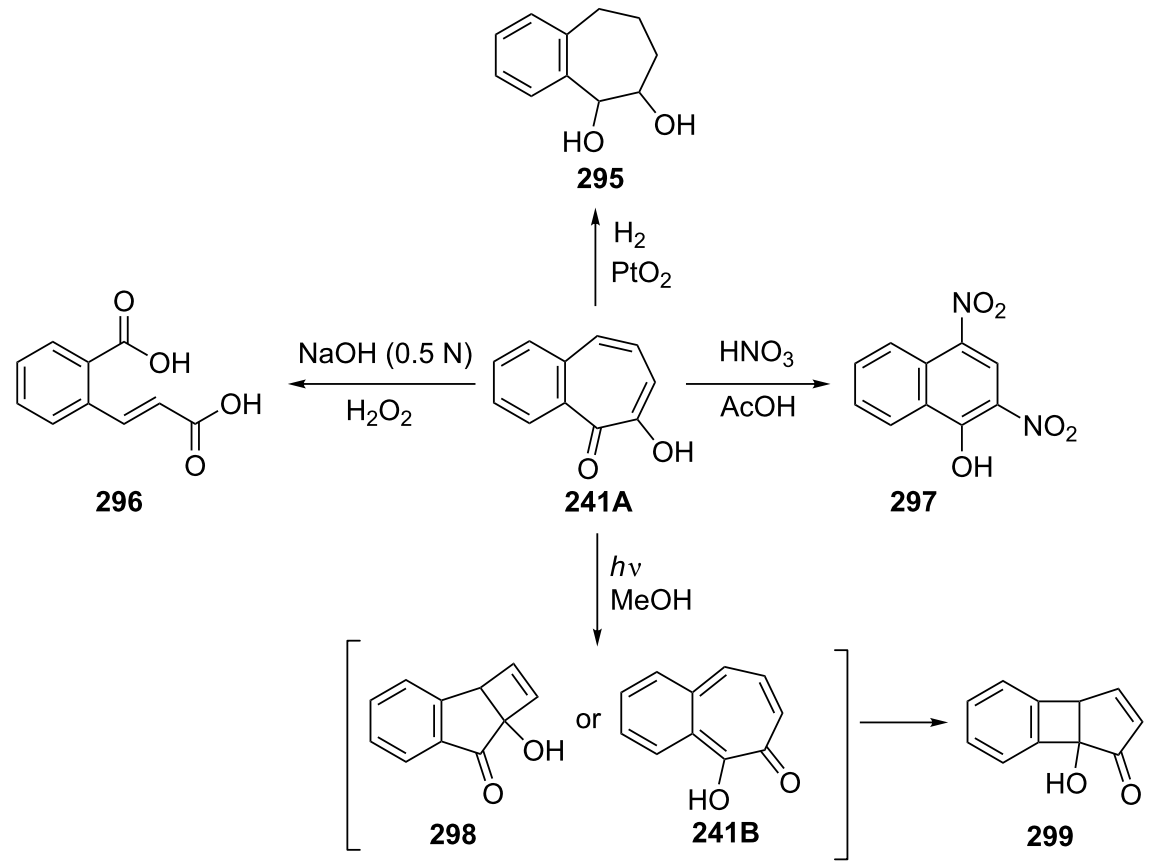

Scheme 49: Reaction of 7-hydroxy-2,3-benzotropone (241) with various reagents.<smiles>[R]C1C(=O)c2ccccc2C(=O)C1[R]</smiles>

$300 ; \mathrm{R}=\mathrm{H}$

301; $\mathrm{R}=\mathrm{CO}_{2} \mathrm{Et}$<smiles></smiles>

302; $\mathrm{R}=\mathrm{H}$

303; $\mathrm{R}=\mathrm{CO}_{2} \mathrm{Et}$<smiles>[R]c1cc(O)c2ccccc2c(=O)c1[R]</smiles>

$174 ; \mathrm{R}=\mathrm{H}$ 304; $\mathrm{R}=\mathrm{CO}_{2} \mathrm{Et}$ 
5.4.2. Reaction of 4-hydroxy-2,3-benzotropone (174): The structure of $\mathbf{1 7 4}$ was confirmed by the reduction of both benzotropolone 174 and diketone $\mathbf{3 0 0}$ into the diol $\mathbf{3 0 5}$ with catalytic hydrogenation (Scheme 51) [178].

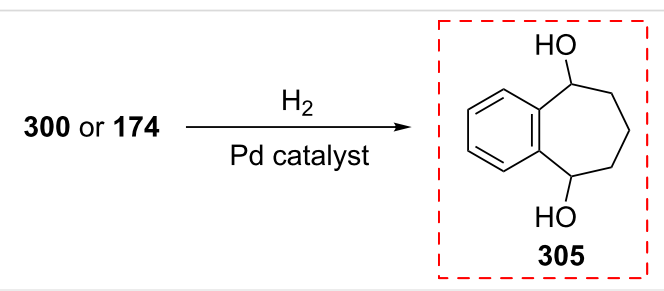

Scheme 51: Catalytic hydrogenation of diketones 300 and 174

\section{Halobenzotropones}

\subsection{Monohalobenzotropones}

6.1.1. One-step synthesis via dihalocarbene addition: Probably one of the most useful methods for the synthesis of halo- benzotropones is the formation of a three-membered intermediate by addition of halocarbenes to alkoxynaphthalenes. The carbene addition step is then a simultaneous ring-opening step to give the corresponding halobenzotropone (Scheme 52). In 1969 , two research groups independently reported the preparation of 2-bromo-4,5-benzotropone via adduct $\mathbf{3 0 8}$ starting from 2-methoxynaphthalene (306) using different dibromocarbene reagents (Scheme 52) [180,181]. The results for the synthesis of halo-benzotropones via carbene addition are shown in Table 2.

As shown in Table 2, the reported yields were extremely low. To further improve the yields of the products, different carbene sources and reaction conditions were tested. Parham's group reported treatment of 2-methoxynaphthalene (306) with 0.75 equivalents of the carbene source (ethyl trichloroacetate) and sodium methoxide to give the chlorobenzotropone 309 in $13 \%$ yield [184]. Uyehara's group also performed the same reaction by changing the ratios of the carbene sources and the
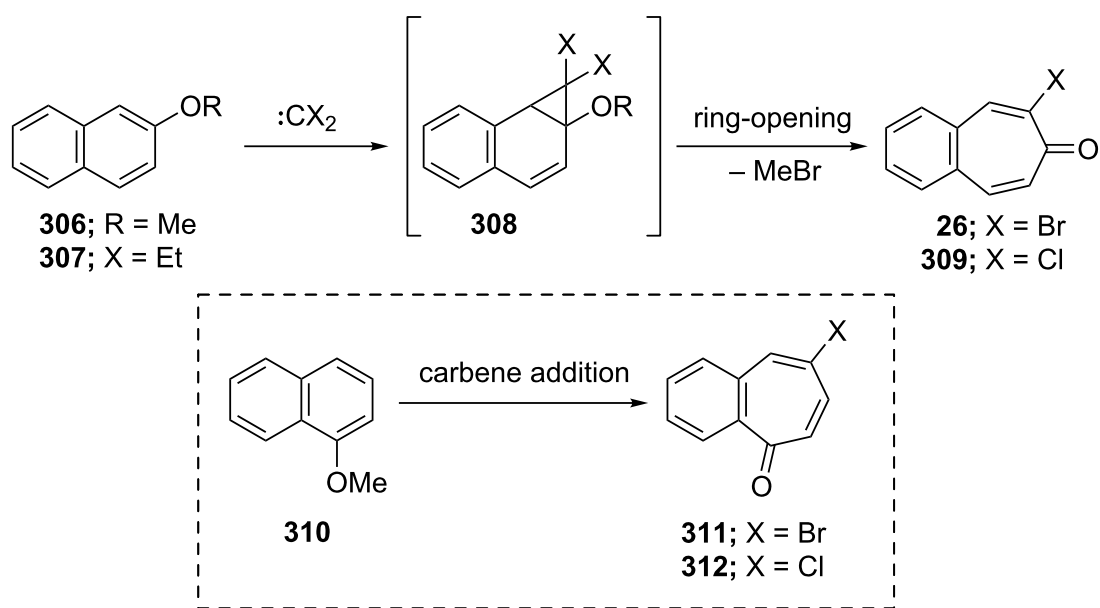

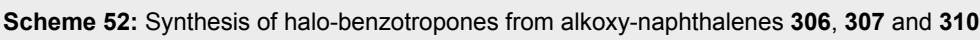

Table 2: Synthesis of some mono-halobenzotropones via carbene addition.

\begin{tabular}{|c|c|c|c|c|c|}
\hline entry & alkoxy-naphthalene & carbene source & product & yield (\%) & reference(s) \\
\hline 1 & \multirow{7}{*}{306} & \multirow{2}{*}{$\mathrm{CHBr}_{3}, t$-BuOK } & \multirow{3}{*}{26} & 11 & {$[181]$} \\
\hline 2 & & & & 20 & [182] \\
\hline 3 & & $\mathrm{PhHgCBr}_{3}$ & & 37 & {$[180]$} \\
\hline 4 & & $\mathrm{PhHgCCl}_{3}$ & \multirow{4}{*}{309} & 37 & {$[183]$} \\
\hline 5 & & $\mathrm{CHCl}_{3}, t$-BuOK & & 18 & {$[181]$} \\
\hline 6 & & $\mathrm{CHCl}_{3}, t$-BuOK & & 13 & [184] \\
\hline 7 & & $\mathrm{Cl}_{3} \mathrm{CCO}_{2} \mathrm{Et}, \mathrm{NaOMe}$ & & $13-33$ & {$[184,185]$} \\
\hline 8 & 307 & $\mathrm{Cl}_{3} \mathrm{CCO}_{2} \mathrm{Et}, \mathrm{NaOMe}$ & 309 & 66 & [185] \\
\hline 9 & \multirow{4}{*}{310} & $\mathrm{CHBr}_{3}, t$-BuOK & \multirow{2}{*}{311} & $15-25$ & {$[180,181]$} \\
\hline 10 & & $\mathrm{PhHgCBr}_{3}$ & & 33 & [181] \\
\hline 11 & & $\mathrm{PhHgCCl}_{3}$ & \multirow{2}{*}{312} & 17 & [183] \\
\hline 12 & & $\mathrm{Cl}_{3} \mathrm{CCO}_{2} \mathrm{Et}, \mathrm{NaOMe}$ & & 11 & {$[184]$} \\
\hline
\end{tabular}


base to the substrate [185]. When 7 equivalents of the carbene source and sodium methoxide were used, however, 309 was obtained in lower yield (33\%) and unexpected byproducts 313-315 were isolated in $6 \%, 23 \%$, and $0.2 \%$ yields, respectively (Figure 13).

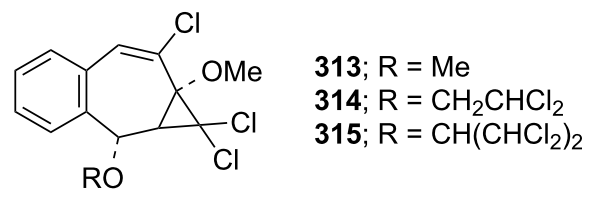

Figure 13: Unexpected byproducts 313-315 during synthesis of chlorobenzotropone 309 .

Several methods for the synthesis of 7-bromo-2,3-benzotropone (316) via dibromocarbene addition to 1-methoxynaphthalene (310) were reported (Figure 14) [180,181]. However, Moncur and Grutzner repeated the reaction as described and their studies led to the structural revision of the previously published structure of 7-bromo-2,3-benzotropone (316) to that of 5-bromo-2,3-benzotropone (311, Scheme 52, Figure 14) [186]. The structure of $\mathbf{3 1 1}$ has also been confirmed by independent extensive experiments and NMR data $[182,187]$. The chloro-derivative $\mathbf{3 1 2}$ was synthesized from the addition of dichlorocarbene to $\mathbf{3 1 0}$ in the same manner [187]. The results indicated that the dihalocarbenes prefer the addition of the 3,4double bond rather than the 1,2-double bond to 1-methoxynaphthalene (310). The position of the halogen substituent in $\mathbf{3 1 1}$ and $\mathbf{3 1 2}$ was also determined by the cycloadducts $\mathbf{3 2 0}$ and $\mathbf{3 2 1}$ between 5-halo-2,3-benzotropones and maleic anhydride (Figure 14) [185,187].

\subsubsection{Multistep synthesis via dihalocarbene addition: As} shown in Scheme 6, the synthesis of the bicyclic ring $\mathbf{3 3}$ from the dichlorocarbene adduct of oxobenzonorbornadiene $\mathbf{3 1}$ has also been reported by Ranken's group in two steps [53]. Hydrolysis of $\mathbf{3 3}$ in water under acidic conditions led to 2-chlorobenzotropone 309 in 20\% yield (Scheme 53) [53].

A multistep method for the synthesis of 2-bromobenzotropone $\mathbf{2 6}$ starting from dihydronaphthalene (322) was also realized by Balci's group (Scheme 54) [188]. After addition of dibromocarbene to 322, the obtained dibromocyclopropane $\mathbf{3 2 3}$ was submitted to silver ion-catalyzed ring expansion/hydrolysis in aqueous acetone (autoclave, $7.5-8.5 \mathrm{~atm}, 120-124{ }^{\circ} \mathrm{C}$ ) to yield a mixture of products, 324, 325, and 326 in 53\%, 3\%, and $8 \%$ yields, respectively. Bromo-alcohol 325 can be converted readily to unsaturated ketone $\mathbf{3 2 4}$ by $\mathrm{MnO}_{2}$ oxidation. Finally, the NBS-mediated bromination of $\mathbf{3 2 4}$ followed by dehydrobromination on silica gel led to the corresponding bromobenzotropone $\mathbf{2 6}$ in $80 \%$ yield.

6.1.3. Synthesis using benzosuberone: Jones' groups reported two synthetic ways for obtaining 7-bromo-2,3-benzotropone (316) starting from benzosuberone (162) (Scheme 55) $[135,136]$. As shown in Scheme 30, brominations of $\mathbf{1 6 2}$ were investigated using both molecular bromine and NBS conditions. On the other hand, excess bromination of benzosuberone 162 with NBS resulted in the formation of tribromide 328. Treatment of tribromide 328 with $\mathrm{LiCl}$ in DMF yielded 7-bromo-2,3benzotropone (316) in high yield. The results have shown that lithium chloride can be used as a mild dehydrobromination base to obtain the corresponding tropones from the multihalo-benzosuberones. Alternatively, 7-bromo-2,3-benzotropone (316) was

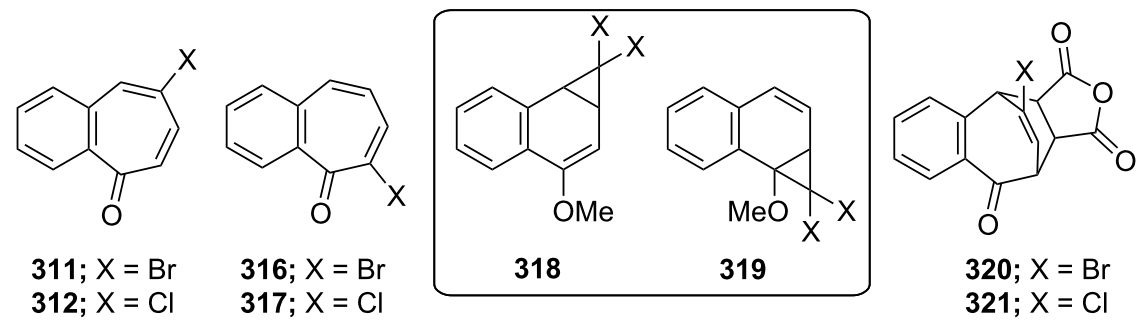

Figure 14: Some halobenzotropones and their cycloadducts.

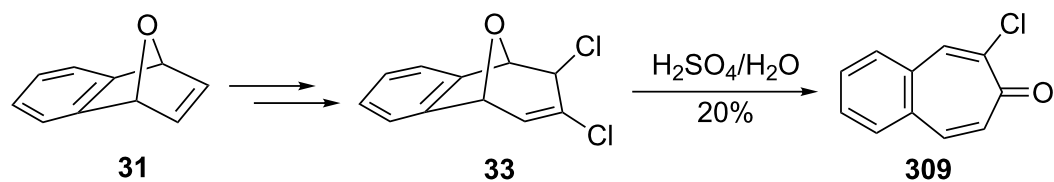

Scheme 53: Multisep synthesis of 2-chlorobenzotropone 309. 


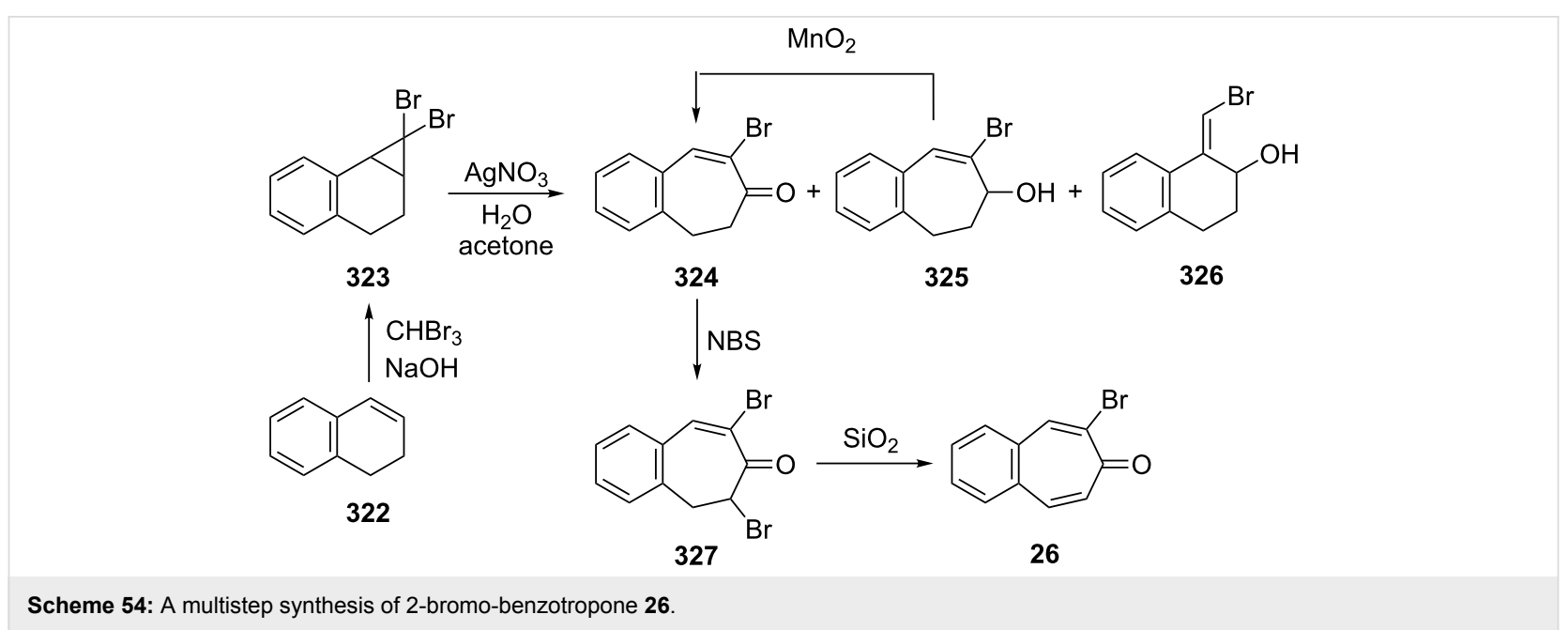

prepared in situ from benzotropone $\mathbf{1 2}$ and bromine in DMF followed by dehydrobromination (Scheme 55). The synthesis of benzotropone 12 from benzosuberone (162) is shown in Scheme 30. Benzosuberone (162) was also used as starting material for the synthesis of 5-bromo-2,3-benzotropone (311) (Scheme 55) [187,189].<smiles>O=C1CCCc2ccccc2C1=C=Cc1ccc2c(=O)c(Br)cc(Br)cc2c1</smiles>

Scheme 55: A multistep synthesis of bromo-2,3-benzotropones $\mathbf{3 1 1}$ and 316 .

6.1.4. Synthesis via oxidation: As shown in Scheme 4, bromobenzotropones $\mathbf{2 3}$ and $\mathbf{2 6}$ were obtained and characterized during the oxidation of both benzylic and allylic positions in 7-bromo-5H-benzo[7]annulene (22) [52]. To the best of those authors' knowledge, this is the first synthesis of 23. With the reaction conditions established, Balci's group next turned their attention to evaluating the scope and limitations of the oxidation reaction with different types of benzo[7]annulene (Scheme 56) [190]. Thus 8-bromo-5H-benzo[7]annulene (329) was oxidized with different oxidants to give a mixture of bromobenzotropones such as $\mathbf{2 3}, \mathbf{3 1 6}$, and $\mathbf{2 6}$. Formation of naphthaldehyde derivative $\mathbf{3 3 0}$ was also reported by $\mathrm{SeO}_{2}$-oxidation reaction (Scheme 56).

6.1.5. Synthesis via benzotropone precursors: Suzuki reported the formation and reactions of 2-carboxylic acid and 2,7dicarboxylic acid derivatives $\mathbf{3 3 1}$ and $\mathbf{3 3 2}$ of 4,5-benzotropone (Scheme 57) [191]. 2-Carboxylic acid-substituted 4,5-benzotropone 331 was converted to 2-bromo-4,5-benzotropone (26) via bromination in acetic acid followed by decarboxylation at $240{ }^{\circ} \mathrm{C}$.

The first synthetic methods for 6-chloro-2,3-benzotropone (335) were presented by Balci's group (Scheme 58) [52]. When dibromide 334 was dehydrobrominated by lithium chloride in $\mathrm{N}, \mathrm{N}$ dimethylformamide, the chloro derivative $\mathbf{3 3 5}$ was formed as a sole product without any other halo derivatives. Independently, the reaction of 6-bromo-2,3-benzotropone (23) with lithium chloride under the same reaction conditions gave 6-chloro-2,3benzotropone (335) in $96 \%$ yield. The proposed mechanism involves the intermediate $\mathbf{3 3 6}$ formed by Michael addition of a chloride ion to the $\beta$-position of the carbonyl group followed by the elimination of a bromide ion as a better leaving group.

\subsection{Reactions of monohalo-benzotropones}

6.2.1. Reactions with nucleophiles: Crabbé's group reported the reactions of 7-bromo-2,3-benzotropone (316) with several primary and secondary amines (Scheme 59) [192]. Amines such as ammonia, dimethylamine, and morpholine analogous amines afforded the corresponding cine-substitution products such as 337, whereas the reactions of compound $\mathbf{3 1 6}$ with various amines such as methylamine, ethylamine isopropylamine, and ethanolamine gave aromatic lactams such as $\mathbf{3 3 8}$ and tricyclic amino derivatives as 339, in addition to the desired cine-substitution products, under similar reaction conditions. It was proposed that the aromatic lactam was formed via cleavage of the 


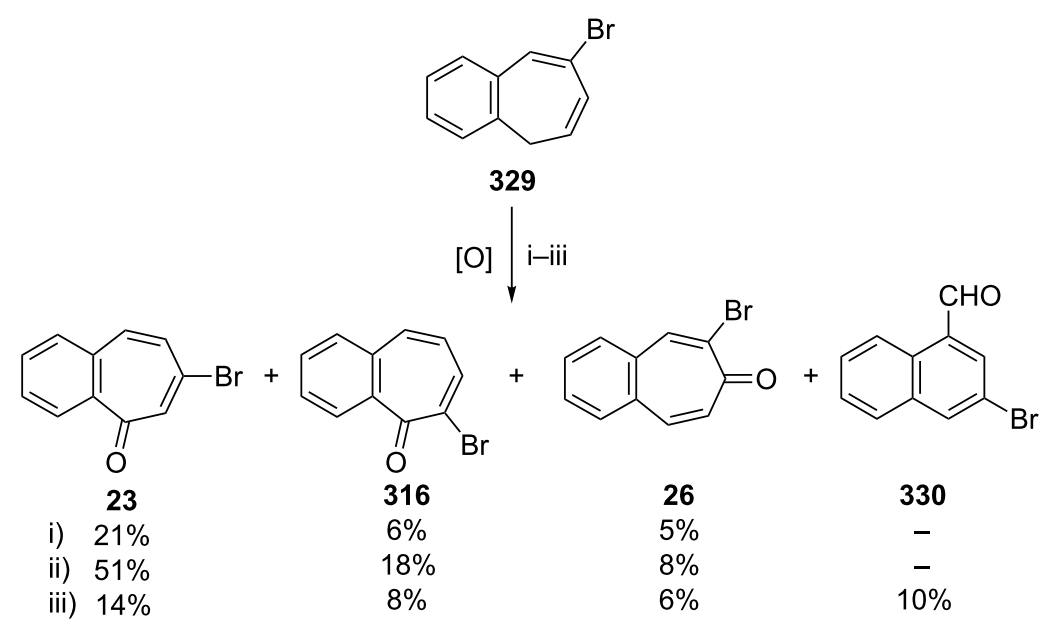

i) $\mathrm{CrO}_{3} / \mathrm{AcOH}$; ii) $\mathrm{CrO}_{3} /$ pyridine; iii) $\mathrm{SeO}_{2} / \mathrm{H}_{2} \mathrm{O}$

Scheme 56: Oxidation reactions of 8-bromo-5H-benzo[7]annulene (329) with some oxidants.

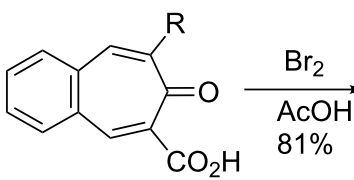

331; $\mathrm{R}=\mathrm{H}$

332; $\mathrm{R}=\mathrm{CO}_{2} \mathrm{H}$<smiles>O=C(O)c1cc2ccccc2cc(Br)c1=O</smiles>

333
26

Scheme 57: Synthesis of 2-bromo-4,5-benzotropone (26)

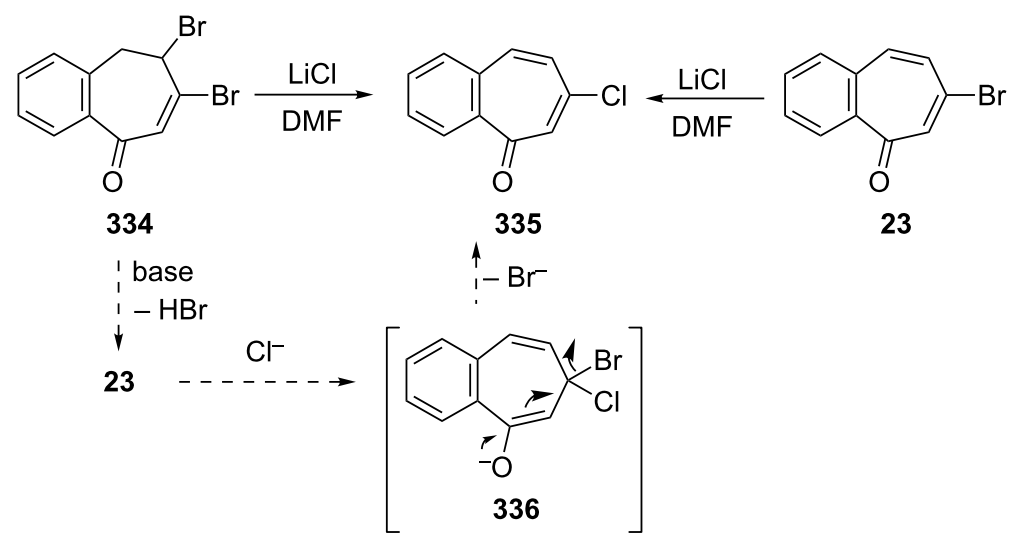

Scheme 58: Synthesis of 6-chloro-2,3-benzotropone (335) using $\mathrm{LiCl}$ and proposed intermediate 336.

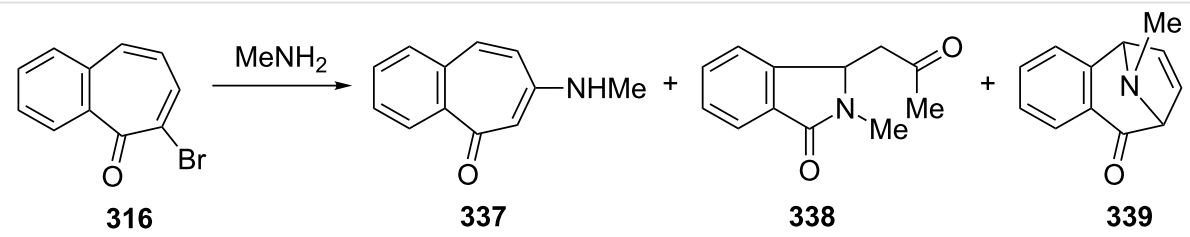

Scheme 59: Reaction of 7-bromo-2,3-benzotropone (316) with methylamine. 
troponoid ring. The tricyclic ring was derived by a sequence of 1,6-addition reaction of the amine to the tropone and intramolecular displacement of the bromine by an attack from the nitrogen.

Namboothiri and Balasubrahmanyam showed that the ipso/cine regioselectivity in the amination of some bromobenzotropones $\mathbf{2 6}$ and $\mathbf{3 1 1}$ was dependent upon the temperature at which the reaction was conducted (Scheme 60) [182]. The reactions of 2-bromo-4,5-benzotropone (26) and 5-bromo-2,3-benzotropone (311) with dimethylamine were carried out at a high temperature and ipso-products (340 and $\mathbf{3 4 2}$ ) were more favorable than cine-products (341 and 343).

Namboothiri and Balasubrahmanyam also investigated transformations in bromo- and alkoxybenzotropones (Scheme 61) [182]. The treatment of bromobenzotropones 26 and $\mathbf{3 1 1}$ with sodium methoxide in methanol under reflux led to a mixture of ipso and cine products. While the ipso product 344 in the case of $\mathbf{3 1 1}$ is dramatically favored over the cine product $\mathbf{3 4 5}$ (96:4), the ipso/cine ratio $\mathbf{3 4 6 / 3 4 7}$ in the case of $\mathbf{2 6}$ is 22:76. However, a small (2\%) amount of 4,5-benzotropone (11) was formed under these conditions via presumably reductive removal of the bromine. In addition, a trapping experiment with 1,3diphenylisobenzofuran (DPIBF) furnished evidence for the formation of benzodehydrotropones $\mathbf{3 4 8}$ and $\mathbf{3 5 0}$, generated by the reaction of $\mathbf{2 6}$ and $\mathbf{3 1 1}$ with $t$-BuOK (Scheme 62).

6.2.2. Miscellaneous reactions: The direct functionalization of important motifs such as benzotropones, cycloheptenones, azepanes, and piperidines is of ubiquitous importance. In 2015, Beng's group focused on the cobalt-catalyzed reductive crosscoupling of versatile $\alpha$-bromo enones with cyclic $\alpha$-bromo enamides under mild conditions (Scheme 63) [193]. The coupling of bromo enecarbamate $\mathbf{3 5 2}$ and 7-bromo-2,3-benzotropone (316) was efficiently accomplished at room temperature<smiles>CN(C)c1cc2ccccc2ccc1=O</smiles>

340

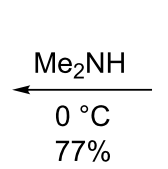

$77 \%$<smiles>O=c1ccc2ccccc2cc1Br</smiles>

26<smiles>CN(C)c1cc(=O)ccc2ccccc12</smiles>

341<smiles>O=c1ccc(Br)cc2ccccc12</smiles><smiles>CN(C)c1ccc(=O)c2ccccc2c1</smiles><smiles>CN(C)c1cccc(=O)c2ccccc12</smiles>

Scheme 60: Reactions of bromo-2,3-benzotropones 26 and 311 with dimethylamine.<smiles></smiles><smiles>O=c1ccc2ccccc2cc1Br</smiles>

26<smiles></smiles>

(22\%)<smiles>COc1cc(=O)ccc2ccccc12</smiles>

347 $(76 \%)$ 

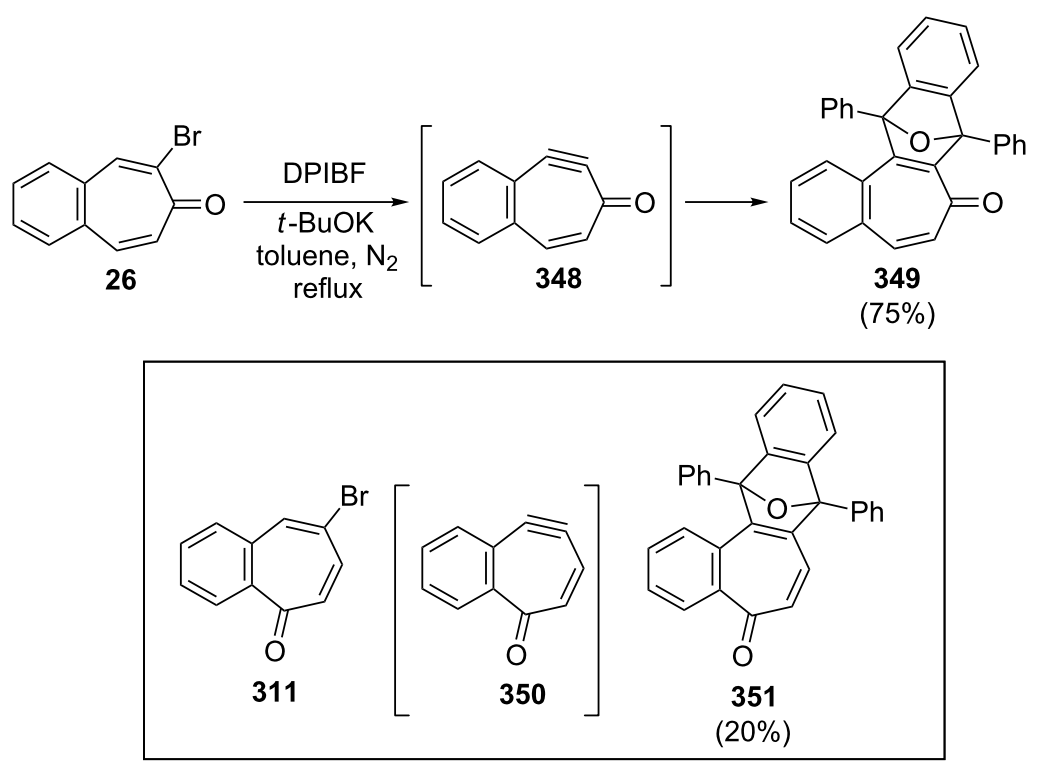

Scheme 62: Reactions of bromobenzotropones 26 and 312 with $t$-BuOK in the presence of DPIBF.
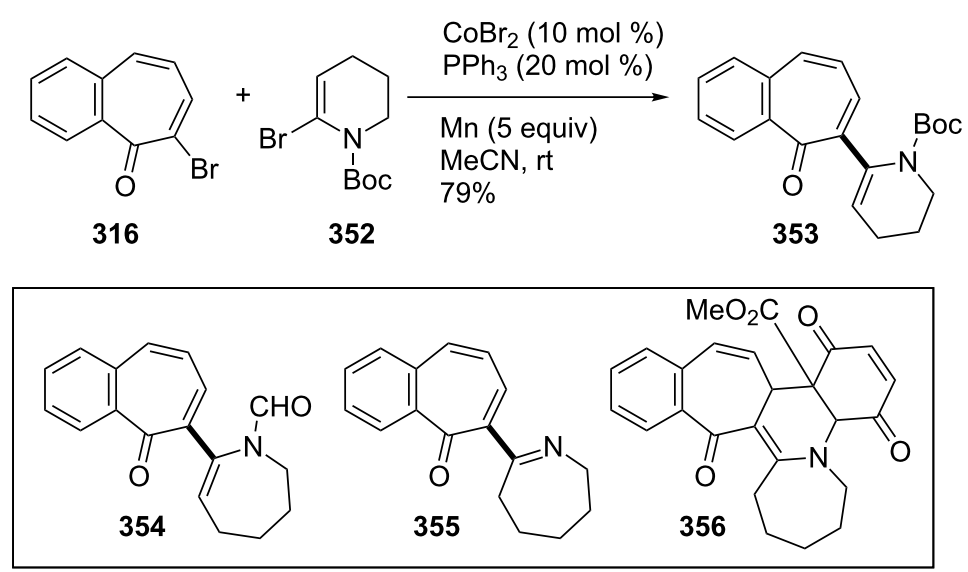

Scheme 63: Cobalt-catalyzed reductive cross-couplings of 7-bromo-2,3-benzotropone (316) with cyclic a-bromo enamides.

using the conditions described in Scheme 61. The coupling product 354 was also prepared by this method. Treatment of imino diene 355 with the corresponding ester-quinone as an activated dienophile resulted in the formation of the highly functionalized pentacyclic 356 (Scheme 63).

As illustrated in Scheme 35 and Figure 14, benzotropones can be used to afford cycloadducts and their photochemical products. In this context, the cycloaddition of 7-bromo-2,3-benzotropone (316) to maleic anhydride was reported by Hassner's group (Figure 15) [148]. The direct and sensitized photolysis of the cycloadduct 357 afforded di- $\pi$-methane rearrangement product 358, which was confirmed by X-ray diffraction.<smiles>O=C1c2ccccc2[C@@H]2C=CC(C(=O)OC2=O)C1Br</smiles>

357

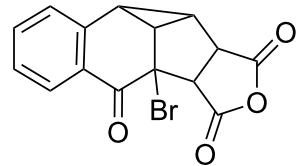

358
Figure 15: Cycloadduct 357 and its di-m-methane rearrangement product 358.

Simple and practical routes to 5,6,8,9-tetrahydro-7 $\mathrm{H}$ benzo[7]annulen-7-one (40) were reported by Uyehara's group [184]. Catalytic hydrogenation of 2-chloro-4,5-benzotropone 
(311) with $5 \%$ palladium on activated charcoal in methanol gave the ketone $\mathbf{4 0}$ in $97 \%$ yield (Scheme 64 ).<smiles>O=c1ccc2ccccc2cc1Cl</smiles>

311<smiles>COC(=O)C(=O)OCc1ccccc1</smiles><smiles>O=C1CCc2ccccc2CC1</smiles>

40
Scheme 64: Catalytic hydrogenation of 2-chloro-4,5-benzotropone (311).

\subsection{Dibromobenzotropones}

6.3.1. Synthesis from benzotropones: Decarboxylation of both diacid- 332 and monoacid-benzotropone 333 by Hunsdiecker-Simonini reaction gave 2,7-dibromo-4,5-benzotropone (359) in $31 \%$ and $12 \%$ yield, respectively (Scheme 65) [191]. Bromination of 2,3-benzotropone (12) afforded tetrabromide 260 only, which underwent dehydrobromination to yield 5,7dibromo-2,3-benzotropone (261A, Scheme 65) [134].

6.3.2. Synthesis from benzosuberone: An alternative protocol for the preparation of the dibromobenzotropones $261 \mathrm{~A}$ and 261B was bromination/dehydrobromination starting from benzosuberone (162) (Scheme 66) [134,163,189].
6.3.3. Reactions of dibromobenzotropones: The transformations of isomeric dibromo-benzotropones 261A and 261B are summarized in Scheme 67 [163,189]. Dibromo-benzotropone $261 \mathrm{~A}$ was treated with $\mathrm{KOH}$ in methanol at room temperature for $24 \mathrm{~h}$ followed by acidification using $\mathrm{HCl}$ to yield 6-methoxy- and 6-hydroxybenzotropones 360 and 361 and an uncharacterized product. Tribromide 362 was prepared by treating 162 with refluxing bromine. Treatment of dibromobenzotropones with hydroxylamine caused a cine-reaction to give oximes 363 and 364. The Diels-Alder adducts 365 and 366 of 261A and 261B with maleic anhydride were used to elucidate the position of the bromo substituents. The reduction of 261B in acetic acid with $4 \mathrm{~mol}$ equivalent of hydrogen in the presence of $5 \%$ palladium-on-charcoal and anhydrous sodium acetate, and by subsequent treatment with 2,4-dinitrophenylhydrazine, resulted in the formation of hydrazone 367. Moreover, the hydrazone 368 was prepared in an analogous manner using 2 equivalents of hydrogen.

\subsection{Halobenzotropolones}

6.4.1. Synthesis of halobenzotropolones: The benzotropolones undergo electrophilic substitution in the form of halogenation and their reactions towards halogens are similar. Hoshino and Ebine reported the formation and reaction of bromo derivatives $\mathbf{3 6 9}$ and $\mathbf{3 7 0}$ of benzotropolone 239B with<smiles>O=C(O)c1cc2ccccc2cc(C(=O)O)c1=O</smiles><smiles>CC(C)(C)c1cc2ccccc2cc(Br)c1=O</smiles><smiles></smiles><smiles>O=c1cc(Br)ccc2ccccc12</smiles>

12<smiles>O=C1c2ccccc2C(Br)C(Br)C(Br)C1Br</smiles>

260

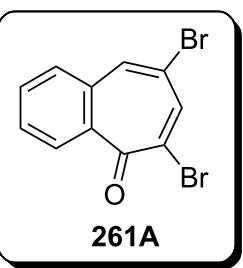

Scheme 65: Synthesis of dibromo-benzotropones from benzotropones.<smiles>CCCc1ccccc1C(=O)OC(C)(C)C</smiles>

162<smiles>O=C1c2ccccc2CCCC1(Br)Br</smiles>

260<smiles>[X]c1cc(Br)c(=O)c2ccccc2c1[X]</smiles>

261A; $X=\mathrm{H}, Y=B r$ 261B; $X=B r, Y=H$ 

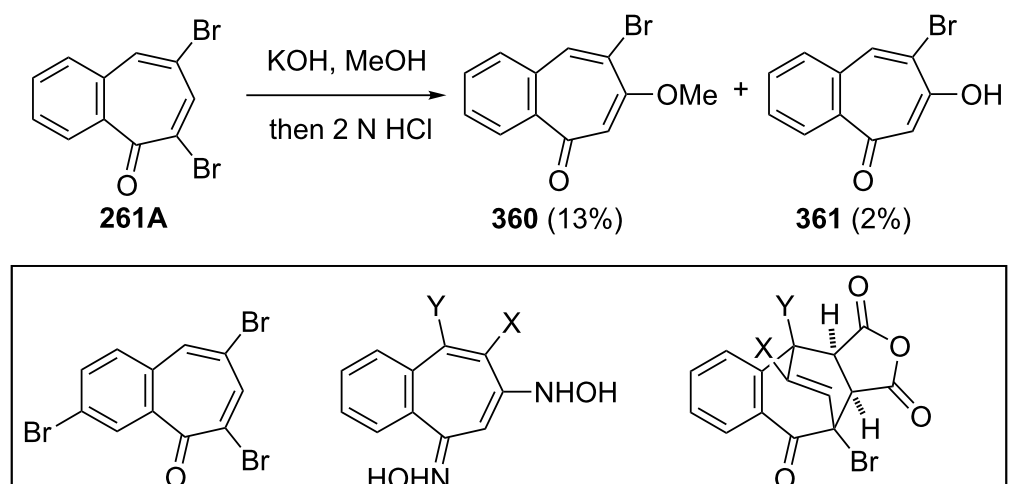<smiles>[X]c1c(NO)cc(=N)c2ccccc2c1[Y]</smiles>

$\mathrm{HOHN}$

$362(29 \%)$

363; $\mathrm{X}=\mathrm{Br}, \mathrm{Y}=\mathrm{H}(71 \%)$

364; $X=H, Y=B r(73 \%)$

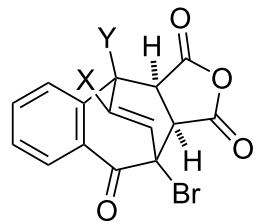

$365 ; \mathrm{X}=\mathrm{Br}, \mathrm{Y}=\mathrm{H}(68 \%)$

366; $X=H, Y=B r(55 \%)$<smiles>N=C1CCCCc2ccccc21</smiles>

367<smiles>[3H]N</smiles><smiles>N=c1ccccc2ccccc12</smiles>

368 $\mathrm{N}$<smiles>Cc1ccc([N+](=O)[O-])cc1[N+](=O)[O-]</smiles><smiles>Cc1ccc([N+](=O)[O-])cc1[N+](=O)[O-]</smiles>

Scheme 67: Some transformations of isomeric dibromo-benzotropones 261A/B

bromine in acetic acid under various conditions (Scheme 68) [194]. Bromobenzotropolones 372-376 and 290 were also synthesized by bromination/dehydrobromination of the corresponding benzotropolenes (Figure 16) [165,179,194-197].

A short communication describing how 3,4-benzotropolone (241A) can be chlorinated to yield monochloro-3,4-benzotropolone was presented by Nozoe's group [174]. Ebine studied in more detail the chlorination and iodination of $241 \mathrm{~A}$
(Scheme 69, Scheme 70 and Figure 17) [194,198]. Treatment of

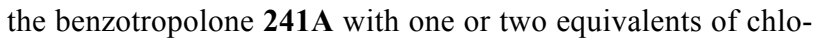
rine in acetic acid afforded 5,7-dichloro-3,4-benzotropolone (378) in low to fair yield. When reacted with a concentrated hydrochloric acid, both $\mathbf{2 9 0}$ and $\mathbf{3 7 5}$ underwent halogen exchange to give $\mathbf{2 8 9}$ and $\mathbf{3 7 8}$, respectively. A similar substitution was also observed when $\mathbf{3 7 5}$ was reacted with thionyl chloride. Bromo-chloro-3,4-benzotropolones 379-381 were prepared using similar procedures (Figure 17). 7-Iodo-3,4-benzo-

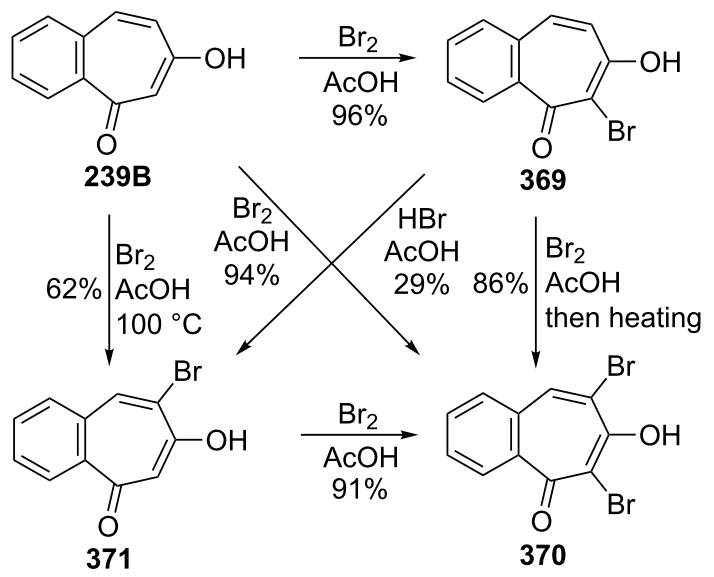

Scheme 68: Transformations of benzotropolone 239B to halobenzotropolones 369-371. 
<smiles>O=c1c(Br)c(O)c(Br)cc2ccccc12</smiles>
372

290<smiles>O=c1c(O)c(Br)ccc2ccccc12</smiles><smiles></smiles>
373<smiles>O=c1c(O)c(Br)cc(Br)c2ccccc12</smiles>

375<smiles>O=c1c(Br)cc2ccccc2c(Br)c1O</smiles>

374<smiles>O=c1c(Br)cc(Br)c(O)c2ccccc12</smiles>

Figure 16: Bromobenzotropolones 372-376 and 290 prepared via bromination/dehydrobromination strategy.

tropolone (382) was also obtained in $40 \%$ yield by the reaction between benzotropolone 241A and sodium iodide/sodium iodate in acetic acid (Scheme 70) [195].

6.4.2. Reaction of halobenzotropolones: Dehalogenation of halobenzotropolones: Hoshino and Ebine reported that palladium-catalyzed hydrogenation of bromobenzotroponoids 369 and 370 resulted in debromination of halogen atoms to give 239B as depicted in Scheme 71 [194]. However, hydrogenation of 375 gave 241A in low yield (Scheme 72) [195]. Debromination of monobromide $\mathbf{2 9 0}$ with hydrobromic acid in acetic acid afforded 241A in 73\% yield, whereas the reaction of dibromide $\mathbf{3 7 5}$ under the same conditions provided monobromide $\mathbf{3 8 3}$ in $85 \%$ yield as the debromination product (Scheme 72) [198].

Oxidation of halobenzotropolones: Oxidation reactions of halo-benzotropolones were often used to determine the structures of benzotroponoids $[194,198,199]$. For clarification of the positions of substituents in the final compounds, Ebine reported

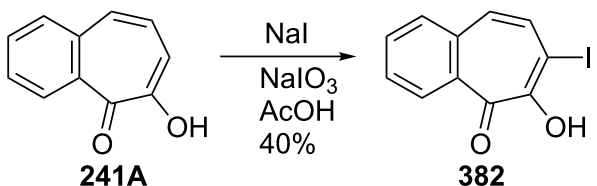

Scheme 70: Synthesis of 7-iodo-3,4-benzotropolone (382)<smiles>O=c1c(O)c(Br)cc(Cl)c2ccccc12</smiles><smiles>O=c1c(O)c(Cl)cc(Br)c2ccccc12</smiles><smiles>O=c1c(Cl)c(O)c(Br)cc2ccccc12</smiles>

Figure 17: Bromo-chloro-derivatives 379-381 prepared via chlorination.<smiles></smiles>

Scheme 71: Hydrogenation of bromobenzotropolones 369 and $\mathbf{3 7 0}$

that oxidation of dihalo-benzotropones $\mathbf{3 7 0}$ and $\mathbf{3 8 1}$ with alkaline hydrogen peroxide gave phthalic acid (385) in $40 \%$ and $35 \%$ yields, respectively, while that of monohalobenzotropolenes 369, 384, and 290 afforded $o$-carboxycinnamic acid (273) in 47\%,33\%, and 33\% yields, respectively (Figure 18) [194]. Bromobenzotropolones 290 and 375 were nitrated in acetic acid to yield the same nitration product $\mathbf{3 8 6}$ in $29 \%$ and<smiles></smiles>

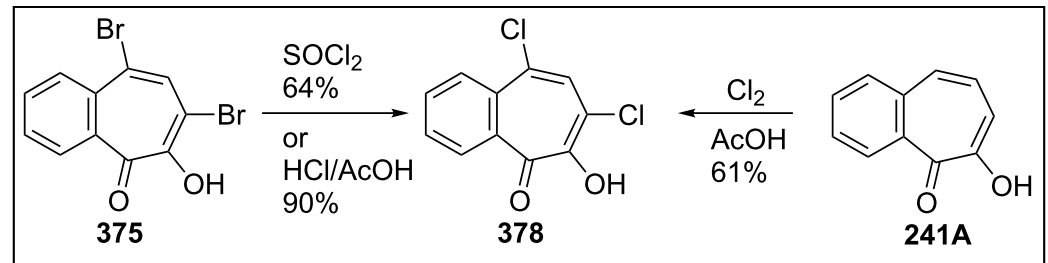




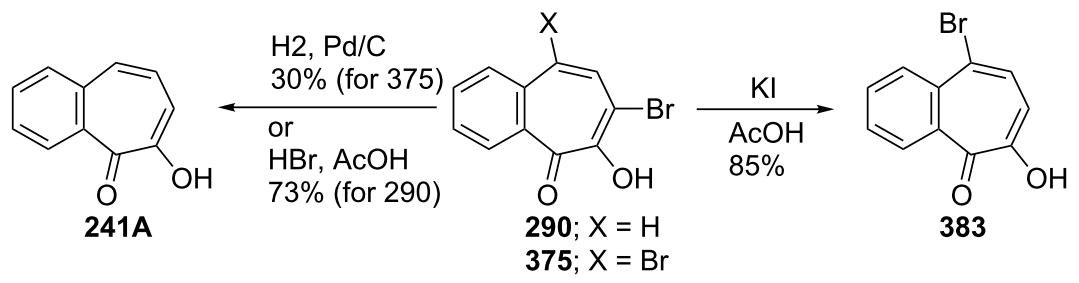

Scheme 72: Debromination reactions of mono- and dibromides 290 and $\mathbf{3 7 5}$.

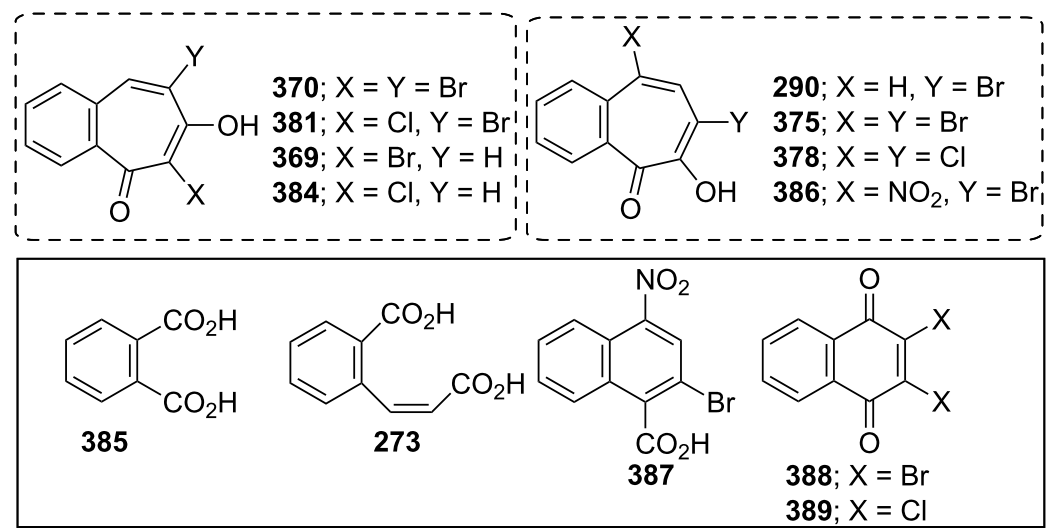

Figure 18: Nitratation and oxidation products of some halobenzotropolenes.

16\% yields (Figure 18) [199]. 5-Nitro-7-bromo-3,4-benzotropolone (386) rearranged to 2-bromo-4-nitro-1-naphthoic acid (387) in $80 \%$ yield with alkali (Figure 18 ). When reacted with exhaustive bromination (or chlorination) in acetic acid, dibromobenzotropolone 375 gave 2,3-dibromo-1,4-naphthoquinones (388) in $81 \%$ yield (or $\mathbf{3 8 9}$ in $35 \%$ yield) as an unexpected product (Figure 18). The nitration of $\mathbf{3 7 5}$ in concentrated sulfuric acid also produced the corresponding $\mathbf{3 8 8}$ in $29 \%$ yield (Figure 18). A reaction of 5,7-dichloro-3,4-benzotropolone (378) under the same conditions gave dichloronaphthoquinone 389 in $16 \%$ yield (Figure 18). The author proposed possible tentative mechanisms for the formation of naphthoquinones.

Azo-coupling reaction of halo-benzotropolones: The azocoupling reaction of 7-bromobenzotropolones 294 with diazonium cations, which are generated by treatment of aromatic amines with nitrous acid and a stronger mineral acid in acetic acid, resulted in 5-phenylazo-7-bromo-3,4-benzotropolone (390) in $28 \%$ yield (Scheme 73) [175]. However, when the same reaction was carried out in a pyridine solution, the formation of rearrangement products 391 and 392 in 29\% and $9 \%$ yields was reported (Scheme 73 ). Azo-coupling reactions of 5,7-dihalo-3,4-benzotropolones $\mathbf{3 7 5}$ and $\mathbf{3 7 8}$ under similar conditions provided the corresponding naphthols $393-395$ in

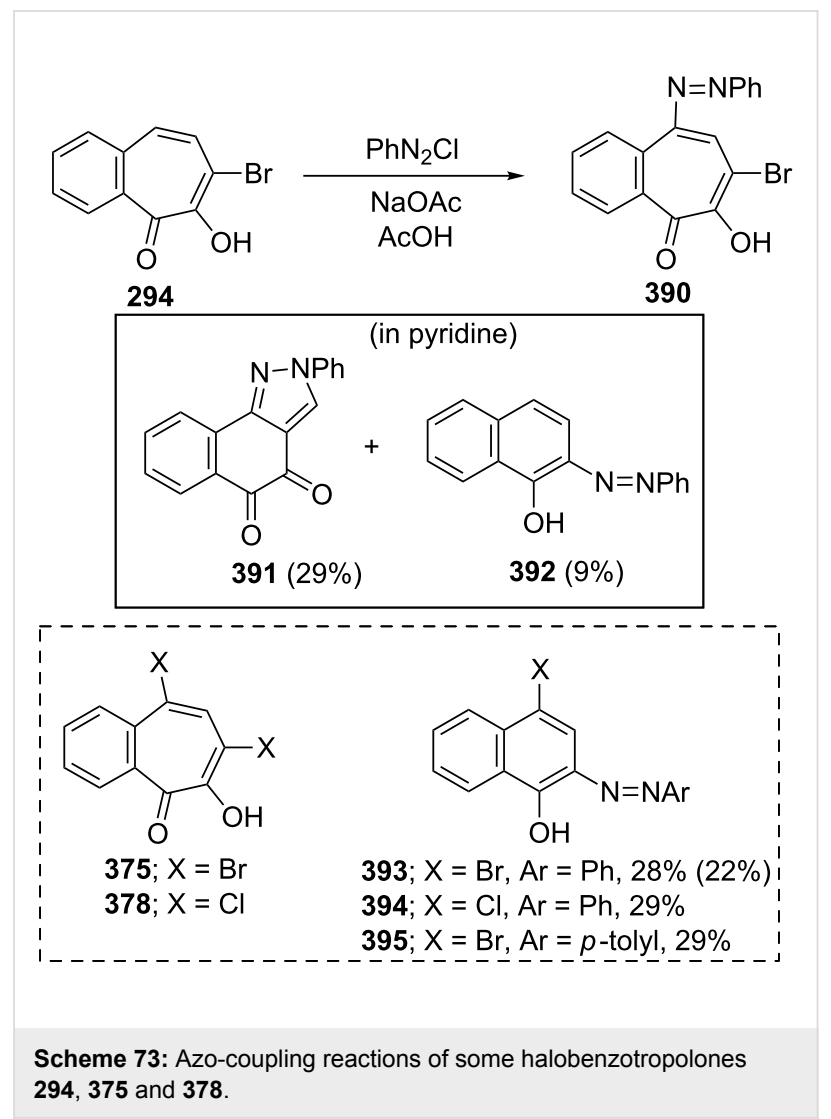


low yields (Scheme 73). The possible courses for the formation of coupling products were discussed [175].

\section{Dibenzotropones}

There are four possible dibenzotropone isomers: 2,3;4,5-dibenzotropone (396), 3,4;5,6-dibenzotropone (397), 2,3;5,6-dibenzotropone (398), and 2,3;6,7-dibenzotropone (399, Figure 19). We reported comprehensive syntheses and applications of dibenzosuberenones [45]. Thus, this section does not cover the chemistry of dibenzotropones.

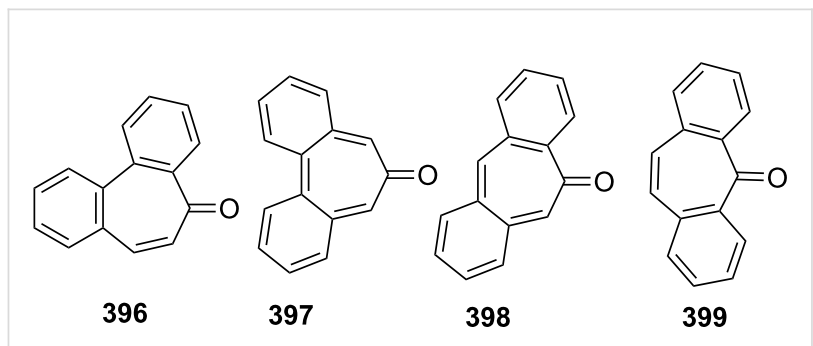

Figure 19: Four possible isomers of dibenzotropones 396-399.

\section{Tribenzotropone (400)}

Tribenzotropone, or $9 H$-tribenzo[a,c,e][7]annulen-9-one (400A), has a tetracyclic structure, consisting of a seven-membered ring fused to benzene rings (Figure 20). Based on experimental observations, it is suggested that tribenzotropone (400) shows structural resistance against planarity arising from an angular strain of a planar 7-membered ring as well as the unfavorable steric interactions between the ortho-hydrogen atoms (Figure 20) [200]. As a measure of the characteristics of tropone, the calculated circuit resonance energies show that tribenzotropone (400) among the other benzotropones has a small circuit resonance energy associated with the number of benzene rings [155]. The charge density for the corresponding uniform reference frame of $\mathbf{4 0 0}$ shows that the oxygen atom occupies the site of the largest charge density.

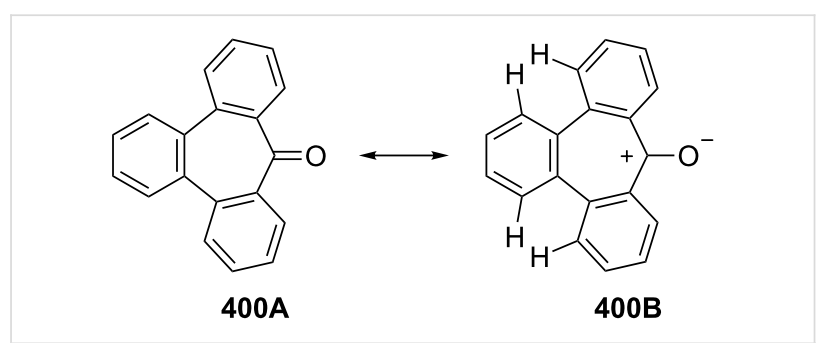

Figure 20: Resonance structures of tribenzotropone (400).

\subsection{Synthesis of tribenzotropone}

The first synthesis of tribenzotropone (400) was simultaneously reported by two groups in 1957. Stiles' group reported the synthesis of $\mathbf{4 0 0}$ in $24 \%$ yield via the rearrangement of the diazonium salt of 9-(2-aminophenyl)-9H-fluoren-9-ol (402) in two steps (Scheme 74) [200]. A multistep preparation with difficulties or poor yields of $\mathbf{4 0 0}$ was reported by Bergmann's group starting from cycloaddition of butadiene and cinnamaldehyde (403) in 12 steps (Scheme 74) [201]. Moreover, Diels-Alder trapping with furan of an alkyne derivative from benzotropone 399 followed by catalytic hydrogenation and polyphosphoric acid (PPA)-assisted dehydration steps provided an excellent approach to the synthesis of tribenzotropone (400) in a $31 \%$ overall yield over five steps (Scheme 75) [202]. Wan's group also reported the deoxygenation with $\mathrm{Fe}_{2}(\mathrm{CO})_{9}$ of the cycloadduct $\mathbf{4 0 4}$ to $\mathbf{4 0 0}$ [203].

Koo's group reported a challenging method for the synthesis of $\mathbf{4 0 0}$ in $38 \%$ overall yield by ring-expansion method as a key step starting from readily available 9,10-phenanthraquinone (406, Scheme 76) [204]. A mild and selective indium-mediated nucleophilic addition of allyl bromide followed by the addition

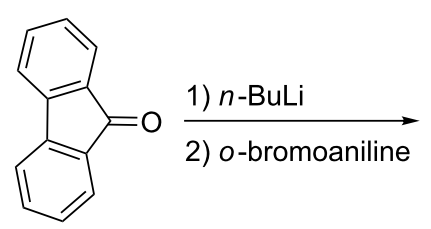

401

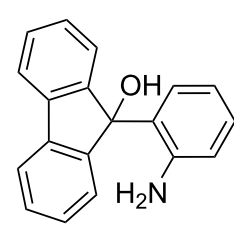

402

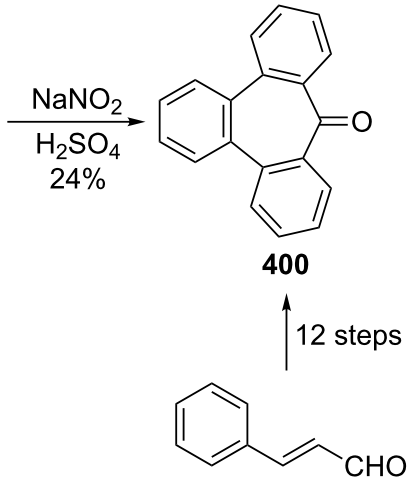

403 


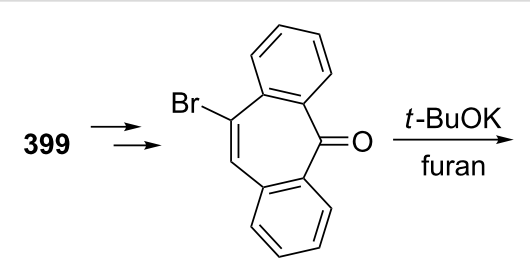

404

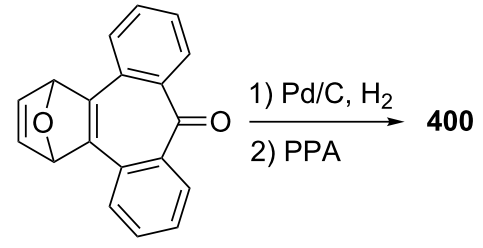

405

Scheme 75: Synthesis of tribenzotropone (400) from dibenzotropone 399.<smiles>O=C1C(=O)c2ccccc2-c2ccccc21</smiles>

406
1) In, allyl bromide $89 \%$

2) vinylmagnesium bromide $83 \%$

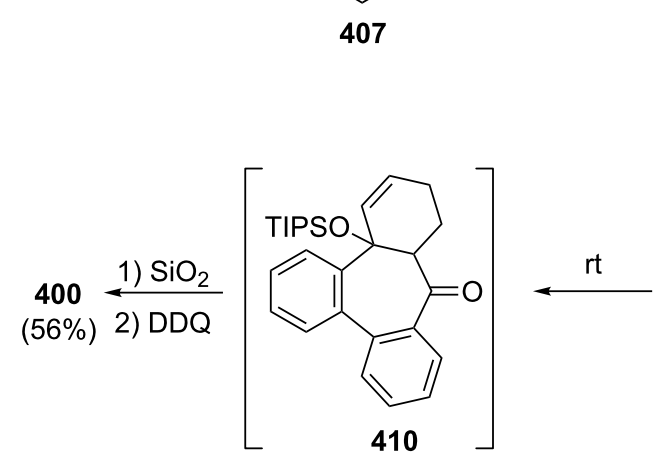<smiles>C=CCC(=O)c1ccccc1-c1ccccc1C(=O)CC=C</smiles>

408

TIPSOTf $\mathrm{Et}_{3} \mathrm{~N}, \mathrm{CH}_{2} \mathrm{Cl}_{2}$ rt, $1.5 \mathrm{~h}$<smiles>C=CCC(=O)c1ccccc1-c1ccccc1OCC(=O)O</smiles>

409

Scheme 76: Synthesis of tribenzotropone (400) from 9,10-phenanthraquinone (406).

of vinylmagnesium bromide led to the formation of diol $\mathbf{4 0 7}$ with allyl and vinyl substituents, which underwent an oxidative ring-opening reaction to form diketone $\mathbf{4 0 8}$. Then the reaction of $\mathbf{4 0 8}$ with triisopropyl triflate (TIPSOTf) in the presence of triethylamine afforded the desired silyl enol ether 409, which contains the required electron-rich diene and electron-deficient dienophile units for intramolecular cycloaddition. Unexpectedly, the intramolecular Diels-Alder reaction of $\mathbf{4 0 9}$ at room temperature followed by filtration from silica gel gave an inseparable mixture of tribenzotropone (400) and dihydro analogue of 400. The crude mixture was reacted with 2,3-dichloro-5,6- dicyano-1,4-benzoquinone in order to complete the oxidation (DDQ).

Papaianina and Amsharaov demonstrated that thermally activated $\gamma$-aluminum oxide can be very effective for $\mathrm{C}-\mathrm{F}$ bond activation in trifluoromethyl-substituted arenes to yield either cyclic ketones or the respective carboxylic acids in good to excellent yields (Scheme 77) [205]. The condensation of trifluoromethyl-substituted arene $\mathbf{4 1 1}$ on activated alumina at $150{ }^{\circ} \mathrm{C}$ resulted in the formation of the intramolecular Friedel-Crafts products 400 (52\% yield) and 412 (8\% yield),

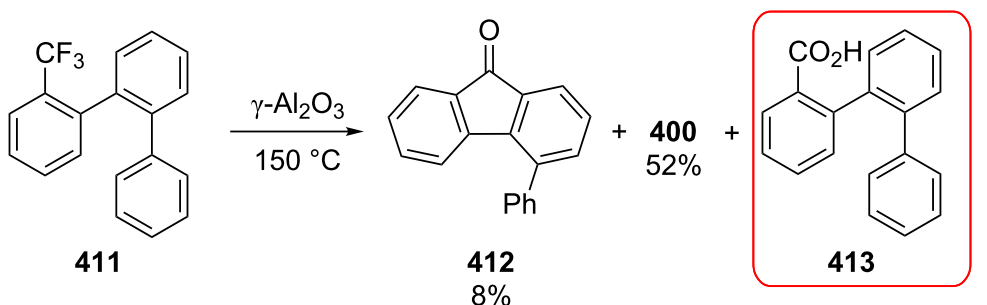


whereas formation of the possible acid $\mathbf{4 1 3}$ was not observed. The prevention of side reactions and the regiochemistry of the process were attributed to the confined space of alumina pores. Furthermore, the non-activated alumina-mediated hydrolysis of 412 at $200{ }^{\circ} \mathrm{C}$ afforded $o$-terphenyl-2-carboxylic acid (413) in close to quantitative yield. A presumable mechanism was also proposed for the formation of acylation and hydrolysis products with $\mathrm{C}-\mathrm{F}$ activation in trifluoromethylated arenes in alumina nanopores.

\subsection{Reactions of tribenzotropone (400)}

Herold's group reported ESR and ENDOR/TRIPLE resonance studies of ion pairs derived from the reduction of tribenzotropone (400), dibenzotropone 399, and dibenzosuberone 414 (Figure 21) with different alkali metals, which may be evidence of the existence of three different stereoisomers [206]. The INDO calculations of the spin densities at the lithium cation also supported the geometries proposed for the three stereoisomers.

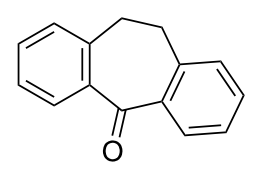

414

Figure 21: Dibenzosuberone (414).

An experimental study on the excited-state carbon acidity of several dibenzosuberene derivatives was reported by Wan's group (Figure 22) [203]. To this end, tribenzotropone (400) from the selected substrate was reduced with both $\mathrm{LiAlH}_{4}$ (with $\mathrm{AlCl}_{3}$ ) and $\mathrm{LiAlD}_{4}$ (with $\mathrm{AlCl}_{3}$ ) to give 415 and $\mathbf{4 1 5}-d_{2}$, respectively. The detectable deuterium (protium) incorporation for photolysis of 415 in $\mathrm{D}_{2} \mathrm{O}-\mathrm{MeCN}(1: 1)$ (or 415- $d_{2}$ in $\left.\mathrm{H}_{2} \mathrm{O}-\mathrm{MeCN}(1: 1)\right)$ was not observed. Photolysis of $\mathbf{4 1 6}$ under similar conditions resulted in mono- $(21 \%)$ and dideuterium (3\%) incorporation at the methylenic position. These results were explained by the fact that benzannelation of the vinyl moiety affects the excited-state carbon acidity for $\mathbf{4 1 5}$ (or 415- $d_{2}$ ). Subsequent photolysis of $\mathbf{4 1 5}$ using $1 \mathrm{M} \mathrm{NaOD/EtOD}$ gave mono- and dideuterium exchange products $415-d(15 \%)$ and 415- $d_{2}$ (3\%). 9H-Tribenzo[ $\left.a, c, e\right][7]$ annulene (415) as one of the model compounds for conformational studies with dynamic NMR was prepared from tribenzotropone (400) via Wolff-Kishner reduction (Figure 22) [207]. Tochtermann's group prepared tribenzotropone dimethyl ketal 417 from 400 and studied the conversion of the boat form of the 7-membered ring by means of the NMR spectra (Figure 22) [208]. The free activation enthalpy for 417 was $23 \mathrm{kcal} / \mathrm{mol}$. The treatment of 400 with polyphosphoric acid (PPA) at $200{ }^{\circ} \mathrm{C}$ yielded 4-phenylfluorenone (412) in 60\% yield via a proposed intermediate, 418 (Figure 23) [202].

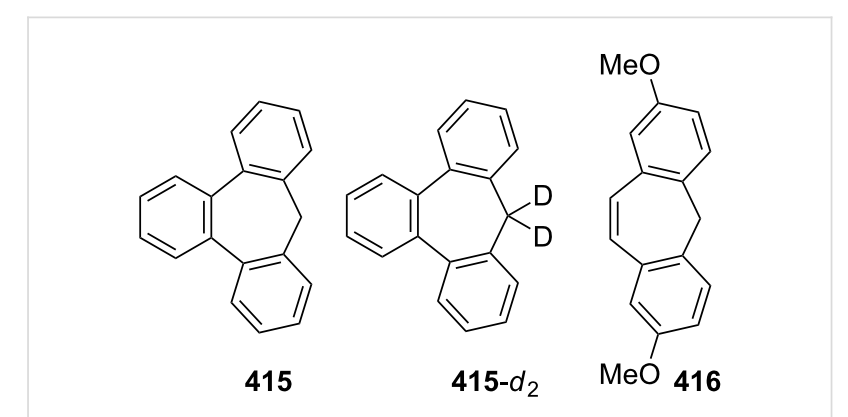

Figure 22: Reduction products 415 and $\mathbf{4 1 6}$ of tribenzotropone (400).
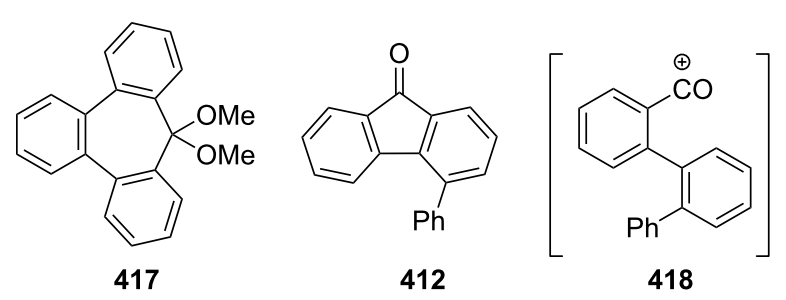

412

418

Figure 23: Structures of tribenzotropone dimethyl ketal 417 and 4-phenylfluorenone (412) and proposed intermediate 418.

Bergmann and Klein reported the synthesis of the condensation product 419a by the reaction of 400 with benzylmagnesium chloride (Figure 24) [201]. The UV absorption spectrum for 419a was measured and it was evaluated that 419a has no fulvenic properties. Later, Tochtermann's group reported the synthesis of the racemic 9-methylene-9Htribenzo[a,c,e][7]annulenes such as $\mathbf{4 2 0}$ via Wittig reaction followed by carboxylation of vinylic bromide using lithium/carbon dioxide (Figure 24) [209]. The classical resolution of the vinyl carboxylic acids as its brucine salt was also studied and the thermal racemization barrier was $31 \mathrm{kcal} / \mathrm{mol}$ at $139{ }^{\circ} \mathrm{C}$. Udayakumar and Schuster were the first to show the direct asymmetric synthesis of a series of 9-benzylidene-9Htribenzo[a,c,e][7]annulenes 419a-e and they examined the photochemistry of optically active potential triggers for physical amplification of a photoresponse in liquid crystalline media (Figure 24) [210]. The optically active compounds were prepared from the reaction of $\mathbf{4 0 0}$ with chiral phosphonamides 421a-d as an application of the Hanessian chiral olefination reaction. The acetyl derivative $419 \mathrm{e}$ was prepared by reaction of $419 \mathrm{c}$ with methyllithium. The optical purities of the compounds were determined to be $92 \%$ and $5 \%$ by NMR spectroscopy in the presence of chiral shift reagents. While UV irradiation of the benzylidene- $9 H$-tribenzo[ $a, c, e][7]$ annulenes resulted 
in high-efficiency photoracemization, thermal racemization was not observed at temperatures below $100{ }^{\circ} \mathrm{C}$.<smiles></smiles>

$419 a-e$<smiles>[X]c1cccc2c1-c1ccccc1/C(=C/C(=O)O)c1ccccc1-2</smiles>

420

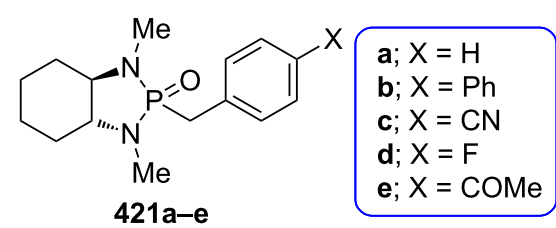

Figure 24: Structures of benzylidene- and methylene- $9 \mathrm{H}$ tribenzo[a,c,e][7]annulenes $\mathbf{4 1 9}$ and $\mathbf{4 2 0}$ and chiral phosphonamides 421.

Although the Grignard reaction between tribenzotropone (400) and 4-methoxyphenylmagnesium bromide provided the alcohol 422 in good yield (72\%), O-dealkylation of the tetracyclic alcohol $\mathbf{4 2 2}$ gave the corresponding $p$-quinone methide $\mathbf{4 2 3}$ in low yield (23\%, Figure 25) [211]. This result was attributed to the relatively low stability of the formed cation $\mathbf{4 2 4}$ due to the aromatic system twisted out of plane. Tribenzotropone (400) was also used as starting material for host molecules $\mathbf{4 2 5}-\mathbf{4 2 7}$ (Figure 26) [212,213].

As outlined in Scheme 78 with regard to the synthesis of a series of non-helical overcrowded derivatives, syn-431 was also prepared using $\mathbf{4 0 0}$ in four steps, which covered pinacol coupling and then pinacol rearrangement, carbonyl reduction, and Wagner-Meerwein rearrangement occured [214]. Isomers syn431 and anti-431 were converted as quantitative to each other at thermal and photochemical conditions as shown in Scheme 78. At the same time, the unambiguous characterization of syn-431 and anti-431 revealed that the previously claimed synthesis of

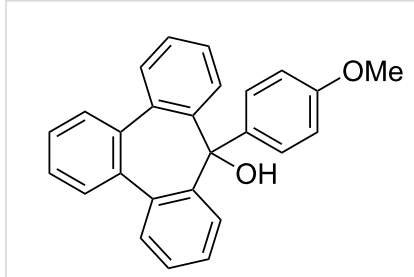

422

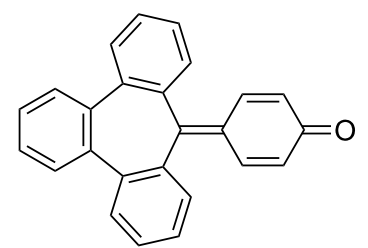

423<smiles>COc1ccc(C2c3ccccc3-c3ccccc3-c3ccccc32)cc1</smiles>

Figure 25: Structures of tetracyclic alcohol 422, p-quinone methide 423 and cation 424

hexabenzooctalene $\mathbf{4 3 2}$ by Tochtermann [215] was incorrect (Figure 27).

\section{Naphthotropones}

Although eight isomers $\mathbf{4 3 3}-\mathbf{4 4 0}$ for naphthotropone, which possess an $\mathrm{X} H$-cyclohepta[ $[y]$ naphthalen-Z-one $(\mathrm{X}=\mathrm{Y}=7,8,9$ or $10 ; \mathrm{y}=\mathrm{a}, \mathrm{b})$ skeleton system, are possible, only five isomers 433-437 were found experimentally (Figure 28). Sudoh's group reported the annulation effects of benzene rings to tropone (1) on the ground-state dipole moment, which can be useful for the study of molecular interactions in solution and excited states, as both the experimental and computational for the first time [216]. The ground-state dipole moments of a series of annulated tropones were computationally calculated using the Hartree-Fock (HF), density functional theory (DFT), and Møller-Plesset second-order perturbation (MP2) methods. While the ground-state dipole moment for 4,5-naphthotropone (433) was experimentally determined as $5.19 \mathrm{D}$, the MP2 method gave the result corresponding best to the experimental one for $\mathbf{4 3 3}$ among the three methods. The electronic transitions observed in tropone and tropolone derivatives condensed with benzene and naphthalene were studied experimentally and<smiles>OC1(c2ccccc2)c2ccccc2-c2ccccc2-c2ccccc21</smiles>

425<smiles>OC1(C#Cc2ccccc2)c2ccccc2-c2ccccc2-c2ccccc21</smiles>

426

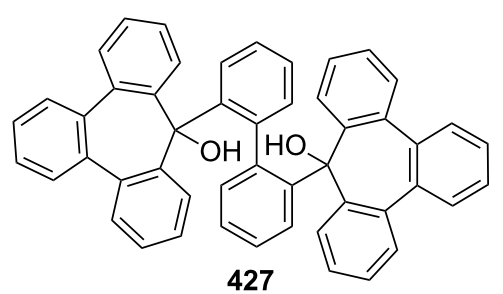

427 


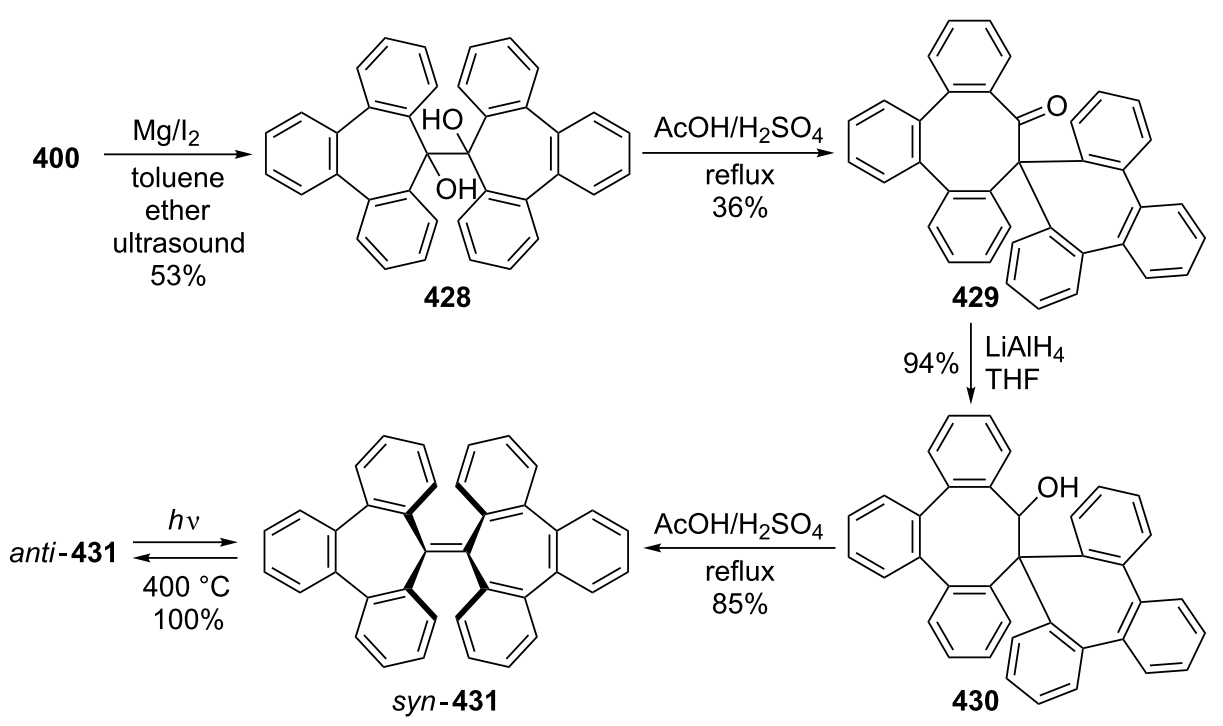

Scheme 78: Synthesis of non-helical overcrowded derivatives syn/anti-431.

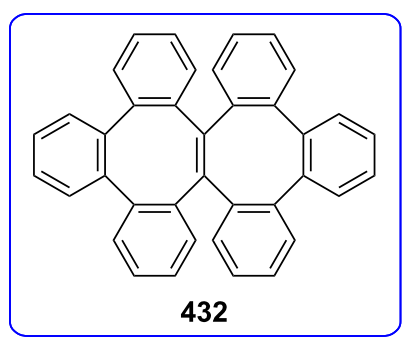

Figure 27: Hexabenzooctalene 432

theoretically [217-219]. Ohkita's group characterized the aromaticity of $\pi$-extended $o$-quinoidal tropone derivatives 433-435 along with five other tropone derivatives via the nucleus-independent chemical shifts (NICS), which is a computational method proven to be the most reliable probe of aromaticity due to its simplicity and efficiency [220,221]. Interestingly, the NICS(1) value calculated for the tropone ring in 433 is negative (-7.4), and indicates significantly increased aromatic character relative to the parent system. Moreover, NICS calculations demonstrated that the annulation of a benzene or naphthalene ring to the 2,3- or 4,5-position of tropone resulted in diminution of aromaticity. Furthermore, the elongations of the calculated $\mathrm{C}=\mathrm{O}$ bond in the studied molecules as $\mathbf{4 3 3}$ were attributed to substantial contributions of polar resonance structures to these molecules.

\subsection{Synthesis and characterization studies of naphthotropones}

Elad and Ginsburg reported the synthesis of a naphthotropone isomer for the first time (Scheme 79) [222]. Catalytic reduction of the key diketone 442 , which was prepared by multi-stage<smiles>O=c1ccc2cc3ccccc3cc2cc1</smiles>

433<smiles>O=c1ccccc2ccc3ccccc3c12</smiles>

437<smiles>CC(C)(C)O</smiles>
434<smiles>O=c1cccc2cc3ccccc3cc2c1</smiles>
435<smiles>O=c1ccc2ccccc2c2c(=O)ccccc12</smiles> 


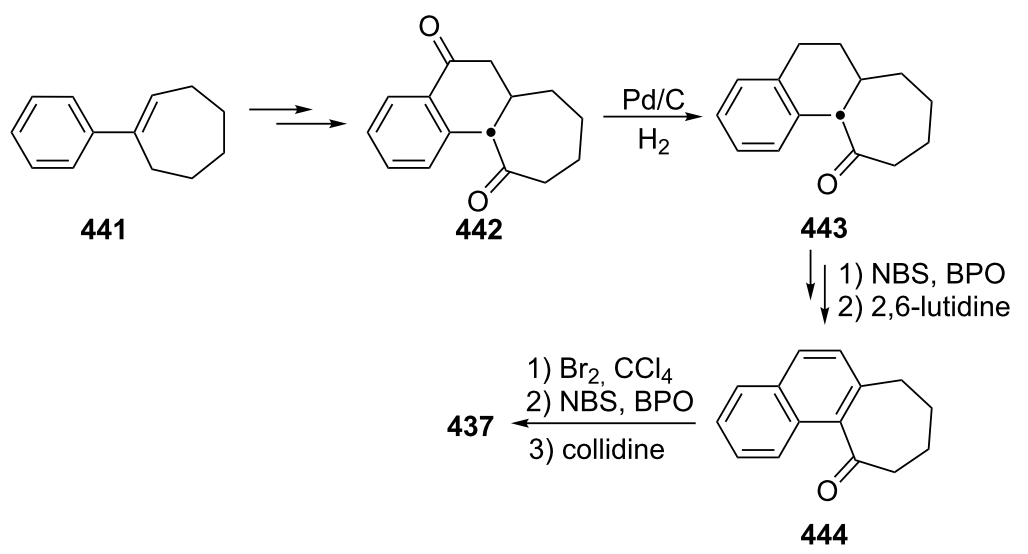

Scheme 79: Synthesis of naphthotropone 437 starting from 1-phenylcycloheptene (441).

synthesis of 1-phenylcycloheptene (441), removed the carbonyl group conjugated to the benzene ring and stepwise bromination and dehydrobromination of ketone $\mathbf{4 4 3}$ afforded the desired $11 H$-cyclohepta[ $a]$ naphthalen-11-one (437) [222,223]. Treibs and Herdmann [224] reported the synthesis of 10-hydroxy-11Hcyclohepta $[a]$ naphthalen-11-one (448) in very low yield starting from 2-naphthaldehyde and diethyl 2-ethylidenemalonate as outlined in Scheme 80 [224]. The condensation product 445 was converted to the ketone $\mathbf{4 4 4}$ in four steps: hydrolysis, catalytic hydrogenation, decarboxylation, and Friedel-Crafts acylation. After hydrolysis of oxime $\mathbf{4 4 6}$ derived from ketone $\mathbf{4 4 4}$, diketone 447 was subjected to an oxidation reaction with elemental sulfur, $\mathrm{Pd} / \mathrm{C}$, or $\mathrm{SeO}_{2}$ to give naphthotropolene $\mathbf{4 4 8}$ in very low yield.

Naville's group completed the series of benzologue tropylium cations up to $\mathrm{C} 15$ by preparing some tropylium cations [225]. This context with synthesis of $8 H$-cyclohepta[b]naphthalen-8one (433) was reported featuring condensation of 2,3-naph- thalenedicarboxaldehyde (449) with diethyl 1,3-acetonedicarboxylate (28) followed by decarboxylative hydrolysis of diester 450 (Scheme 81). Ito's group reported the simple synthesis of two naphthotropone isomers utilizing the cycloaddition of tropone (1) (Scheme 82) [226]. Cycloaddition of exocyclic diene $451 \mathrm{a}$, obtained from $o$-xylylene 154 with excess 1 in DMF resulted in the formation of the [6+4] adduct 452 and $[4+2]$ adduct 453 . After separation by silica gel chromatography, both of the cycloadducts were independently subjected to dehydrogenation with triphenylcarbinol in trifluoroacetic acid under reflux to yield naphthotropones $\mathbf{4 3 3}$ and $\mathbf{4 3 4}$ as the sole product in each respective reaction. Multistep synthesis of these naphthotropones was also performed through the reaction of dibromo-o-xylylene 451b generated in situ from 1,2bis(dibromomethyl)benzene at $80{ }^{\circ} \mathrm{C}$ with $\mathbf{1}$ (Scheme 82). The proposed mechanism for the transformation of $\mathbf{4 5 2}$ to $\mathbf{4 3 4}$ includes dehydrogenation, disrotatory electrocyclic ringclosing, thermal [1,5]-sigmatropic rearrangement, and again dehydrogenation steps as depicted in Scheme 83. Kanematsu's

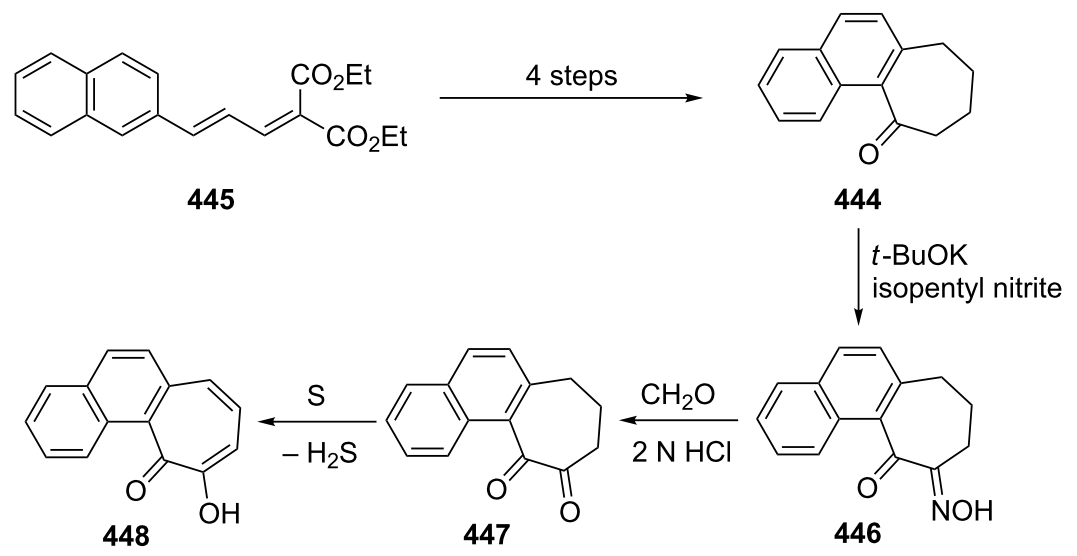

Scheme 80: Synthesis of 10-hydroxy-11H-cyclohepta[a]naphthalen-11-one (448) from diester 445. 


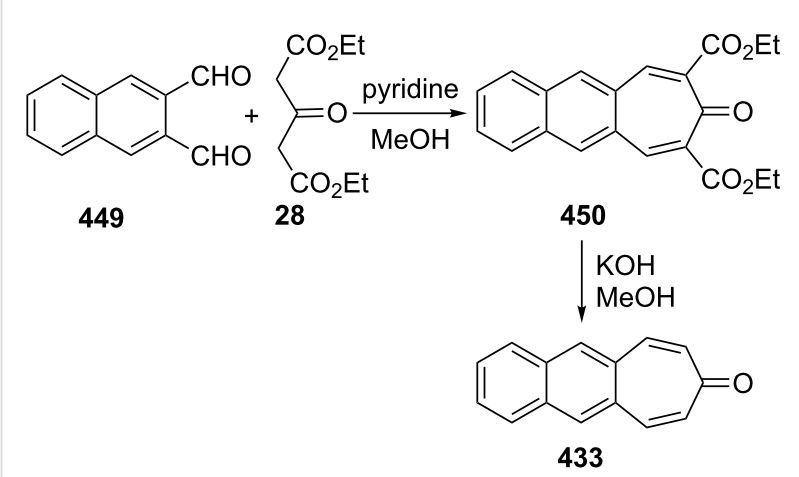

Scheme 81: Synthesis of naphthotropone 433.

group reported a selective reaction at the 2,3-position of tricarbonyl(tropone)iron 458a with $o$-quinodimethane 451a using the masking effect of tricarbonyliron complex to yield exclusively $[4+2]$ adduct 459a with no formation of other cycloadducts (Figure 29) [227]. The reaction of 459a with $o$-chloranil in refluxing methylene chloride to remove the tricarbonyliron moiety afforded the previously unobtainable product 460 a, whereas treatment of $\mathbf{4 5 9} \mathrm{b}$ with trimethylamine oxide provided naphthotropone 434 in 15\% yield along with 460 a and its isomers. While a similar reaction of tricarbonyl(2-chlorotropone)iron 458b and 451a yielded the sole product $459 \mathrm{~b}$ (55\%), 2-chlorotropone reacted poorly with 451 a to afford naphthotropone $433(13 \%)$ as the only isolable product via [4+2] cycloaddition reaction followed probably by dehydrobromination and aromatization.

Jones' group prepared naphthotropone $\mathbf{4 3 6}$ using published procedures and known intermediates (Scheme 84) [228-231]. The ketone 461 prepared in 11 steps starting from naphthalene (17) was converted to $\mathbf{4 6 2}$ through ring-opening of cyclopropane with a base followed by oxidation. After previous successful

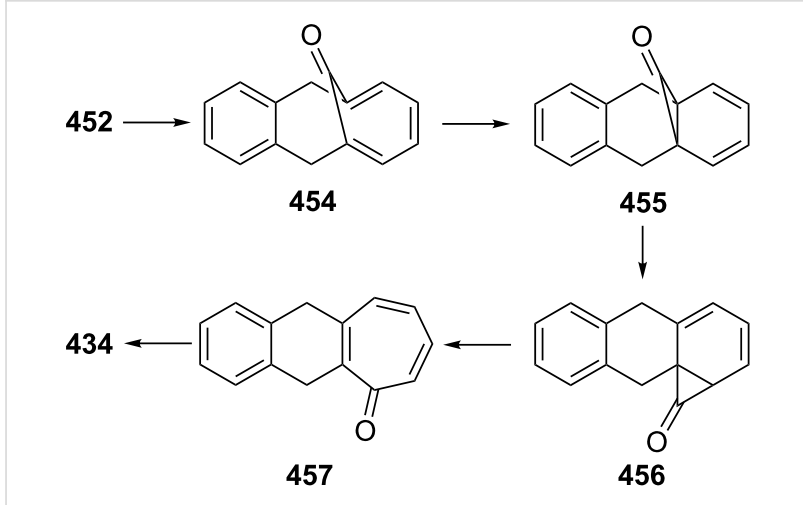

Scheme 83: Synthesis of naphthotropone $\mathbf{4 3 4}$ starting from $\mathbf{4 5 2}$.

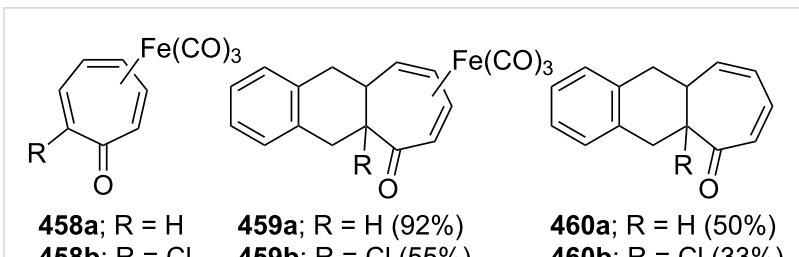

458b; $\mathrm{R}=\mathrm{Cl} \quad$ 459b; $\mathrm{R}=\mathrm{Cl}(55 \%) \quad$ 460b; $\mathrm{R}=\mathrm{Cl}(33 \%)$

Figure 29: Structures of tricarbonyl(tropone)irons 458, and possible cycloadducts 459 .

generation of $\mathbf{1 3}$ from the corresponding benzocyclobutene $\mathbf{2 3 0}$, Ohkita's group also reported the synthesis of $\mathbf{4 6 5}$ as a precursor for naphthotropone 435 (Scheme 85) [220,221]. Photopromoted $[2+2]$ cycloaddition of 2-cyclopentenone with $(E)$ 1,4-dichloro-2-butene followed by protection of the carbonyl group and subsequent dehydrohalogenation afforded diene 463 , which was converted to $\mathbf{4 6 5}$ after a series of reactions including the Diels-Alder reaction with benzyne, dehydrogenation with DDQ, bromination, dehydrobromination, and acid-catalyzed hydrolysis of the ketal group. Irradiation of $\mathbf{4 6 5}$ in a rigid class at $-196{ }^{\circ} \mathrm{C}$ resulted in the formation of the hitherto unknown

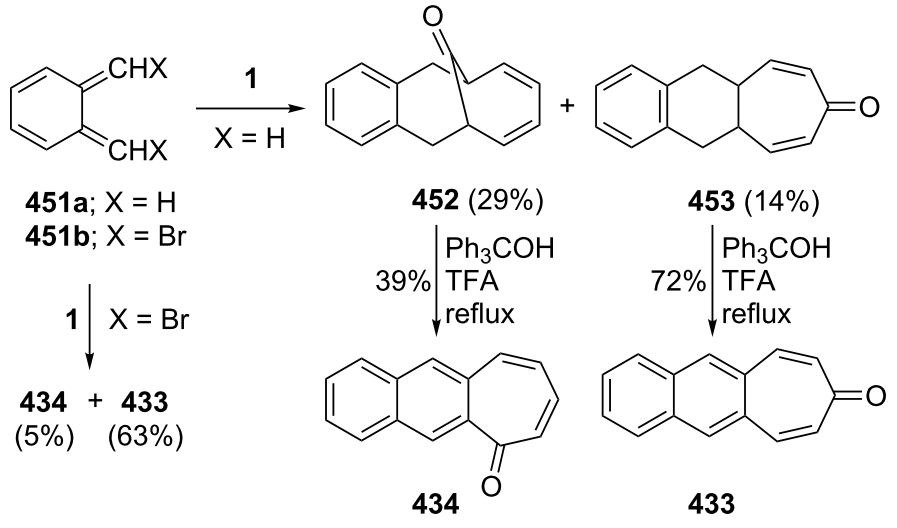

Scheme 82: Synthesis of naphthotropones $\mathbf{4 3 3}$ and $\mathbf{4 3 4}$ via cycloaddition reaction. 


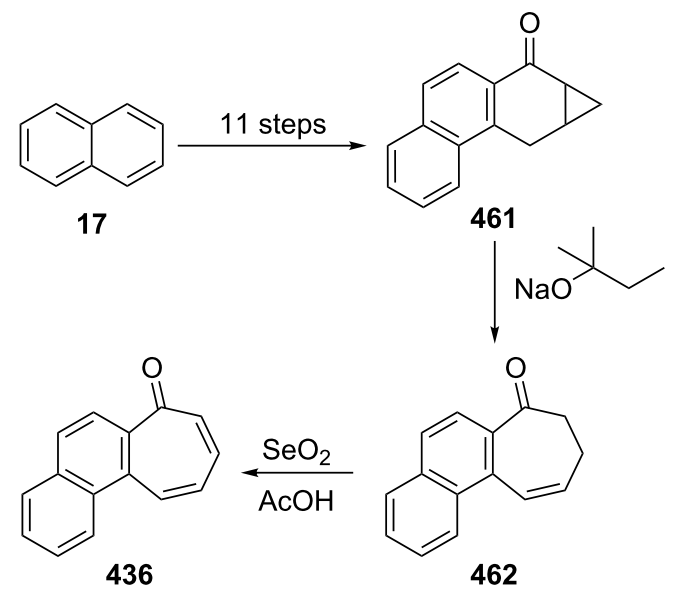

Scheme 84: Synthesis of naphthotropone 436.

7H-cyclohepta $[b]$ naphthalen-7-one (435), which displayed characteristic UV-vis absorption extending to $700 \mathrm{~nm}$ and underwent rapid dimerization to give the dimers 467 and 468 (Scheme 86). However, Okhita's group applied this strategy to generate the corresponding anthracene-tropone from 466 under the same reaction conditions (Scheme 85). However, anthrocyclobutene derivative $\mathbf{4 6 6}$ failed to result in ring-opening for the expected tropone and the starting material 466 was recovered quantitatively. The products were unambiguously characterized as $s y n$-[ $\pi 12+\pi 14]$ dimers 467 and 468 by X-ray crystallography, and the preferential syn-dimerization was attributed to the extended secondary orbital interactions. Sato's group also reported the IR spectra of $\mathbf{4 3 5}$ generated in nitrogen matrices at $13 \mathrm{~K}$ by monochromic irradiation with a $\mathrm{XeCl}$ excimer laser to investigate medium effects on the molecular structures of tropones [156].

\subsection{Applications of naphthotropones}

In connection with the completion of the benzologue tropylium series, Naville's group also prepared the tropylium cations $\mathbf{4 6 9}$ and 470 from the corresponding naphthotropones 433 and 436 and described the absorption spectra and the relative acidities of all cations (Figure 30) [225]. After hydride reduction of tropones, the alcohols in sulfuric acid provided the corresponding cations.

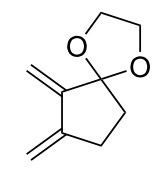

463
1) o-dibromobenzene $n$-BuLi, toluene, $54 \%$ 2) $\mathrm{DDQ}$, benzene, $85 \%$<smiles></smiles>

464

1) $\mathrm{PyHBr}_{3}, \mathrm{CH}_{2} \mathrm{Cl}_{2}, 57 \%$

2) $t$-BuOK, 18-crown-6, $84 \%$

3) $1 \mathrm{~N} \mathrm{HCl}, \mathrm{THF}, 80 \%$

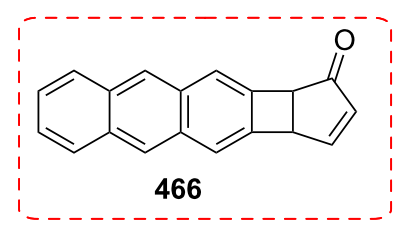<smiles>O=C1C=CC2c3cc4ccccc4cc3C12</smiles>

Scheme 85: Synthesis of precursor 465 for naphthotropone 435.

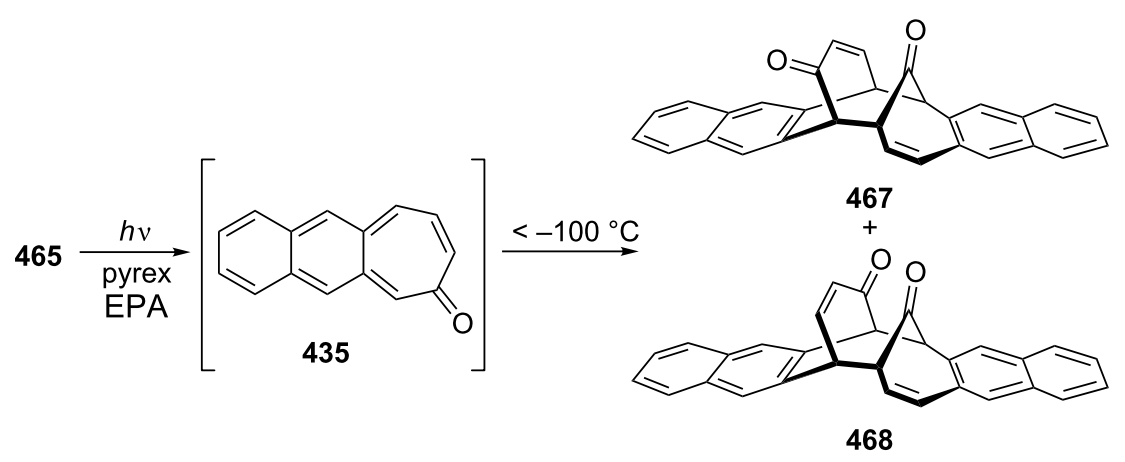

Scheme 86: Generation of naphthotropone 435 from 465 


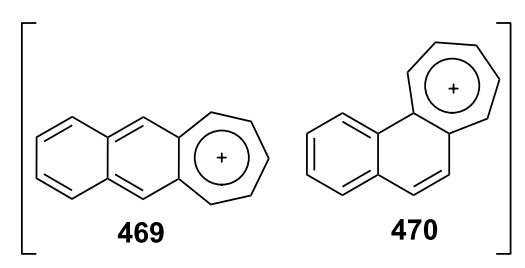

Figure 30: Structures of tropylium cations 469 and $\mathbf{4 7 0}$

Due to encouraging initial results obtained regarding the synthesis, properties, and reactivity of catacondensed aromatic $\pi$-systems as well as their photoinduced autorecycling oxidizing reactions toward some alcohol and amines [66-71], Nitta's group focused on novel tropylium ions $\mathbf{4 7 1}^{+} \cdot \mathrm{BF}_{4}^{-}, \mathbf{4 7 2}^{+} \cdot \mathrm{BF}_{4}{ }^{-}$, and $\mathbf{4 7 3}^{+} \cdot \mathrm{BF}_{4}{ }^{-}$containing heterocyclic moieties (Figure 31 ) [232]. The synthesis of $\mathbf{4 7 1}^{+} \cdot \mathrm{BF}_{4}^{-}$was achieved by three-step reactions in modest yield (19\%) starting from naphthotropone 433 while generation of $\mathbf{4 7 9}^{+} \cdot \mathrm{ClO}_{4}{ }^{-}$was not observed (Scheme 87). The napthotropylium cation $\mathbf{4 7 9}^{+} \cdot \mathrm{ClO}_{4}{ }^{-}$was pre- pared in $64 \%$ yield by the reduction of 433 with $\mathrm{NaBH}_{4}$ in EtOH in the presence of $\mathrm{CeCl}_{3}$ followed by subsequent treatment of 474 with $60 \%$ aqueous $\mathrm{HClO}_{4}$ in $\mathrm{Ac}_{2} \mathrm{O}$. The synthesis of $\mathbf{4 7 2}^{+} \cdot \mathrm{BF}_{4}{ }^{-}$and $\mathbf{4 7 3}^{+} \cdot \mathrm{BF}_{4}{ }^{-}$as a mixture was carried out in similar ways starting from benzotropone $\mathbf{1 1}$ and its separation was performed by fractional recrystallization from $\mathrm{MeCN} /$ EtOAc to give pure samples. While the compounds $471^{+} \cdot \mathrm{BF}_{4}{ }^{-}$, $\mathbf{4 7 2}^{+} \cdot \mathrm{BF}_{4}^{-}$, and $\mathbf{4 7 3}^{+} \cdot \mathrm{BF}_{4}^{-}$were fully characterized on the basis of spectroscopic methods as well as elemental analysis and $\mathrm{X}$-ray analysis, their chemical shifts provided quite noteworthy information for determining structural properties such as diatropicity and bond alternation. The carbocation stability is expressed in terms of its $\mathrm{p} K_{\mathrm{R}}+$ value, which is the affinity of the carbocation toward hydroxide ions, and this value is the most common criterion for carbocation stability. Although the $\mathrm{p} K_{\mathrm{R}+}$ values for cations $\mathbf{4 7 1}^{+}, \mathbf{4 7 2}^{+}$, and $\mathbf{4 7 3}^{+}$were determined spectrophotometrically as the values of ca. $0.5-9.0$, the $\mathrm{p} K_{\mathrm{R}+\text { value }}$ of napthotropylium ion $\mathbf{4 7 9}^{+}$was clarified as much lower, at $<0$. Autorecycling oxidation properties of some amines as well as<smiles></smiles>

$471^{+} \cdot \mathrm{BF}_{4}^{-}$<smiles></smiles>

$472^{+} \cdot \mathrm{BF}_{4}^{-}$

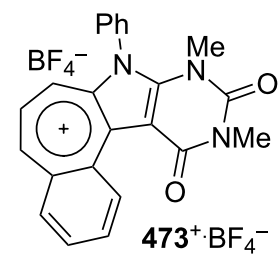

Figure 31: Structures of tropylium ions $471^{+} \cdot \mathrm{BF}_{4}^{-}, 472^{+} \cdot \mathrm{BF}_{4}^{-}$, and $473^{+} \cdot \mathrm{BF}_{4}^{-}$.

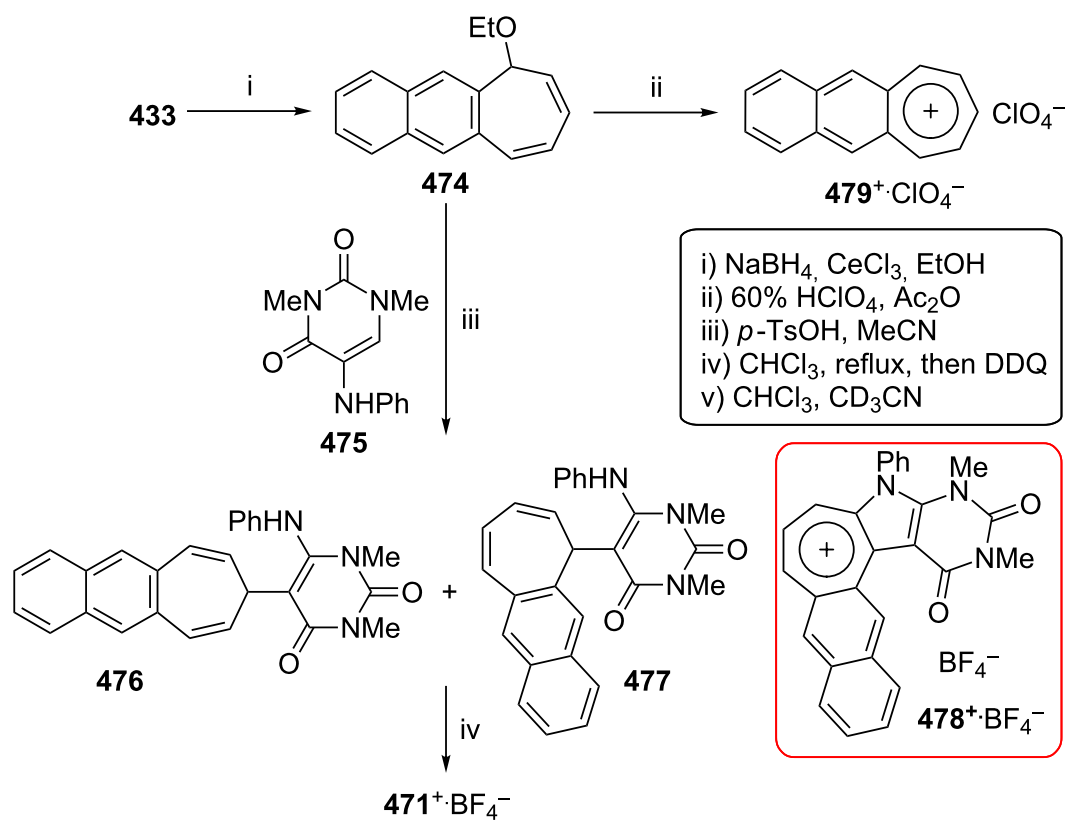

Scheme 87: Synthesis of tropylium ions $471^{+} \cdot \mathrm{BF}_{4}{ }^{-}$and $479^{+} \cdot \mathrm{ClO}_{4}{ }^{-}$. 
the reduction potentials and the reactions with some nucleophiles of the compounds $4 \mathbf{4 1}^{+} \cdot \mathrm{BF}_{4}^{-}, \mathbf{4 7 2}^{+} \cdot \mathrm{BF}_{4}^{-}$, and $\mathbf{4 7 3}^{+} \cdot \mathrm{BF}_{4}{ }^{-}$ were also reported. The oxidations of benzylamine, 1-phenylethylamine, hexylamine, and cyclohexylamine with $\mathbf{4 7 1}^{+} \cdot \mathrm{BF}_{4}{ }^{-}$, $\mathbf{4 7 2}^{+} \cdot \mathrm{BF}_{4}^{-}$, and $\mathbf{4 7 3}^{+} \cdot \mathrm{BF}_{4}^{-}$produced the corresponding imines under aerobic and photoirradiation conditions.

The napthotropones $\mathbf{4 3 3}$ and $\mathbf{4 3 6}$ were also used to prepare tosylhydrazones and their salts in the usual manner as precursors of the corresponding carbenes. Hackenberger and Dürr reported the generation and chemistry of naphtho[b]tropylidene 483 (Scheme 88) [233,234]. Carbene 483 generated by flash solvolysis from the salt $\mathbf{4 8 0}$ in the gas-phase led to the formation of 1- and 2-methylanthracene ( 481 and 482 ) via carbene-carbene rearrangement to anthrylcarbene 486 to 487 as a decisive step (Scheme 88 ). In the condensed phase, while the trapping of the carbene $\mathbf{4 8 3}$ with olefins yielded cycloaddition products 488 and insertion products 489 , the cycloadducts 490 through intermediate anthrylcarbene $\mathbf{4 8 6}$ also occurred as byproducts (Figure 32). However, if electron-deficient alkenes were used, the amount of cycloadduct 490 increased. The intermediate $\mathbf{4 8 5}$ was trapped by 2,3-dimethylbut-2-ene to afford 491 (Figure 32). The reactions and products described were attributed to an equilibrium mixture of singlet $\mathbf{4 8 3}$, triplet $\mathbf{4 8 3}$, and bicycle $\mathbf{4 8 5}$.

Jones' group also reported the generation and properties of a naphthoannelated cycloheptatrienylidene-cycloheptatetraene intermediate from both the corresponding salt $\mathbf{4 9 2}$ derived from 436 or a mixture of bromocycloheptatrienes 499 and $\mathbf{5 0 0}$ (Scheme 89) [228]. While thermolysis of salt $\mathbf{4 9 2}$ in cyclohexane or benzene afforded only a mixture of naphthoannelated heptafulvalenes 493 and $\mathbf{4 9 4}$, thermolysis in the pres-

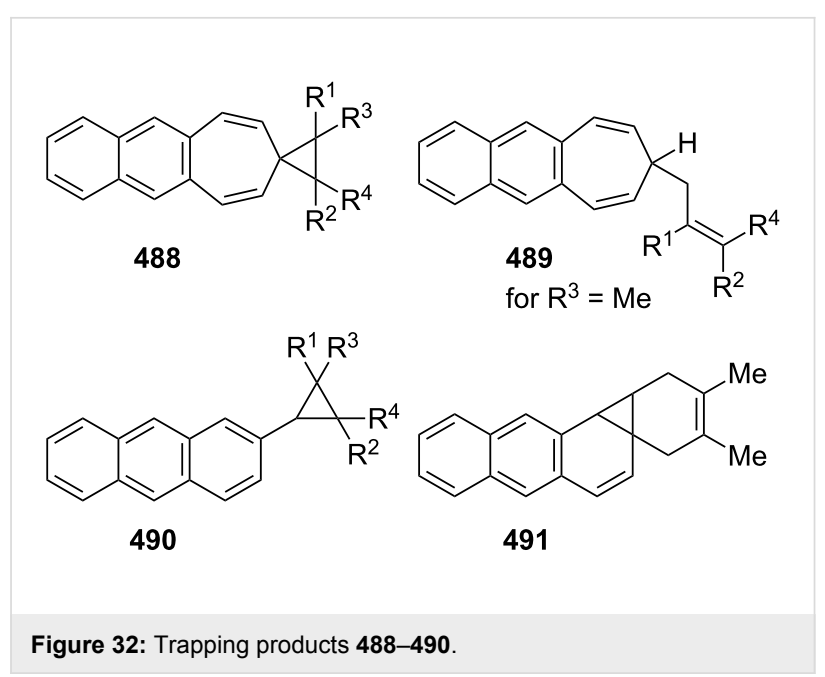

ence of dimethyl fumarate (495) yielded the expected spirocyclopropane 496 along with trace amounts of the same two dimers. Thermolysis of $\mathbf{4 9 2}$ in the presence of diphenylisobenzofuran (DBI, 497) gave a new adduct, 498. Dehydrobromination of a mixture of bromocycloheptatrienes 499 and $\mathbf{5 0 0}$ with potassium tert-butoxide in the presence of $\mathbf{4 9 7}$ resulted in the formation of the rearranged adduct 498 along with carbenedimer products 493 and $\mathbf{4 9 4}$. Valance isomerization of carbene 501 to allene 502 plays a critical role in the proposed mechanism for the formation of the adduct $\mathbf{5 0 0}$, which was formed by Diels-Alder addition of $\mathbf{4 9 7}$ to the allene $\mathbf{5 0 2}$ followed by rearrangement as depicted in Scheme 90. Based on INDO calculations of a number of the carbenes and allenes, Jones' group deduced that while the chemistry of cycloheptatrienylidene and in some its annelated relatives are dominant in some cases by the allene form and in others by triplet carbene, the role of singlet carbene is uncertain.

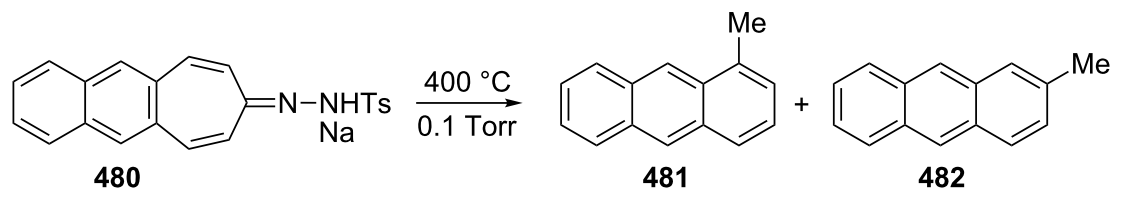<smiles>C=C[C@@H]1/C=C\c2cc3ccccc3cc2C=C[C@@H]1C=C</smiles> 


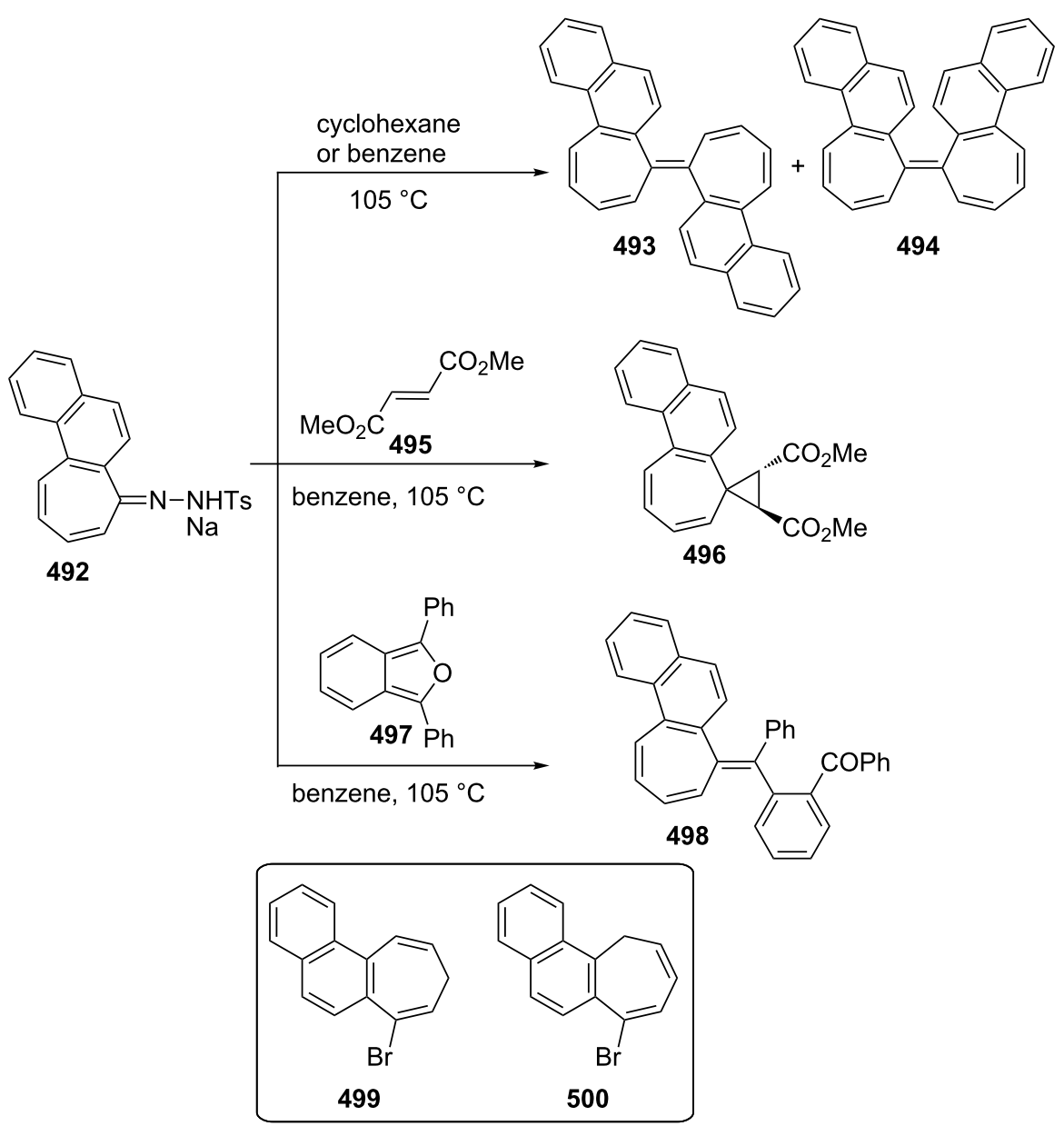

Scheme 89: Generation and chemistry of a naphthoannelated cycloheptatrienylidene-cycloheptatetraene intermediate from salt 492.

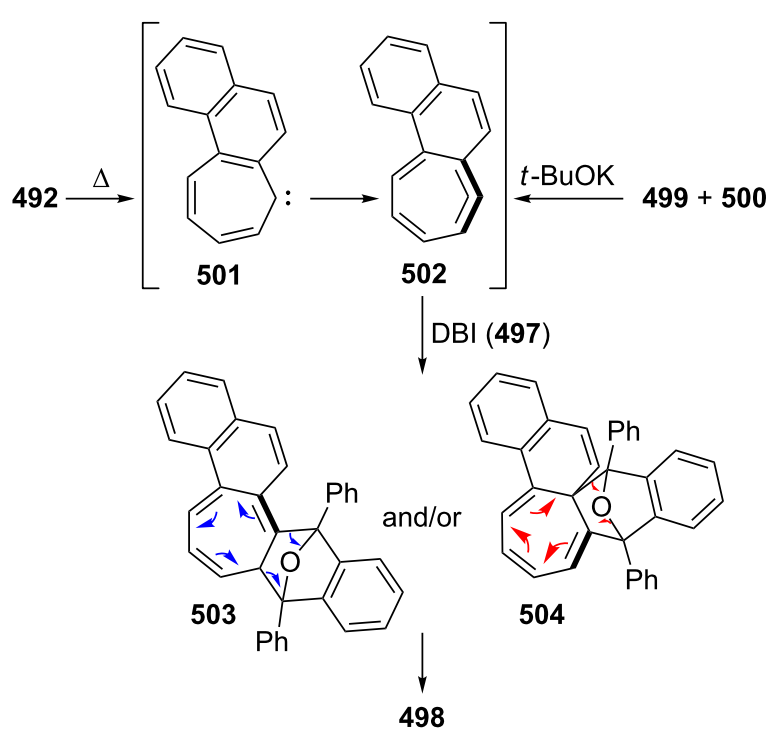

Scheme 90: Proposed intermediates and reaction pathways for adduct 498.
Jang and Kelley studied the exited-state intramolecular proton transfer (ESIPT) and relaxation of 7-hydroxy- $8 H$-cyclohepta $[b]$ naphthalen-8-one (505) in room temperature solutions studied using static and time-resolved absorption as well as emission spectra for the equations indicated in Scheme 91 [235,236]. Dual fluorescence (normal and tautomer fluorescence) is observed in the protic solvent (ethanol), while only tautomer fluorescence is observed in the nonpolar solvent (cyclohexane). The dual green and red fluorescence arise from the intermolecular hydrogen-bonded normal molecules and the tautomer molecules with proton transfer in the excited state (ESIPT), respectively. The observed fluorescence lifetimes and quantum yields in ethanol and cyclohexane solutions could be attributed to competition between intersystem crossing and proton transfer in the first excited singlet state.

\section{Miscellaneous benzotroponoids 10.1. Benzoditropones}

Although benzoditropone has many isomeric possibilities, only two isomers $\mathbf{5 0 6}$ and $\mathbf{5 0 7}$ of the benzoditropone system have 


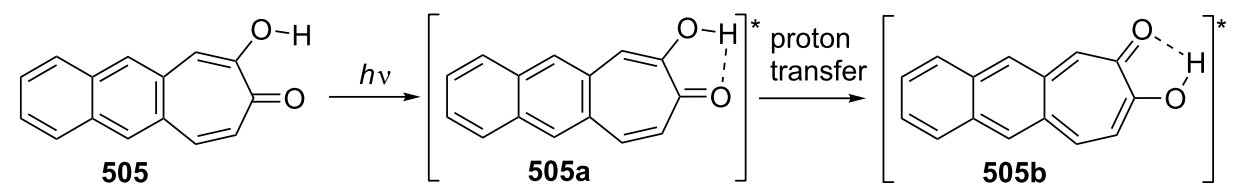

Scheme 91: Exited-state intramolecular proton transfer of $\mathbf{5 0 5 .}$

been reported (Figure 33). The X-ray diffraction studies for benzo[1,2:4,5]di[7]annulene-3,9-dione (506e) as the main skeleton revealed a nearly planar geometry [237]. The intermolecular distances confirmed good agreement with normal van der Waals interactions, while the intramolecular distances led to a significant bond alternation within the seven-membered rings.

Aldol-type cyclizations provide an expedient access to the benzoditropones in a single step. Föhlisch and Widmann applied aldol-type cyclization for the synthesis of benzoditropones 506c-e (Scheme 92) [238]. In an analogous manner, Soyer and Kerfento, and subsequently Soyer, attempted Aldoltype condensations of benzene-1,2,4,5-tetracarbaldehyde with the corresponding acetone derivatives to give the benzoditropone derivatives 506a-k (Figure 33) [237-239]. An increasing bathochromic effect was observed for $506 e\left(R^{1}-R^{4}=H\right)<508 c$ $\left(\mathrm{R}^{1}-\mathrm{R}^{4}=\mathrm{CO}_{2} \mathrm{Et}\right)<\mathbf{5 0 6 a}\left(\mathrm{R}^{1}-\mathrm{R}^{4}=\mathrm{Me}\right)<\mathbf{5 0 6} \mathrm{b}\left(\mathrm{R}^{1}-\mathrm{R}^{4}=\mathrm{Ph}\right)$.

Kato's group reported the synthesis of benzoditropones $\mathbf{5 0 7}$ via cycloaddition between tropone (1) and 7,7-dibromo-3,4-dimethylenebicyclo[4.1.0]heptane (512, Scheme 93) [240]. To this end, diene 512 reacted with $\mathbf{1}$ to give a mixture (77\% yield, syn/ anti $=3.8: 1)$ of $[6+4]$ cycloadducts 513 in refluxing toluene, while the reaction proceeded with high regioselectivity $(90 \%$ yield, syn/anti $=9: 1)$ in benzene in a sealed tube at

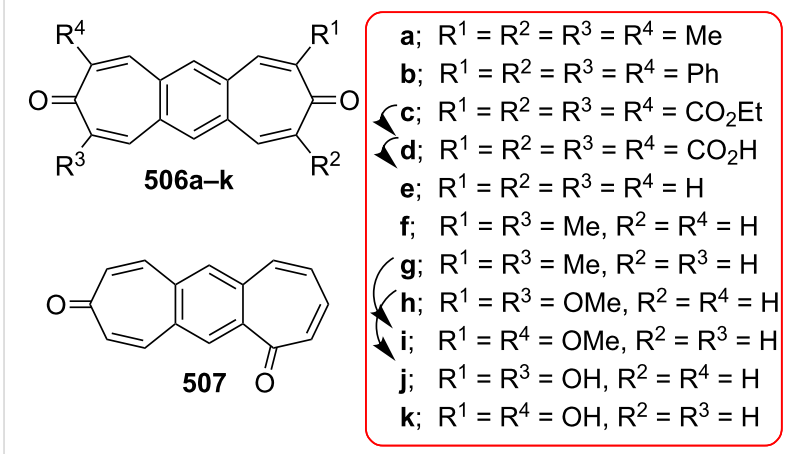

Figure 33: Benzoditropones 506 and $\mathbf{5 0 7}$

$100{ }^{\circ} \mathrm{C}$. Epoxidation of $\mathbf{5 1 3}$ with $\mathrm{m}$-chloroperbenzoic acid ( $m$ CPBA) afforded a mixture containing epoxide $\mathbf{5 1 4}$ as a major product. This epoxide was then converted to benzoditropones 507 after direct or indirect steps. Bromination of $\mathbf{5 1 5}$ with molecular bromine followed by dehydrobromination by heating at $100{ }^{\circ} \mathrm{C}$ in $\mathrm{N}, \mathrm{N}$-dimethylformamide (DMF) also provided an improved route to $\mathbf{5 0 7}$ (56\% yield). Formation of $\mathbf{5 0 7}$ and $\mathbf{5 1 6}$ from 515 occurs by the three mechanisms depicted in Scheme 94. Firstly, the protonated $\mathbf{5 1 7}$ may undergo two different 1,2-cationic rearrangements via 518 and 519 intermediates to yield 516 and 507. Secondly, tropone-ketone 515 undergoes<smiles>CCOC(=O)COCCOC=O</smiles><smiles>CCOC(=O)c1cc2cc(C)c(C)cc2cc(C(=O)O)c1=O</smiles><smiles>CCOC(=O)c1cc2cc(C=O)c(C=O)cc2cc(C(=O)OCC)c1=O</smiles><smiles>CCOC(=O)c1cc2cc(CBr)c(CBr)cc2cc(C(=O)OCC)c1=O</smiles>

1) $\mathrm{OC}\left(\mathrm{CH}_{2} \mathrm{CO}_{2} \mathrm{Et}\right)_{2}$
2) $\mathrm{H}_{3} \mathrm{O}^{+}$
3) $-\mathrm{CO}_{2}$ 
<smiles>[R16]C1CC2C(CC1=C)C2(Br)Br</smiles>

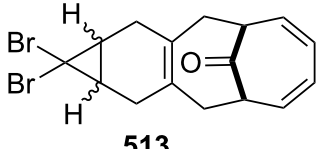

513

$(77 \% ;$ syn/anti $=3.8: 1)$<smiles>O=C1C=CC2C=CC=CC1Cc1ccccc1C2</smiles>

515 toluene $80^{\circ} \mathrm{C}$

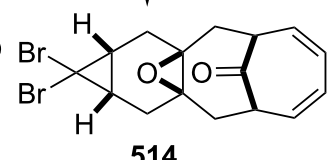

(59\%, major product)<smiles>O=C1C=CC2=C(C=CC(=O)C(=O)c3ccccc3C2)C1</smiles>

TCA toluene

507

$(27 \%)$

Scheme 93: Synthetic approaches for dibenzotropone 507 via tropone (1).

a thermal [1,5]-sigmatropic shift followed by successive dehydrogenation to give benzoditropone 507. Lastly, initial dehydrogenation of $\mathbf{5 1 5}$ to bistropone $\mathbf{5 2 2}$ followed by $6 \pi$-electrocyclic ring-opening and a [1,5]-sigmatropic shift of the carbonyl carbon results in norcaradienone $\mathbf{5 2 4}$, which undergoes $6 \pi$-retrocyclization followed by oxidation to give $\mathbf{5 0 7}$.

Agranat and Avnir reported the synthesis of the benzoditropone systems 525 and 526, which may be considered double dibenzotropones (Scheme 95) [241]. Double Perkin condensation between pyromellitic dianhydride (527) and phenylacetic acid gave a mixture of the two isomeric lactones, $\mathbf{5 2 8}$ and 529, in the ratio of $5: 3$, which were separable by repeated fractional crystallization. The reduction of $\mathbf{5 2 8}$ and $\mathbf{5 2 9}$ with red phosphorus in boiling hydroiodic acid led to the formation of isophthalic acid derivatives (such as 530), which underwent intramolecular Friedel-Crafts acylation by polyphosphoric acid (PPA) to construct a seven-membered ring. The synthesis of benzoditropones $\mathbf{5 2 5}$ and $\mathbf{5 2 6}$ involved the dehydrogenation of the corresponding Friedel-Crafts products with $\mathrm{N}$-bromosuccinimide (NBS) in the presence of benzoyl peroxide followed by treatment with trimethylamine.

\subsection{Benzocyclobutatropones}

Cyclobutadiene (532), the smallest annulene, is an unstable hydrocarbon with an extremely short lifetime in the free state and has attracted much attention from both experimental and theoretical viewpoints (Figure 34). Although 532 rapidly dimerizes via a Diels-Alder reaction, its dibenzo-derivative $\mathbf{5 3 3}$ (biphenylene) is thermally stable and shows many of the properties associated with aromatic compounds (Figure 33) [242246]. Three possible isomeric benzocyclobutatropones, 534-536, which are analogues of biphenylene in which one benzenoid ring has been replaced by the tropone ring, are of significant interest due to the question of the extent of $\pi$-electron delocalization in the seven-membered ring (Figure 34). Benzo-

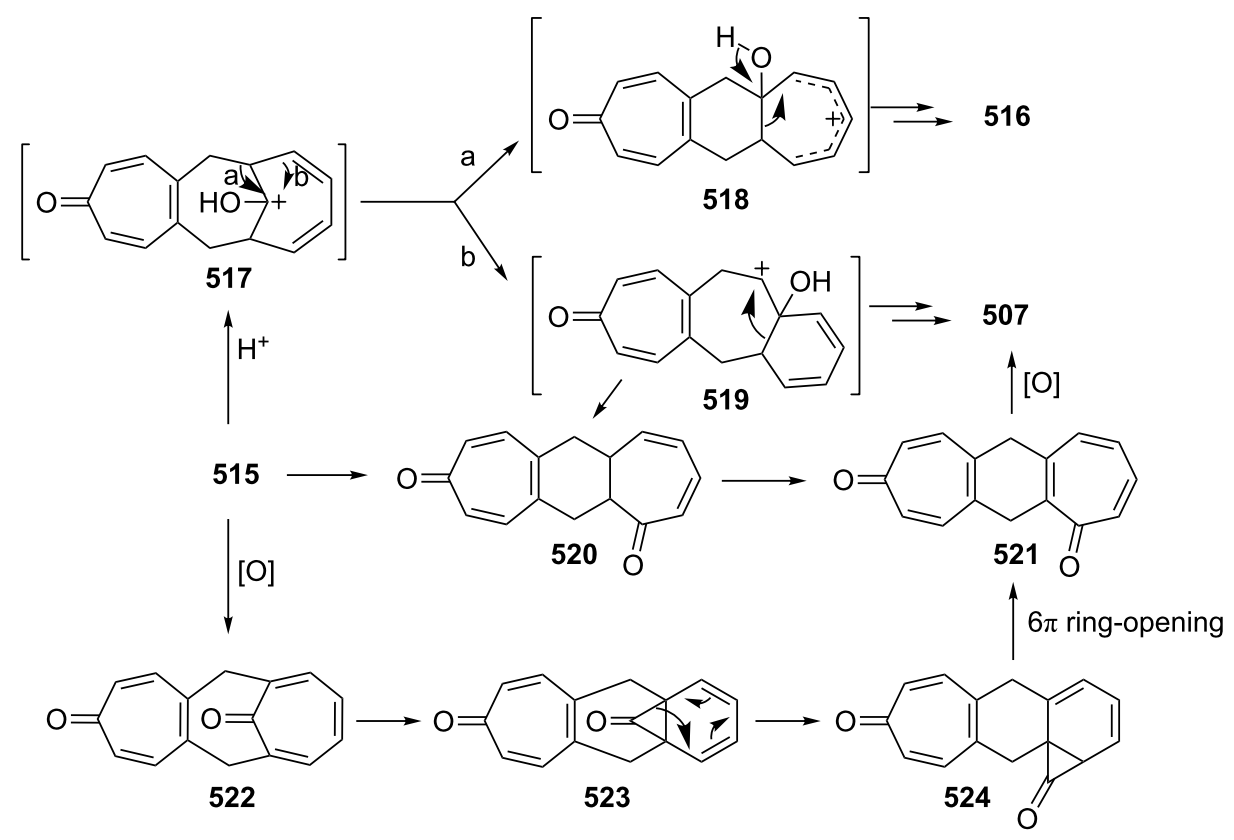




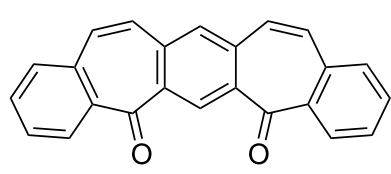<smiles></smiles>

525 526<smiles>O=c1oc(=O)c2cc3c(=O)oc(=O)c3cc12</smiles>

527<smiles>C#[13C]C(=O)O[Na]</smiles><smiles>O=C1O/C(=C\c2ccccc2)c2cc3c(cc21)/C(=C/c1ccccc1)OC3=O</smiles>

528<smiles>O=C1Oc2cc3c(cc2/C1=C/c1ccccc1)C(=O)O/C3=C\c1ccccc1</smiles><smiles>[3H]I=[V]</smiles>

526<smiles>CC(C)(C)c1cc2c(cc1C(=O)O)C(Cc1ccccc1)OC2=O</smiles>

Scheme 95: Synthesis of benzoditropones $\mathbf{5 2 5}$ and $\mathbf{5 2 6}$ from pyromellitic dianhydride (527).

cyclobutatropones $\mathbf{5 3 5}$ and 534, which possess a formal benzocylobutadienoid double bond, are also of particular interest.

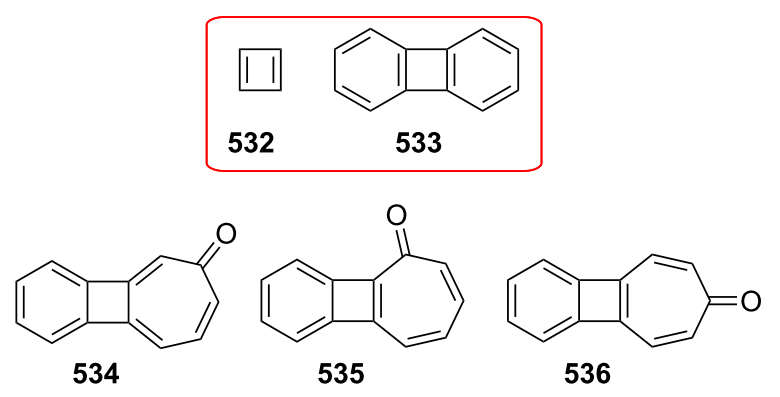

Figure 34: Possible three benzocyclobutatropones 534-536.
Wege's group attempted to prepare the main analogues 534-536 of a benzocyclobutatropone system [247-249]. Allylic oxidation of diene $\mathbf{5 3 7}$ with chromium trioxide-pyridine complex in dichloromethane occurred to afford dienone 538 in $21 \%$ yield, which was exposed to DDQ in refluxing benzene to give 534 in low yield (9-10\%) as a stable and crystalline solid at room temperature along with some of the starting material 537 (Scheme 96) [247,248]. Deuterated derivative 539 was prepared to confirm structural assignments. NMR results showed that the seven-membered ring of $\mathbf{5 3 4}$ has a more localized $\pi$-bond system than tropone itself [248]. The $\mathrm{CrO}_{3}$-oxidation product 542 of the benzyne-cycloheptatriene adduct $\mathbf{5 4 0}$ was also converted to $\mathbf{5 3 4}$ after a sequence of NBS-bromination and dehydrobromination with DBU. However, the major oxidation product 542 did not react with DDQ in refluxing benzene.

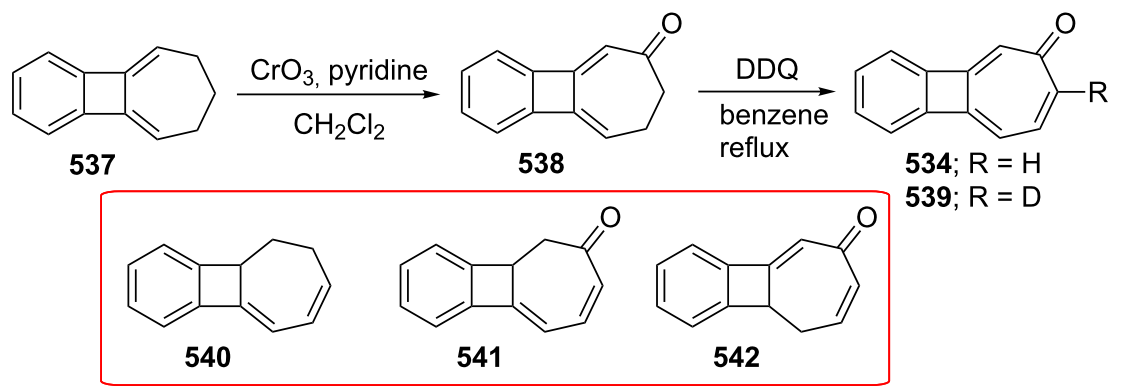


All attempts to prepare the other benzocyclobutatropone, $\mathbf{5 4 5}$, have failed so far (Scheme 97). The potential precursor 543 of $\mathbf{5 4 5}$ was verified to be extremely acid-sensitive, and ketone $\mathbf{5 4 3}$ was rearranged to afford the bridged ketone $\mathbf{5 4 5}$ in high yield via cationic intermediates [247,248]. Another attempt then aimed to introduce a second double bond into the seven-membered ring of ketone 546, which reacted with $N$-bromosuccinimide followed by treatment with tetrabutylammonium bromide to yield fluoren-9-ol (547) as the only isolable product [248]. After unsuccessful attempts resulting from the propensity of reaction intermediates to undergo skeletal rearrangements, Wege's group attempted the preparation of ketone $\mathbf{5 4 8}$, in which $\pi$-electrons binding to the iron carbonyl moiety as the driving force for isomerization should be suppressed [248]. However, attempts towards the preparation of the complex $\mathbf{5 4 8}$ were not successful.

To access the symmetrical tropone derivative 536, the cycloadduct $\mathbf{5 3 7}$ was again used as a starting material since this compound contains the necessary ring skeleton of $\mathbf{5 3 6}$ and possesses the diene function permitting the introduction of the essential carbonyl group (Scheme 98) [248,249]. Compound 537 was transformed to monobromo 549 in 8 steps, which reacted with trimethylamine in the presence of cyclopentadiene (202) in dichloromethane at $0{ }^{\circ} \mathrm{C}$ to give the trapping product $\mathbf{5 5 0}$ in $20 \%$ yield as $[6+4]$ cycloadduct. This result was attributed to the formation of benzocyclobutatropone 536. The reaction performed without $\mathbf{2 0 2}$ gave no recognizable product.

Ebine's group were the first to report the addition reaction between 1-methoxybiphenylene (551) and dichlorocarbene generated from chloroform to give chloro-benzocyclobutatropone $552(1.7 \%)$ together with two fluorenone derivatives, 553a $(0.8 \%)$ and 553b (1.3\%), in very low yields (Scheme 99) [250]. The formation mechanism for the products is also provided as depicted in Scheme 99. Moreover, Ebine's group investigated the reaction of 1,2-dimethoxybiphenylene with dichlorocarbene

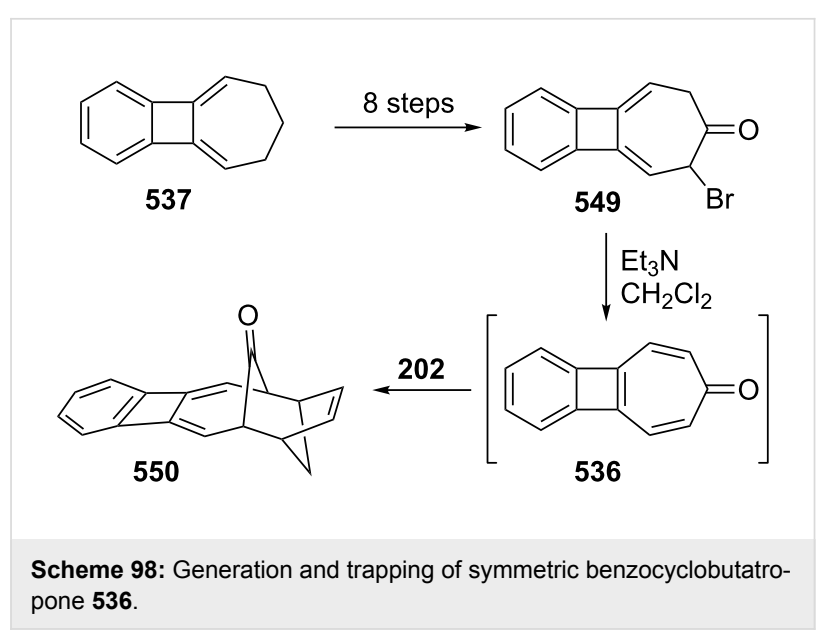

to detect the bond fixation in biphenylene derivatives [251]. While the reaction gave two chloro-methoxy-benzocyclobutatropones and four fluorenones with chloro and methoxy substituents, similar products were obtained with dibromocarbene. The formation of these products was attributed to unequivocal chemical evidence for bond fixation of 1,2-dimethoxybiphenylene. Furthermore, cleavage of the ether functionality with boron tribromide in dichloromethane at $-65{ }^{\circ} \mathrm{C}$ provided the first example of tropolone analogue 559a (93\%) of biphenylene (Scheme 100). Electronic spectra and NMR coupling constants of the compound showed that 559a exists as only one tautomer due to instability of the antiaromatic cyclobutadiene structure in the central four-membered ring of $\mathbf{5 5 9 b}$.

At the same time, Ebine's group reported the reaction of biphenylene-2,3-quinone (560) with diazomethane in the presence of boron trifluoride etherate to give another tropolone analogue 561 and its boron difluoride chelate 562, which was hydrolyzed in acidic aqueous ethanol to $\mathbf{5 6 1}$ quantitatively (Scheme 101) [252,253]. On the other hand, some electrophilic reactions, including nitration, bromination, and azo coupling for 561 yielded only 7 -substituted tropolones.

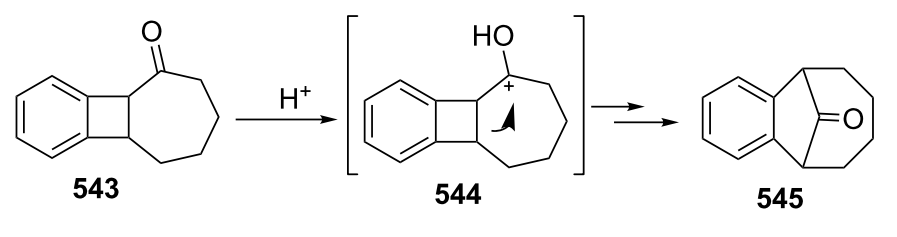

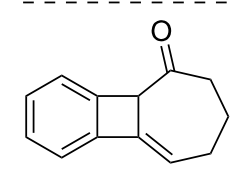

546<smiles>OC1c2ccccc2-c2ccccc21</smiles>

547

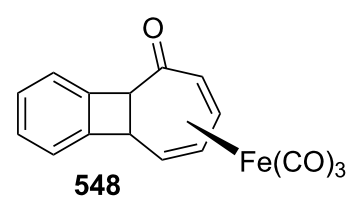


<smiles>COc1cccc2c1-c1ccccc1-2</smiles>

551

i<smiles>O=c1cccc2c(Cl)c1-c1ccccc1-2</smiles>

552<smiles>[X]c1cccc2c1C(=O)c1ccccc1-2</smiles>

553a; $X=\mathrm{OMe}$ 553b; $X=\mathrm{Cl}$<smiles>CC12C=CC=CC(Cl)(c3ccccc31)C2(C)Cl</smiles>

$552+553 a$<smiles>COC1=CC(Cl)=CC=C2c3ccccc3C1(O)C2(O)c1ccccc1</smiles>

$1 k$

$\mathrm{MeO}$

553b<smiles>COC1(O)C=C(Cl)C=CC12c1ccccc1C2(O)CO</smiles>

557

Scheme 99: Synthesis of chloro-benzocyclobutatropone 552 and proposed mechanism of fluorenone derivatives.<smiles>COc1c(C(=O)O)cc(Cl)c2c1-c1ccccc1-2</smiles><smiles>C=Cc1cc(Cl)c2c(c1O)-c1ccccc1-2</smiles>

$559 a$<smiles>CC(C)(C)S(=O)(=O)c1ccccc1Cl</smiles>

Scheme 100: Synthesis of tropolone analogue 559<smiles>CCOCCN(C)CC</smiles>

560<smiles>O=c1cc2c(ccc1[OH2+])-c1ccccc1-2</smiles>

561<smiles>C1CCCCC1</smiles>

562

Scheme 101: Synthesis of tropolones 561 and 562.

\subsection{Benzotropoquinones}

Benzene annulations to $o$ - and $p$-tropoquinone rings (563 and 564) have also attracted interest due to their unique quinone characteristics as in benzoquinone series of $o$ - and $p$-tropoquinones (Figure 35). Both 566 and 567 of possible benzo analogues containing tropoquinone rings were synthesized, and their properties were described (Figure 34) [254,255]. Oxidation of hydroxybenzotropone 568 with DDQ in acetone at room temperature followed by addition of water provided 1,2,3benzotropoquinone hydrate $\mathbf{5 6 9}$ in $85 \%$ yield, which was carefully sublimated to afford the desired 1,2,3-benzotropoquinone 566 in low yield (18\%, Scheme 102) [254]. The synthesis of starting 568 was reported by Hartwig's group [197]. Benzo- tropoquinone 566 is gradually decomposed in dry air and is highly hygroscopic, giving 569. 1,2,5-Benzotropoquinone 567 was prepared by starting from the Diels-Alder reaction between 1-acetoxy-1,3-butadiene (570) and $p$-tropoquinone (564) in a four-step synthesis (Scheme 103) [255]. The acetylation of cycloadduct $\mathbf{5 7 1}$ or $\mathbf{5 7 2}$ provided the diacetoxybenzotropone 573, which was converted to benzotropoquinone 567 after acid hydrolysis and oxidation steps.

Due to the highly hygroscopic nature of $\mathbf{5 6 6}$, chemical reactions of hydrated $\mathbf{5 6 9}$ were studied [254]. The reaction of 569 with $o$-phenylenediamine at room temperature afforded the quinoxaline derivative 575 (15\%) along with 


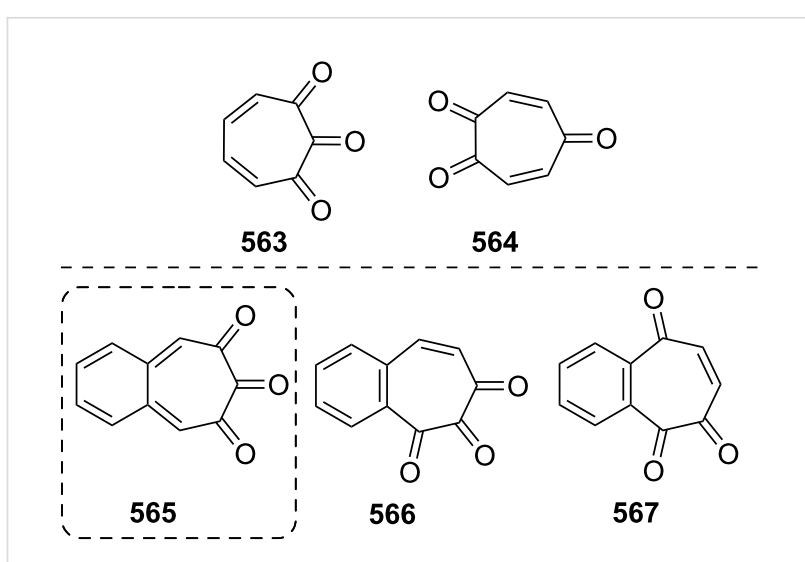

Figure 35: o/p-Tropoquinone rings (563 and 564) and benzotropoquinones (565-567).

$$
\underset{568}{\stackrel{D D Q}{\longrightarrow}=0}
$$

Scheme 102: Synthesis of benzotropoquinone 566

benzo[ $a]$ phenazine $(13 \%$, Figure 36$)$. While the reaction between $\mathrm{NaN}_{3}$ and $\mathbf{5 6 9}$ gave $\mathbf{5 7 6}$ through conjugate addition followed by dehydration (Figure 36), treatment of $\mathbf{5 6 9}$ with concentrated $\mathrm{HCl}$ at room temperature provided $\mathbf{5 6 8}$ in $80 \%$ yield. Furthermore, the corresponding diacetate $\mathbf{5 7 7}$ was obtained in $87 \%$ yield from the acetylation of $\mathbf{5 6 9}$ in the presence of $\mathrm{H}_{2} \mathrm{SO}_{4}$ (Figure 36). Acetylation of $\mathbf{5 6 9}$ with $\mathrm{BF}_{3}$ catalyst resulted in the formation of 1,2-diacetoxy-naphthalene (25\%) and 3,3',4,4'-tetraacetoxy-1,1'-binaphthyl (15\%) together with $577(15 \%)$.<smiles>CC(=O)OC1(OC(C)=O)C(=O)C=Cc2ccccc2C1=O</smiles>

Figure 36: Products $\mathbf{5 7 5 - 5 7 7}$ through 1,2,3-benzotropoquinone hydrate 569.

Although 1,2,5-benzotropoquinone $\mathbf{5 6 7}$ is highly sensitive to moisture, it is stable under anhydrous conditions in the dark and, its hygroscopic form returns to $\mathbf{5 6 7}$ when dried under a vacuum. While the reaction of tropoquinone $\mathbf{5 6 7}$ with $o$-phenylenediamine gives a quinoxaline derivative $\mathbf{5 7 8}$, the reduction of $\mathbf{5 6 7}$ to $\mathbf{5 7 9}$ was realized via catalytic hydrogenation with $\mathrm{Pd} / \mathrm{C}$ (Scheme 104) [252]. A naphthaldehyde derivative $\mathbf{5 8 0}$ was derived from Thiele acetylation $\left(\mathrm{Ac}_{2} \mathrm{O}, \mathrm{H}_{2} \mathrm{SO}_{4}\right.$, room temperature) of $\mathbf{5 6 7}$ in $11 \%$ yield. Treatment of tropoquinone $\mathbf{5 6 7}$ with hydrogen chloride in ethanol gave the adduct 581 (74\% yield), which was oxidized with silver carbonatecelite to yield the indigoid $\mathbf{5 8 2}$ (30\%). Upon the addition of methanol, $\mathbf{5 6 7}$ reversibly forms a mixture of the corresponding methyl acetals through adjacent diketone.

\subsection{Dibenzotropoquinones}

Two possible structures for dibenzotropoquinone, $5 H$-dibenzo$[a, c][7]$ annulene-5,6,7-trione (583) and 5H-dibenzo$[a, d][7]$ annulene-5,10,11-trione (584), are already known (Figure 37). Firstly, triketone $\mathbf{5 8 3}$ was prepared by oxidation of<smiles>C=C/C=C\OC(C)=O</smiles><smiles>CC(=O)Oc1ccc(OC(C)=O)c2c(O)c([O-])ccc12</smiles> 


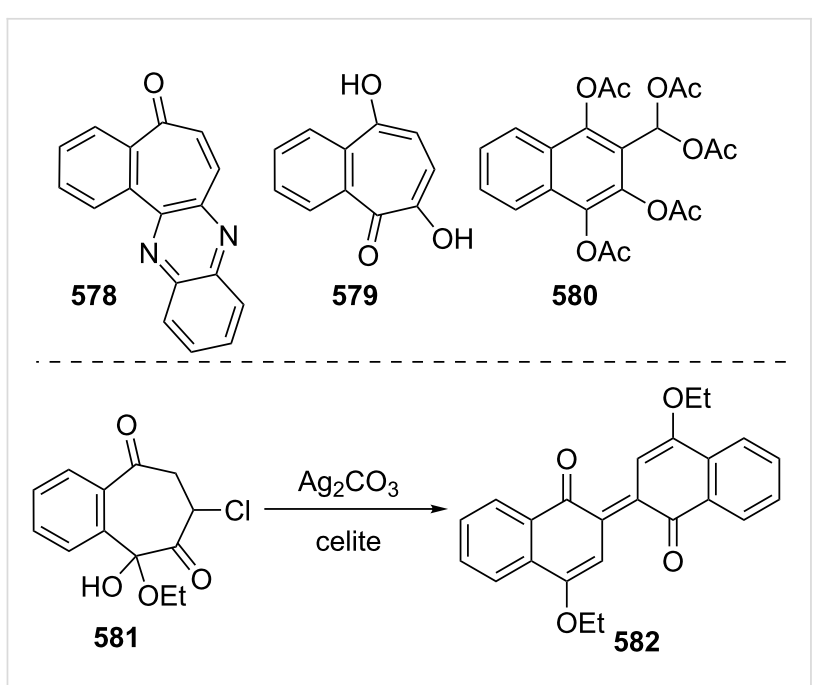

Scheme 104: Structures 578-582 prepared from tropoquinone 567.

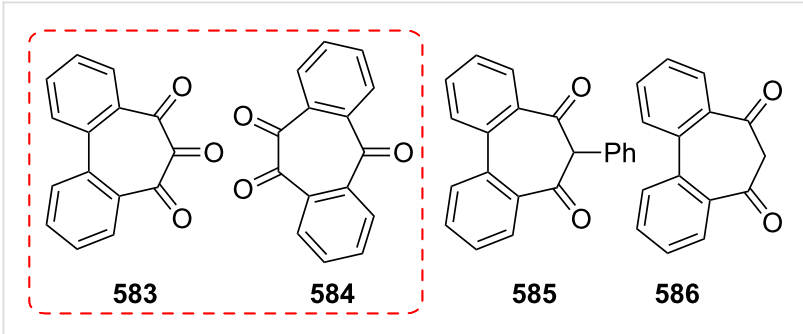

Figure 37: Two possible structures $\mathbf{5 8 3}$ and $\mathbf{5 8 4}$ for dibenzotropoquinone, and precursor compound $\mathbf{5 8 5}$ for 583 .

the activated methylene group of diketone $\mathbf{5 8 6}$ with selenium dioxide [256,257]. Oxidative degradation of diketone $\mathbf{5 8 5}$ with nitric acid also provided $\mathbf{5 8 3}$ (Figure 36) [258,259]. The synthesis of dibenzotropoquinone $\mathbf{5 8 4}$ was realized via $\mathrm{SeO}_{2}$-mediated oxidation of $5 \mathrm{H}$-dibenzo[a,d][7] annulen-5-one (399, Figure 19) [260,261].

Conjugated carbon nanomaterials such as fullerenes, carbon nanotubes, and graphene have received tremendous attention and have great potential application in nanoscience due to their exceptional electrical, thermal, chemical, and mechanical properties. Starting from dibenzotropoquinone 584, Miao's group reported the synthesis of saddle-shaped ketone $\mathbf{5 9 2}$ containing two tropone subunits embedded in the well-known framework of peri-hexabenzocoronene as depicted in Scheme 105 [261]. However, bistropone $\mathbf{5 9 2}$ was used as a precursor for the successful synthesis of two novel large aromatic saddles $\left(\mathrm{C}_{70} \mathrm{H}_{26}\right.$ and $\mathrm{C}_{70} \mathrm{H}_{30}$ ) by reactions on the carbonyl groups. Local aromaticity and nonplanarity of individual rings in these saddleshaped $\pi$-backbones were confirmed by crystal structure analysis. Moreover, preliminary studies on semiconductor properties were performed.

\section{Conclusion}

Tropones and tropolones are an important class of seven-membered aromatic compounds. In addition, hundreds of tropone or tropolone derivatives are known in the literature. These kinds of products have a wide range of biological activity and are building blocks in the synthesis of many molecules. All these factors have made these molecules a focus of intense interest among both organic chemists and medical chemists for nearly a century. This chemistry is one of the milestones leading to a deeper understanding of static, dynamic, and multidisciplinary aspects of organic chemistry such as spectroscopic studies, mechanistic and synthetic investigations, theoretical calculations, aromaticity, evolution, and design of bioactive molecules and molecular materials.

In this review, we have described the numerous efforts concerning synthesis and applications in benzotropone chemistry spanning over 100 years, from the first works up to the most recent. The review covers isomeric benzotropones and tribenzotropones as well as their benzotropolone analogues. As it is well known, halogenated compounds are very valuable as they are the key compounds for many functionalizations. Therefore, halogenated benzotropones and benzotropolones are also included in this review. Tropoquinones are a topic of interest in organic research and these compounds are used for many functionalization reactions. Works on benzo analogues of tropoquinones are also summarized in this review. Carbene-carbene and carbene-allene rearrangements on benzo[7] annulene ringderived benzotropones are investigated in detail in the literature and discussed in this review. Carbene insertion reaction, synthesis of azocine, synthesis and physical properties of homo- and bis-homobenzotropones, and their conversation to corresponding homotropolium cations are also other well-investigated issues reviewed in this work. Knowledge of the chemistry of benzocyclobutenotropones, naphthotropones, and their tropolone analogues is limited and more research on those compounds is required in the future.

Numerous synthetic efforts towards the synthesis and chemical reactivity of benzotropones and benzotropolones were reported from the 20th century to date. In addition to being natural products, many benzotropone derivatives can be prepared directly by oxidation of seven-membered rings. They can also be derived from cyclization, ring expansion, or cycloaddition of appropriate precursors followed by elimination or rearrangement. The oxidation of seven-membered rings generally gives a mixture, whereas cyclization of suitable acylic compounds or ring expansion reactions generally produces one isomer in high yield. Although 2,3- and 4,5-benzotropone have been investigated in detail, research on 3,4-benzotropone is rather limited due to instability of this kind of compound, which is attributed 


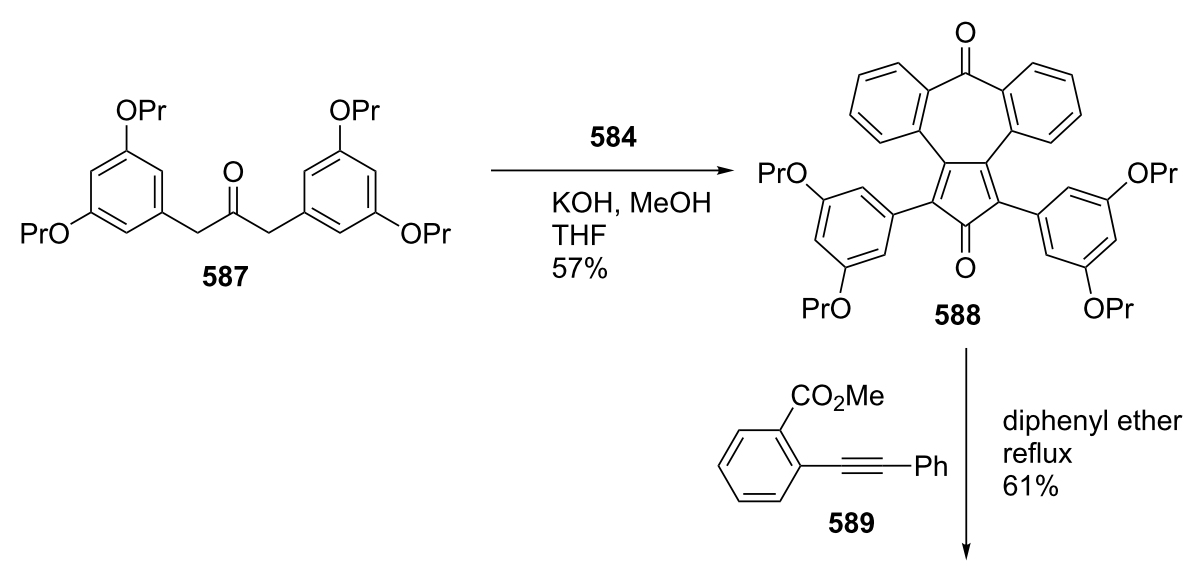

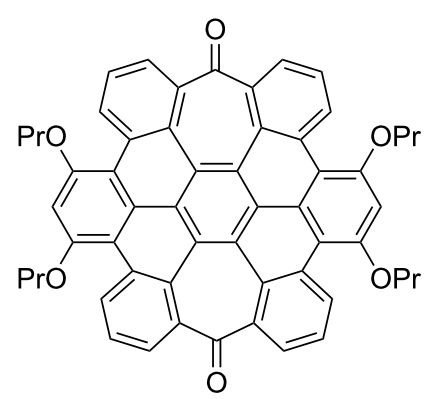

\section{1) $\mathrm{DDQ}, \mathrm{CF}_{3} \mathrm{SO}_{3} \mathrm{H}$ $\mathrm{CH}_{2} \mathrm{Cl}_{2}$ \\ 2) $\mathrm{CH}_{3} \mathrm{SO}_{3} \mathrm{H}$ $45 \%$}

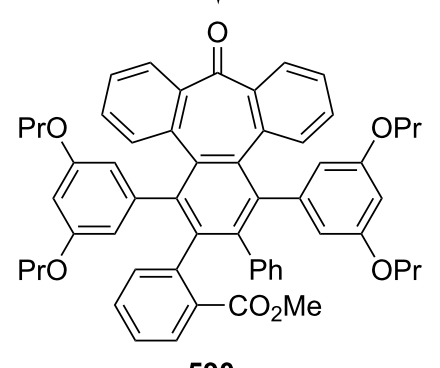

591

1) $\mathrm{BBr}_{3}, \mathrm{CH}_{2} \mathrm{Cl}_{2}$

2) $\mathrm{K}_{2} \mathrm{CO}_{3}, \mathrm{RBr}$, DMF

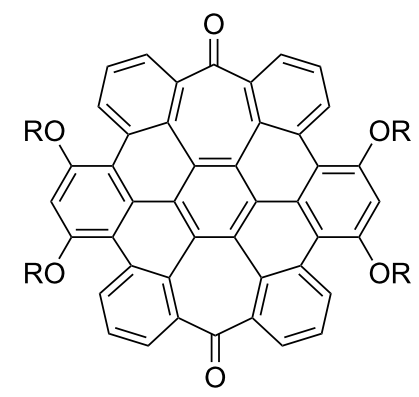

592a; $\mathrm{R}=n$-octyl $(42 \%)$

592b; $\mathrm{R}=n$-hexyl $(43 \%)$

Scheme 105: Synthesis of saddle-shaped ketone 592 using dibenzotropoquinone 584.

to the $o$-quinoidal structure, and because it does not have a sextet electron system in the benzene ring.

In general, two kinds of reactions on benzotropone and their analogues are common: i) reaction on the carbonyl group, which is generally a nucleophilic addition or condensation, ii) reaction on the double bond in the seven-membered ring, which is generally with a nucleophile since the tropone ring is behaving as an electrophile. The double bonds in the seven-membered ring give a cycloaddition reaction as both a diene and a dienophile. Although many reactions on this hydrocarbon have been reported, we think that there is still a need for the scientific community to develop many synthetic methods and investigate their possible interesting synthetic applications in various fields. We consider the objectives of this review as helping in the systematization of the literature data collected to date and allowing a better understanding of them, and possibly bringing new ideas to the field. We strongly believe that the synthetic potential and applications of this chemistry have not yet been fully revealed, and there are certainly further challenges and opportunities for reinvestigation, and plenty of room for further studies on the chemistry of benzotropones for medicinal, material, and synthetic organic chemists. Based on the progress in benzotropone chemistry including synthesis and applications summarized in this work, we feel certain that this review will find broad interest and will continue to attract much attention in 
organic synthesis applications. We hope that this review will facilitate the synthesis of tropolone-containing compounds discovered in nature or designed by medicinal chemists. They are also expected to be applied in new material fields due to their high functionalization capacity via their benzene ring, seven-membered ring, and carbonyl group.

\section{Acknowledgments}

The authors thank Professor Hasan Seçen, Assoc. Prof. Dr. Murat Guney, Assoc. Prof. Dr. Harun Budak, Professor Duygu Ekinci, Professor Mustafa Arik, Professor Murat Alanyalioglu, Assist. Prof. Dr. Erdin Dalkilic, Assist. Prof. Dr. Bilal Nisanci, Dr. Sara Taskesenlioglu, Ph.D. student Farrokh Lafzi (Ataturk University) and Professor Arif Baran (Sakarya University) for providing some of the references and their kind help.

\section{ORCID ${ }^{\circledR}$ iDs}

Arif Dastan - https://orcid.org/0000-0002-9577-2251

Haydar Kilic - https://orcid.org/0000-0002-7009-9953

Nurullah Saracoglu - https://orcid.org/0000-0002-1504-7480

\section{References}

1. Banwell, M. G. Aust. J. Chem. 1991, 44, 1-36. doi:10.1071/CH9910001

2. Asao, T.; Oda, M. Methoden Der Organischen Chemie. In Houben Weyl; Regitz, E. M., Ed.; George Thieme Verlag: Stuttgart, 1985; Vol. 5/2c, pp 710-768.

3. Pietra, F. Acc. Chem. Res. 1979, 12, 132-138. doi:10.1021/ar50136a004

4. Pietra, F. Chem. Rev. 1973, 73, 293-364. doi:10.1021/cr60284a002

5. Pauson, P. L. Chem. Rev. 1955, 55, 9-136. doi:10.1021/cr50001a002

6. Dauben, H. J., Jr.; Ringold, H. J. J. Am. Chem. Soc. 1951, 73, 876. doi:10.1021/ja01146a536

7. Doering, W. v. E.; Detert, F. L. J. Am. Chem. Soc. 1951, 73, 876-877. doi:10.1021/ja01146a537

8. Nozoe, T. Pure Appl. Chem. 1971, 28, 239-280. doi:10.1351/pac197128020239

9. Liu, N.; Song, W.; Schienebeck, C. M.; Zhang, M.; Tang, W. Tetrahedron 2014, 70, 9281-9305. doi:10.1016/j.tet.2014.07.065

10. Piettre, S. R.; Ganzhorn, A.; Hoflack, J.; Islam, K.; Hornsperger, J.-M. J. Am. Chem. Soc. 1997, 119, 3201-3204. doi:10.1021/ja9634278

11. Piettre, S. R.; André, C.; Chanal, M.-C.; Ducep, J.-B.; Lesur, B.; Piriou, F.; Raboisson, P.; Rondeau, J.-M.; Schelcher, C.; Zimmermann, P.; Ganzhorn, A. J. J. Med. Chem. 1997, 40, 4208-4221. doi:10.1021/jm9701942

12. Tomita, K.; Hoshino, Y.; Nakakita, Y.; Umezewa, S.; Miyaki, T.; Oki, T.; Kawaguchi, H. J. Antibiot. 1989, 42, 317-321. doi:10.7164/antibiotics.42.317

13. Banwell, M. G.; Corbett, M.; Mackay, M. F.; Richards, S. L. J. Chem. Soc., Perkin Trans. 1 1992, 1329-1334. doi:10.1039/P19920001329

14. Saleh, N. A.; Zfiefak, A.; Mordarski, M.; Pulverer, G. Zbl. Bakt. Hyg. A 1988, 270, 160-170.

15. Suziki, H.; Ueda, T.; Juránek, I.; Yamamoto, S.; Katoh, T.; Node, M.; Suziki, T. Biochem. Biophys. Res. Commun. 2000, 275, 885-889. doi:10.1006/bbrc. 2000.3390
16. Kitamura, S.; lida, T.; Shiarata, K.; Kase, H. J. Antibiot. 1986, 39, 589-593. doi:10.7164/antibiotics.39.589

17. Trust, T. J.; Coombs, R. W. Can. J. Microbiol. 1973, 19, 1341-1346. doi:10.1139/m73-216

18. Zhao, J.; Sakai, K. J. Exp. Bot. 2003, 54, 647-656. doi:10.1093/jxb/erg062

19. Arima, Y.; Nakai, Y.; Hayakawa, R.; Nishino, T. J. Antimicrob. Chemother. 2003, 51, 113-122. doi:10.1093/jac/dkg037

20. Zhao, J.; Fujita, K.; Yamada, J.; Sakai, K. Appl. Microbiol. Biotechnol. 2001, 55, 301-305. doi:10.1007/s002530000555

21. Krenn, B. M.; Gaudernak, E.; Holzer, B.; Lanke, K.; Van Kuppeveld, F. J. M.; Seipelt, J. J. Virol. 2009, 83, 58-64. doi:10.1128/JVI.01543-08

22. Shih, M.-F.; Chen, L.-Y.; Tsai, P.-J.; Cherng, J.-Y. Int. J. Immunopathol. Pharmacol. 2012, 25, 39-48. doi:10.1177/039463201202500106

23. Oblak, E. Z.; Bolstad, E. S. D.; Ononye, S. N.; Priestley, N. D.; Hadden, M. K.; Wright, D. L. Org. Biomol. Chem. 2012, 10, 8597-8604. doi:10.1039/c2ob26553b

24. Buta, J. G.; Flippen, J. L.; Lusby, W. R. J. Org. Chem. 1978, 43, 1002-1003. doi:10.1021/jo00399a047

25. Frey, B.; Wells, A. P.; Rogers, D. H.; Mander, L. N. J. Am. Chem. Soc. 1998, 120, 1914-1915. doi:10.1021/ja9738081

26. Su, J.-Y.; Zhu, Y.; Zeng, L.-M.; Xu, X.-H. J. Nat. Prod. 1997, 60, 1043-1044. doi:10.1021/np970149x

27. Albert, A.; Van Nguyen, T. H.; Langer, P. J. Org. Chem. 2004, 69, 3417-3424. doi:10.1021/jo049736v

28. Gill, M.; Steglich, W. Prog. Chem. Org. Nat. Prod. 1987, 51, 1-297. doi:10.1007/978-3-7091-6971-1_1

29. Dürckheimer, W.; Paulus, E. F. Angew. Chem., Int. Ed. Engl. 1985, 24, 224-225. doi:10.1002/anie.198502241

30. Levy, M.; Spino, M.; Read, S. E. Pharmacotherapy 1991, 11, 196-211.

31. Yeh, H. J. C.; Chrzanowska, M.; Brossi, A. FEBS Lett. 1988, 229 , 82-86. doi:10.1016/0014-5793(88)80802-0

32. Shi, Q.; Verdier-Pinard, P.; Brossi, A.; Hamel, E.; Lee, K.-H. Bioorg. Med. Chem. 1997, 5, 2277-2282. doi:10.1016/S0968-0896(97)00171-5

33. Shi, Q.; Verdier-Pinard, P.; Brossi, A.; Hamel, E.; Mcphail, A. T.; Lee, K.-H. J. Med. Chem. 1997, 40, 961-966. doi:10.1021/jm960663k

34. Shi, Q.; Chen, K.; Brossi, A.; Verdier-Pinard, P.; Hamel, E.; Mcphail, A. T.; Lee, K.-H. Helv. Chim. Acta 1998, 81, 1023-1037. doi:10.1002/hlca.19980810516

35. Boye, O.; Brossi, A. In Alkaloids; Brossi, A., Ed.; Academic Press: New York, 1983; Vol. 41, p 125.

36. Banwell, M. G.; Fam, M.-A.; Gable, R. W.; Hamel, E. J. Chem. Soc., Chem. Commun. 1994, 2647-2949. doi:10.1039/c39940002647

37. Srivastava, K. C.; Dev, S. Tetrahedron 1972, 28, 1083-1091. doi:10.1016/0040-4020(72)80167-4

38. Mousseron, M.; Christol, H.; Plenat, F.; Delhoste, Y. C. R. Hebd. Seances Acad. Sci. 1959, 248, 1743-1745.

39. Roberts, E. A. H.; Cartwright, R. A.; Oldschool, M. J. Sci. Food Agric. 1957, 8, 72-80. doi:10.1002/jsfa.2740080203

40. Lin, J.-K. Arch. Pharmacal Res. 2002, 25, 561-571. doi:10.1007/BF02976924

41. Mukamal, K. J.; Maclure, M.; Muller, J. E.; Sherwood, J. B.; Mittleman, M. A. Circulation 2002, 105, 2476-2481. doi:10.1161/01.CIR.0000017201.88994.F7 
42. Hakim, I. A.; Alsaif, M. A.; Alduwaihy, M.; Al-Rubeaan, K.; Al-Nuaim, A. R.; Al-Attas, O. S. Prev. Med. 2003, 36, 64-70. doi:10.1006/pmed.2002.1130

43. Mackenzie, T.; Comi, R.; Sluss, P.; Keisari, R.; Manwar, S.; Kim, J.; Larson, R.; Baron, J. A. Metabolism 2007, 56, 1694-1698. doi:10.1016/j.metabol.2007.07.013

44. Celik, F.; Celik, M.; Akpolat, V. J. Diabetes Complications 2009, 23, 304-309. doi:10.1016/j.jdiacomp.2008.02.005

45. Dastan, A.; Kilic, H.; Saracoglu, N. Synthesis 2018, 50, 391-439. doi:10.1055/s-0036-1589518

46. Thiele, J.; Schneider, J. Justus Liebigs Ann. Chem. 1909, 369, 287-299. doi:10.1002/jlac.19093690304

47. Thiele, J.; Weitz, E. Justus Liebigs Ann. Chem. 1910, 377, 1-22. doi:10.1002/jlac.19103770102

48. Cook, M. J.; Forbes, E. J. Tetrahedron 1968, 24, 4501-4508. doi:10.1016/S0040-4020(01)96287-8

49. Föhlisch, B.; Fischer, C.; Widmann, E.; Wolf, E. Tetrahedron 1978, 34, 533-539. doi:10.1016/0040-4020(78)80048-9

50. Ibata, K.; Shimanouchi, H.; Sasada, Y.; Hata, T. Acta Crystallogr., Sect. B 1975, 31, 2313-2321. doi:10.1107/S0567740875007455

51. Pomerantz, M.; Swei, G.-S. Tetrahedron Lett. 1982, 23, 3027-3030. doi:10.1016/S0040-4039(00)87524-3

52. Daştan, A.; Yildiz, Y. K.; Balci, M. Synth. Commun. 2001, 31, 3807-3815. doi:10.1081/SCC-100108231

53. Ranken, P. F.; Harty, B. J.; Kapicak, L.; Battiste, M. A. Synth. Commun. 1973, 3, 311-315. doi:10.1080/00397917308065924

54. Ewing, G. D.; Paquette, L. A. J. Org. Chem. 1975, 40, 2965-2966. doi:10.1021/jo00908a028

55. Müller, P.; Bernardinelli, G.; Thi, H. C. G.-N. Helv. Chim. Acta 1989, 72, 1627-1638. doi:10.1002/hlca.19890720723

56. Sonogashira, K. J. Organomet. Chem. 2002, 653, 46-49. doi:10.1016/S0022-328X(02)01158-0

57. Heck, R. F.; Nolley, J. P. J. Org. Chem. 1972, 37, 2320-2322. doi:10.1021/jo00979a024

58. Keshipour, S.; Shojaei, S.; Shaabani, A. Cellulose 2013, 20, 973-980. doi:10.1007/s10570-012-9852-8

59. Hori, M.; Kataoka, T.; Shimmizu, H.; Satoh, H.; Mikawa, H.; Nogami, T. Heterocycles 1983, 20, 2039-2046. doi:10.3987/R-1983-10-2039

60. Halton, B.; Buckland, S. J.; Mei, Q.; Stang, P. J. Tetrahedron Lett. 1986, 27, 5159-5160. doi:10.1016/S0040-4039(00)85159-X

61. Halton, B.; Buckland, S. J.; Lu, Q.; Mei, Q.; Stang, P. J. J. Org. Chem. 1988, 53, 2418-2422. doi:10.1021/jo00246a005

62. Sugimura, Y.; lino, K.; Kuwano, H.; Soma, N.; Kishida, Y. Chem. Pharm. Bull. 1972, 20, 2515-2521. doi:10.1248/cpb.20.2515

63. Föhlisch, B.; Bürgle, P.; Krockenberger, D. Chem. Ber. 1968, 101, 2717-2730. doi:10.1002/cber.19681010814

64. Kitahara, Y.; Murata, I.; Katagiri, S. Angew. Chem., Int. Ed. Engl. 1965, 4, 353. doi:10.1002/anie.196503531

65. Jutz, C. Chem. Ber. 1964, 97, 2050-2065. doi:10.1002/cber.19640970740

66. Nitta, M.; lino, Y.; Sugiyama, T.; Akaogi, A. Tetrahedron Lett. 1993, 34, 831-834. doi:10.1016/0040-4039(93)89024-K

67. Nitta, M.; lino, Y.; Sugiyama, T.; Toyota, A. Tetrahedron Lett. 1993, 34, 835-838. doi:10.1016/0040-4039(93)89025-L

68. Nitta, M.; Nishimura, K.; lino, Y. Tetrahedron Lett. 1993, 34, 2151-2160. doi:10.1016/S0040-4039(00)60370-2

69. Nitta, M.; Kawaji, H.; Kanomata, N. Tetrahedron Lett. 1992, 33, 251-254. doi:10.1016/0040-4039(92)88063-B
70. Ito, K.; Kawaji, H.; Nitta, M. Tetrahedron Lett. 1994, 35, 2561-2564. doi:10.1016/S0040-4039(00)77171-1

71. Naya, S.-i.; Tokunaka, T.; Nitta, M. J. Org. Chem. 2003, 68, 9317-9321. doi:10.1021/jo035274u

72. Hynes, R. O. Cell 2002, 110, 673-687. doi:10.1016/S0092-8674(02)00971-6

73. Perron-Sierra, F.; Dizier, D. S.; Bertrand, M.; Genton, A.; Tucker, G. C.; Casara, P. Bioorg. Med. Chem. Lett. 2002, 12, 3291-3296. doi:10.1016/S0960-894X(02)00696-0

74. Jones, W. M.; Joines, R. C.; Myers, J. A.; Mitsuhashi, T.; Krajca, K. E.; Waali, E. E.; Davis, T. L.; Turner, A. B. J. Am. Chem. Soc. 1973, 95, 826-835. doi:10.1021/ja00784a033

75. Kirmse, W.; Sluma, H. D. J. Org. Chem. 1988, 53, 763-767. doi:10.1021/jo00239a012

76. Chateauneuf, J. E.; Horn, K. E.; Savino, T. G. J. Am. Chem. Soc. 1988, 110, 539-545. doi:10.1021/ja00210a038

77. Jones, W. M. Acc. Chem. Res. 1977, 10, 353-359. doi:10.1021/ar50118a001

78. Bonvallet, P. A.; Todd, E. M.; Kim, Y. S.; McMahon, R. J. J. Org. Chem. 2002, 67, 9031-9042. doi:10.1021/jo020304z

79. Asao, T.; Morita, N.; Kitahara, Y. Synth. Commun. 1972, 2, 353-355. doi:10.1080/00397917208081779

80. Staudinger, H.; Kon, N. Justus Liebigs Ann. Chem. 1911, 384, 38-135. doi:10.1002/jlac.19113840103

81. Jutz, C.; Rommel, I.; Lengyel, I.; Feeney, J. Tetrahedron 1966, 22, 1809-1819. doi:10.1016/S0040-4020(01)82254-7

82. Regitz, M.; Urgast, K.; Maas, G. Z. Naturforsch., B: Chem. Sci. 1985, 40B, 67-76.

83. Franck-Neumann, M.; Martina, D. Tetrahedron Lett. 1975, 16, 1755-1758. doi:10.1016/S0040-4039(00)75246-4

84. Trindade, A. C. L. B.; Dos Santos, D. C.; Gil, L.; Marazano, C.; Gil, R. P. d. F. Eur. J. Org. Chem. 2005, 1052-1057. doi:10.1002/ejoc.200400728

85. Paquette, L. A.; Hansen, J. F.; Kakihana, T. J. Am. Chem. Soc. 1971, 93, 168-173. doi:10.1021/ja00730a029

86. Paquette, L. A.; Anderson, L. B.; Hansen, J. F.; Lang, S. A., Jr.; Berk, H. J. Am. Chem. Soc. 1972, 94, 4907-4915. doi:10.1021/ja00769a020

87. Paquette, L. A.; Ewing, G. D.; Ley, S. V.; Berk, H. C.; Traynor, S. G. J. Org. Chem. 1978, 43, 4712-4720. doi:10.1021/jo00419a007

88. Paquette, L. A.; Watson, T. J. J. Org. Chem. 1994, 59, 5708-5716. doi:10.1021/jo00098a032

89. Secen, H.; Sutbeyaz, Y.; Salamci, E.; Balci, M. Turk. J. Chem. 1992, 16, 237-245.

90. Morita, N.; Ito, S.; Asao, T.; Kabuto, C.; Sotokawa, H.; Hatano, M.; Tajiri, A. Chem. Lett. 1990, 1527-1530. doi:10.1246/cl.1990.1527

91. Morita, N.; Ito, S.; Asao, T.; Sotokawa, H.; Hatano, M.; Tajiri, A. Chem. Lett. 1990, 1639-1642. doi:10.1246/cl.1990.1639

92. Tajiri, A.; Sotokawa, H.; Morita, N.; Kabuto, C.; Hatano, M.; Asao, T. Tetrahedron Lett. 1987, 28, 6465-6468. doi:10.1016/S0040-4039(00)96889-8

93. Hanquet, B.; Guilard, R. Can. J. Chem. 1986, 64, 1310-1321. doi:10.1139/v86-225

94. Childs, R. F.; Rogerson, C. V. J. Am. Chem. Soc. 1980, 102, 4159-4166. doi:10.1021/ja00532a030

95. Oda, M.; Ito, Y. Chem. Lett. 1978, 7, 1323-1324. doi:10.1246/cl.1978.1323

96. Prinzbach, H.; Seppelt, W.; Fritz, H. Angew. Chem., Int. Ed. Engl. 1977, 16, 198-199. doi:10.1002/anie.197701981 
97. Oda, M.; Sato, T.; Kitahara, Y. Synthesis 1974, 721-722. doi:10.1055/s-1974-23418

98. Holmes, J. D.; Pettit, R. J. Am. Chem. Soc. 1963, 85, 2531-2532. doi:10.1021/ja00899a050

99. Chapman, O. L.; Fugiel, R. A. J. Am. Chem. Soc. 1969, 91, 215-216. doi:10.1021/ja01029a054

100.von Rosenburg, J. L.; Mahler, J. E.; Pettit, R. J. Am. Chem. Soc. 1962, 84, 2842-2843. doi:10.1021/ja00873a051

101.Winstein, S.; Kaesz, H. D.; Kreiter, C. G.; Freilich, E. C. J. Am. Chem. Soc. 1965, 87, 3267-3269. doi:10.1021/ja01092a060

102. Winstein, S.; Kreiter, C. G.; Brauman, J. I. J. Am. Chem. Soc. 1966, 88, 2047-2048. doi:10.1021/ja00961a037

103. Brockhart, M.; Ogliaruso, M.; Winstein, S. J. Am. Chem. Soc. 1967, 89, 1965-1966. doi:10.1021/ja00984a045

104.Alkorta, I.; Elguero, J.; Eckert-Maksić, M.; Maksić, Z. B. Tetrahedron 2004, 60, 2259-2265. doi:10.1016/j.tet.2004.01.031

105.Paquette, L. A.; Watson, T. J.; Friedrich, D.; Bishop, R.; Bacque, E. J. Org. Chem. 1994, 59, 5700-5707. doi:10.1021/jo00098a031

106.Barzaghi, M.; Gatti, C. J. Mol. Struct.: THEOCHEM 1988, 167, 275-300. doi:10.1016/0166-1280(88)80232-X

107.Scott, L. T.; Hashemi, M. M. Tetrahedron 1986, 42, 1823-1830. doi:10.1016/S0040-4020(01)87601-8

108. Childs, R. F.; Faggiani, R.; Colin, J. L.; Mahendran, M. J. Am. Chem. Soc. 1986, 108, 3613-3617. doi:10.1021/ja00273a011

109. Ohkata, K.; Paquette, L. A. J. Am. Chem. Soc. 1980, 102, 1082-1092. doi:10.1021/ja00523a027

110.Willner, I.; Minsky, A.; Rabinovitz, M. J. Org. Chem. 1979, 44, 4440-4443. doi:10.1021/jo01338a041

111.Scott, L. T.; Brunsvold, W. R. J. Am. Chem. Soc. 1978, 100 6535-6536. doi:10.1021/ja00488a062

112. Matescue, G. D.; Nenitzescu, C. D.; Olah, G. A. J. Am. Chem. Soc. 1968, 90, 6235-6236. doi:10.1021/ja01024a062

113.Tsunetsugu, J.; Sugahara, M.; Heima, K.; Ogawa, Y.; Kosugi, M.; Sato, M.; Ebine, S. J. Chem. Soc., Perkin Trans. 1 1983, 1983-1988. doi:10.1039/p19830001983

114.Wood, J. L.; Smith, A. B., III. J. Am. Chem. Soc. 1992, 114, 10075-10076. doi:10.1021/ja00051a058

115. Suginome, H.; Itoh, M.; Kobayashi, K. J. Chem. Soc., Perkin Trans. 1 1988, 491-496. doi:10.1039/P19880000491

116.Suginome, H.; Liu, C. F.; Tokuda, M.; Furusaki, A. J. Chem. Soc., Perkin Trans. 1 1985, 327-329. doi:10.1039/P19850000327

117. Hehre, W. J. J. Am. Chem. Soc. 1972, 94, 8908-8910. doi:10.1021/ja00780a046

118. Hehre, W. J. J. Am. Chem. Soc. 1974, 96, 5207-5217. doi:10.1021/ja00823a030

119. Haddon, R. C. Tetrahedron Lett. 1974, 15, 2797-2800. doi:10.1016/S0040-4039(01)91746-0

120. Haddon, R. C. Tetrahedron Lett. 1974, 15, 4303-4304. doi:10.1016/S0040-4039(01)92148-3

121. Haddon, R. C. Tetrahedron Lett. 1975, 16, 863-866. doi:10.1016/S0040-4039(00)72004-1

122. Haddon, R. C. J. Am. Chem. Soc. 1975, 97, 3608-3615. doi:10.1021/ja00846a009

123. Haddon, R. C. J. Org. Chem. 1979, 44, 3608-3616. doi:10.1021/jo01335a002

124.Merk, W.; Pettit, R. J. Am. Chem. Soc. 1968, 90, 814-816. doi:10.1021/ja01005a061

125. Sugimura, Y.; Soma, N.; Kishida, Y. Tetrahedron Lett. 1971, 12, 91-94. doi:10.1016/S0040-4039(01)96367-1
126. Bodennec, G.; St-Jacques, M. Can. J. Chem. 1977, 55, 1199-1206. doi:10.1139/v77-167

127. Ménard, D.; St-Jacques, M. Tetrahedron 1983, 39, 1041-1060. doi:10.1016/S0040-4020(01)91866-6

128. Bertelli, D. J.; Rossiter, W. J. Tetrahedron 1968, 24, 609-618. doi:10.1016/0040-4020(68)88011-1

129. Riley, P. E.; Davis, R. E.; Allison, N. T.; Jones, W. M. J. Am. Chem. Soc. 1980, 102, 2458-2460. doi:10.1021/ja00527a056

130.Ried, W.; Müller, H. Chem. Ber. 1961, 94, 1046-1050. doi:10.1002/cber.19610940422

131. Holzmann, G.; Frenking, G.; Steiner, B. J. Chem. Soc., Perkin Trans. 2 1984, 1943-1948. doi:10.1039/p29840001943

132. Cavazza, M.; Morganti, G.; Pietra, F. Recl. Trav. Chim. Pays-Bas 1979, 98, 165-167. doi:10.1002/recl.19790980405

133. Heise, I.; Leitich, J. Chem. Ber. 1985, 118, 332-339. doi:10.1002/cber.19851180130

134.Buchanan, G. L.; Lockhart, D. R. J. Chem. Soc. 1959, 3586-3594. doi:10.1039/JR9590003586

135. Collington, E. W.; Jones, G. J. Chem. Soc. C 1969, 2656-2661. doi:10.1039/J39690002656

136. Collington, E. W.; Jones, G. Chem. Commun. 1968, 958-959. doi:10.1039/c19680000958

137.Sarkar, S.; Saha, G.; Ghosh, S. J. Org. Chem. 1992, 57, 5771-5773. doi:10.1021/jo00047a038

138. Nicolaou, K. C.; Montagnon, T.; Baran, P. S.; Zhong, Y.-L. J. Am. Chem. Soc. 2002, 124, 2245-2258. doi:10.1021/ja012127+

139. Nicolaou, K. C.; Zhong, Y.-L.; Baran, P. S. J. Am. Chem. Soc. 2000, 122, 7596-7597. doi:10.1021/ja001825b

140.Sato, M.; Tanaka, T.; Tsunetsugo, J.; Ebine, S. Bull. Chem. Soc. Jpn. 1975, 48, 2395-2396. doi:10.1246/bcsj.48.2395

141. Rennhard, H. H.; Heilbronner, E.; Eschenmoser, A. Chem. Ind. (London) 1955, 40, 415-416.

142. Rennhard, H. H.; Di Modica, G.; Simon, W.; Heilbronner, E.; Eschenmoser, A. Helv. Chim. Acta 1957, 40, 957-968. doi:10.1002/hlca.19570400410

143. Machiguchi, T. Chem. Lett. 1994, 23, 1677-1678. doi:10.1246/cl.1994.1677

144.Looker, J. J. J. Org. Chem. 1972, 37, 1059-1060. doi:10.1021/jo00972a035

145. Coates, R. M.; Johnson, E. F. J. Am. Chem. Soc. 1971, 93, 4016-4027. doi:10.1021/ja00745a033

146. El-Fayoumy, M. A. G.; Bell, H. M.; Ogliaruso, M. A.; Arison, B. H. J. Org. Chem. 1979, 44, 3057-3062. doi:10.1021/jo01331a019

147.El-Fayoumy, M. A. G.; Bell, H. M.; Ogliaruso, M. A. J. Org. Chem. 1981, 46, 1603-1606. doi:10.1021/jo00321a014

148. Hassner, A.; Middlemiss, D.; Murray-Rust, J.; Murray-Rust, P. Tetrahedron 1982, 38, 2539-2546. doi:10.1016/0040-4020(82)85089-8

149. Güney, M.; Daştan, A.; Balci, M. Helv. Chim. Acta 2005, 88, 830-838. doi:10.1002/hlca.200590061

150. Bauld, N. L.; Brown, M. S. J. Am. Chem. Soc. 1967, 89, 5417-5421. doi:10.1021/ja00997a021

151.Tajiri, A.; Morita, N.; Asao, T.; Hatano, M. Angew. Chem., Int. Ed. Engl. 1985, 24, 329-330. doi:10.1002/anie.198503291

152. Hauser, F. M.; Yin, H. Org. Lett. 2000, 2, 1045-1047. doi:10.1021/ol0055869

153. Ohkita, M.; Tsuji, T.; Nishida, S. J. Chem. Soc., Chem. Commun. 1989, 924-926. doi:10.1039/c39890000924 
154.Ohkita, M.; Nishida, S.; Tsuji, T. J. Am. Chem. Soc. 1999, 121, 4589-4597. doi:10.1021/ja984348u

155.Kurihara, T.; Ishikawa, S.; Nozeo, T.; Aihara, J.-i. Bull. Chem. Soc. Jpn. 1990, 63, 2531-2539. doi:10.1246/bcsj.63.2531

156. Sato, T.; Niino, H.; Okhita, M. J. Phys. Chem. A 2004, 108, 721-726. doi:10.1021/jp035650e

157. Tarbell, D. S.; Bill, J. C. J. Am. Chem. Soc. 1952, 74, 1234-1238. doi:10.1021/ja01125a028

158. Turner, R. W.; Seden, T. Chem. Commun. 1966, 13, 399. doi:10.1039/c19660000399

159.Stevens, H. C.; Rinehart, J. K.; Lavanish, J. M.; Trenta, G. M. J. Org. Chem. 1971, 36, 2780-2784. doi:10.1021/jo00818a012

160. Christol, H.; Delhoste, Y.; Mousseron, M. Bull. Soc. Chim. Fr. 1959, 1238-1243.

161.Galantay, E.; Simpson, W. R. J. J. Chem. Soc., Chem. Commun. 1970, 754-755. doi:10.1039/c29700000754

162. Eberle, M. K.; Kahle, G. G. J. Heterocycl. Chem. 1981, 18, 525-526. doi:10.1002/jhet.5570180317

163. Ebine, S.; Hoshino, M.; Takahashi, K. Bull. Chem. Soc. Jpn. 1968, 41, 2942-2948. doi:10.1246/bcsj.41.2942

164.Hoshino, M.; Ebine, S. Bull. Chem. Soc. Jpn. 1970, 43, 1778-1782. doi:10.1246/bcsj.43.1778

165. Yoshioka, M.; Hoshino, M. Tetrahedron Lett. 1971, 12, 2413-2416. doi:10.1016/S0040-4039(01)96877-7

166. Cook, J. W.; Somerville, A. R. Nature 1949, 163, 410. doi:10.1038/163410a0

167.Cook, J. W.; Gibb, A. R. M.; Raphael, R. A.; Somerville, A. R. J. Chem. Soc. 1952, 603-607. doi:10.1039/JR9520000603

168. Maignan, C.; Grandguillot, J. C.; Rouessac, F. Bull. Soc. Chim. Fr. 1970, 2019-2020.

169.Sato, M.; Tsunetsugu, J.; Ebine, S. Bull. Chem. Soc. Jpn. 1972, 45, 638-639. doi:10.1246/bcsj.45.638

170.Balci, M. Chem. Rev. 1981, 81, 91-108. doi:10.1021/cr00041a005

171.Oda, M.; Kitahara, Y. Tetrahedron Lett. 1969, 10, 3295-3296. doi:10.1016/S0040-4039(01)88413-6

172.Dastan, A.; Saracoglu, N.; Balci, M. Eur. J. Org. Chem. 2001, 3519-3522. doi:10.1002/1099-0690(200109)2001:18<3519::AID-EJOC3519>3.0.C $0 ; 2-2$

173.Arican, D.; Brückner, R. Org. Lett. 2013, 15, 2582-2585. doi:10.1021/ol400510j

174.Nozoe, T.; Kitahara, Y.; Ando, T. Proc. Jpn. Acad. 1951, 27, 107-109.

175. Ebine, S. Bull. Chem. Soc. Jpn. 1965, 38, 2029-2034. doi:10.1246/bcsj.38.2029

176. Yoshioka, M.; Saito, I.; Hoshino, M.; Ebine, S. J. Chem. Soc. D 1970, 782. doi:10.1039/c29700000782

177. Nishina, N.; Mutai, T.; Aihara, J.-i. J. Phys. Chem. A 2017, 121, 151-161. doi:10.1021/acs.jpca.6b11684

178. Buchanan, G. L. J. Chem. Soc. 1954, 1060-1063. doi:10.1039/jr9540001060

179.Buchanan, G. L.; Sutherland, J. K. J. Chem. Soc. 1956, 2620-2628. doi:10.1039/jr9560002620

180.Saraf, S. D. Can. J. Chem. 1969, 47, 1169-1171. doi:10.1139/v69-190

181.Saxena, M. K.; Bokadia, J. J. Indian Chem. Soc. 1969, 66, 855-856.

182. Namboothiri, I. N. N.; Balasubrahmanyam, S. N. Indian J. Chem., Sect. B 1993, 32B, 1029-1034.

183.Saraf, S. D. Synthesis 1971, 264. doi:10.1055/s-1971-35028

184.Parham, W. E.; Bolon, D. A.; Schweizer, E. E. J. Am. Chem. Soc. 1961, 83, 603-606. doi:10.1021/ja01464a026
185. Uyehara, T.; Ichida, A.; Funamizu, M.; Nanbu, H.; Kitahara, Y. Bull. Chem. Soc. Jpn. 1979, 52, 273-274. doi:10.1246/bcsj.52.273 186. Moncur, M. V.; Grutzner, J. B. J. Chem. Soc., Chem. Commun. 1972, 667-668. doi:10.1039/c39720000667

187. Ebine, S.; Hoshino, M.; Machiguchi, T. Bull. Chem. Soc. Jpn. 1971, 44, 3480-3481. doi:10.1246/bcsj.44.3480

188. Yildiz, Y. K.; Seçen, H.; Krawiec, M.; Watson, W. H.; Balci, M. J. Org. Chem. 1993, 58, 5355-5359. doi:10.1021/jo00072a016

189. Woods, M. C.; Ebine, S.; Hoshino, M.; Takahashi, K.; Miura, I. Tetrahedron Lett. 1969, 10, 2879-2982. doi:10.1016/S0040-4039(01)88297-6

190.Dastan, A.; Yildiz, Y. K.; Balci, M. Turk. J. Chem. 2002, 26, 143-151. 191.Suzuki, Y. Iwate Daigaku Gakugei Kenkyu Nempo 1964, 24, 5-10.

192. Iriarte, J.; Camargo, C.; Crabbé, P. J. Chem. Soc., Perkin Trans. 1 1980, 2077-2080. doi:10.1039/P19800002077

193.Beng, T. K.; Sincavage, K.; Silaire, A. W. V.; Alwali, A.; Bassler, D. P.; Spence, L. E.; Beale, O. Org. Biomol. Chem. 2015, 13, 5349-5353. doi:10.1039/C5OB00517E

194. Hoshino, M.; Ebine, S. Bull. Chem. Soc. Jpn. 1968, 41, 2949-2953. doi:10.1246/bcsj.41.2949

195. Ebine, S. Bull. Chem. Soc. Jpn. 1962, 35, 114-117. doi:10.1246/bcsj.35.114

196. Ebine, S. Bull. Chem. Soc. Jpn. 1961, 34, 887. doi:10.1246/bcsj.34.887

197.Fernholz, H.; Hartwig, E.; Salfeld, J.-C. Justus Liebigs Ann. Chem. 1952, 576, 131-146. doi:10.1002/jlac. 19525760209

198. Ebine, S. Bull. Chem. Soc. Jpn. 1962, 35, 117-121. doi:10.1246/bcsj.35.117

199. Ebine, S. Bull. Chem. Soc. Jpn. 1962, 35, 122-124. doi:10.1246/bcsj.35.122

200.Stiles, M.; Libbey, A. J., Jr. J. Org. Chem. 1957, 22, 1243-1246. doi:10.1021/jo01361a032

201.Bergmann, E. D.; Klein, J. J. Org. Chem. 1958, 23, 512-517. doi:10.1021/jo01098a002

202. Tochtermann, W.; Oppenlaender, K.; Walter, U. Chem. Ber. 1964, 97 , 1329-1336. doi:10.1002/cber.19640970516

203.Shukla, D.; Lukeman, M.; Shi, Y.; Wan, P. J. Photochem. Photobiol., A 2002, 154, 93-105. doi:10.1016/S1010-6030(02)00311-8

204. Choi, J.; Jung, H.; Yeo, J.-E.; Koo, S. Synthesis 2015, 47, 2957-2960. doi:10.1055/s-0034-1381045

205. Papaianina, O.; Amsharov, K. Y. Chem. Commun. 2016, 52, 1505-1508. doi:10.1039/C5CC08747C

206. Luisa, M.; Franco, T. M. B.; Celina, M.; Lazana, R. L. R.; Herold, B. J. J. Chem. Soc., Perkin Trans. 2 1990, 513-520. doi:10.1039/P29900000513

207. Nogradi, M. Acta Chim. Acad. Sci. Hung. 1978, 96, 393-904.

208. Tochtermann, W.; Schnabel, G.; Mannschreck, A. Justus Liebigs Ann. Chem. 1967, 705, 169-184. doi:10.1002/jlac.19677050120

209. Tochtermann, W.; Küppers, H.; Franke, C. Chem. Ber. 1968, 101, 3808-3815. doi:10.1002/cber.19681011121

210. Udayakumar, B. S.; Schuster, G. B. J. Org. Chem. 1993, 58, 4165-4169. doi:10.1021/jo00067a068

211. Taljaard, B.; Taljaard, J. H.; Imrie, C.; Caira, M. R. Eur. J. Org. Chem. 2005, 2607-2619. doi:10.1002/ejoc.200400754

212. Weber, E.; Doerpinghaus, N.; Csöregh, I. J. Chem. Soc., Perkin Trans. 2 1990, 2167-2177. doi:10.1039/P29900002167 
213.Adams, T. C.; Dupont, A. C.; Carter, J. P.; Kachur, J. F.; Guzewska, M. E.; Rzeszotarski, W. J.; Farmer, S. G.; Noronha-Blob, L.; Kaiser, C. J. Med. Chem. 1991, 34, 1585-1593. doi:10.1021/jm00109a010

214.Luo, J.; Song, K.; Gu, F. I.; Miao, Q. Chem. Sci. 2011, 2, 2029-2034. doi:10.1039/c1sc00340b

215. Tochtermann, W. Angew. Chem. 1963, 75, 418-419. doi:10.1002/ange.19630750908

216.Kudoh, M.; Satoh, T.; Ikeda, H.; Nakazawa, T.; Miyashi, T.; Katagiri, S.; Sudoh, S. Bull. Chem. Soc. Jpn. 2009, 82, 70-75. doi:10.1246/bcsj.82.70

217. Inuzuka, K.; Yokota, T. J. Mol. Spectrosc. 1966, 21, 272-279. doi:10.1016/0022-2852(66)90150-0

218. Hagen, R.; Heilbronner, E.; Straub, P. A. Helv. Chim. Acta 1967, 50, 2504-2520. doi:10.1002/hlca.19670500837

219.Dewar, M. J. S.; Trinajstic, N. Croat. Chem. Acta 1970, 42, 1-12.

220.Ohkita, M.; Sano, K.; Suzuki, T.; Tsuji, T.; Sato, T.; Niino, H. Org. Biomol. Chem. 2004, 2, 1044-1050. doi:10.1039/B400080N

221. Ohkita, M.; Sano, K.; Suzuki, T.; Tsuji, T. Tetrahedron Lett. 2001, 42, 7295-7297. doi:10.1016/S0040-4039(01)01496-4

222. Elad, D.; Ginsburg, D. J. Chem. Soc. 1957, 1286-1289. doi:10.1039/jr9570001286

223. Ginsburg, D.; Pappo, R. J. Am. Chem. Soc. 1953, 75, 1094-1097. doi:10.1021/ja01101a025

224. Treibs, W.; Herdmann, G. Justus Liebigs Ann. Chem. 1957, 609, 70-74. doi:10.1002/jlac.19576090107

225. Naville, G.; Strauss, H.; Heilbronner, E. Helv. Chim. Acta 1960, 43, 1221-1243. doi:10.1002/hlca.19600430508

226. Fujise, Y.; Saito, H.; Itô, S. Tetrahedron Lett. 1976, 17, 1117-1120. doi:10.1016/S0040-4039(00)93766-3

227. Hayakawa, K.; Hori, N.; Kanematsu, K. Chem. Pharm. Bull. 1983, 31 , 1809-1811. doi:10.1248/cpb.31.1809

228. Balci, M.; Winchester, W. R.; Jones, W. M. J. Org. Chem. 1982, 47, 5180-5186. doi:10.1021/jo00147a028

229. Fieser, L. F.; Gates, M. D., Jr. J. Am. Chem. Soc. 1940, 62, 2335-2341. doi:10.1021/ja01866a021

230.Bardhan, J. C.; Nasipuri, D.; Adhya, R. N. J. Chem. Soc. 1956, 355-358. doi:10.1039/JR9560000355

231. Julia, S.; Bonnet, Y. Bull. Soc. Chim. Fr. 1957, 1340-1347.

232. Naya, S.-i.; Ohtoshi, H.; Nitta, M. J. Org. Chem. 2006, 71, 176-184. doi:10.1021/jo051777j

233. Hackenberger, A.; Dürr, H. Chem. Ber. 1984, 117, 2644-2659. doi:10.1002/cber.19841170808

234. Hackenberger, A.; Dürr, H. Tetrahedron Lett. 1979, 20, 4541-4544. doi:10.1016/S0040-4039(01)86644-2

235. Jang, D. J.; Kelley, D. F. J. Phys. Chem. 1985, 89, 209-211. doi:10.1021/j100248a004

236.Jang, D. J. Bull. Korean Chem. Soc. 1991, 12, 441-444.

237. L'Haridon, P. L.; Maunaye, M.; Soyer, N. Acta Crystallogr., Sect. B 1976, 32, 170-175. doi:10.1107/S0567740876002537

238. Föhlisch, B.; Widmann, E. Z. Naturforsch. 1969, 24, 464-465.

239. Soyer, N.; Kerfanto, M. Comptes Rendus 1972, 275, 901-904.

240.Kato, M.; Mitsuda, M.; Shibuya, T.; Furuchi, K. Bull. Chem. Soc. Jpn. 1991, 64, 2081-2087. doi:10.1246/bcsj.64.2081

241.Agranat, I.; Avnir, D. J. Chem. Soc., Perkin Trans. 11974 , 1155-1161. doi:10.1039/P19740001155

242.Bally, T.; Masamune, S. Tetrahedron 1980, 36, 343-370. doi:10.1016/0040-4020(80)87003-7

243. Maier, G. Angew. Chem., Int. Ed. Engl. 1988, 27, 309-332. doi:10.1002/anie. 198803093
244. Kiliç, H.; Balci, M.; Yurtsever, E. J. Org. Chem. 1997, 62, 3434-3435. doi:10.1021/jo970458s

245.McKee, M. L.; Balci, M.; Kilic, H.; Yurtsever, E. J. Phys. Chem. A 1998, 102, 2351-2356. doi:10.1021/jp972966b

246. Adam, W.; Balci, M.; Kiliç, H. J. Org. Chem. 1998, 63, 8544-8546. doi:10.1021/jo972308n

247.Lombardo, L.; Wege, D. Tetrahedron Lett. 1975, 16, 115-118. doi:10.1016/S0040-4039(00)72485-3

248. Lombardo, L.; McCulloch, R. K.; Wege, D. Aust. J. Chem. 1978, 31 , 1585-1605. doi:10.1071/CH9781585

249. McCulloch, R. K.; Wege, D. Tetrahedron Lett. 1976, 17, 3213-3216. doi:10.1016/S0040-4039(00)93883-8

250.Sato, M.; Ebine, S.; Tsunetsugu, J. J. Chem. Soc., Chem. Commun. 1974, 846-847. doi:10.1039/c39740000846

251.Sato, M.; Inaba, K.; Ebine, S.; Tsunetsugu, J. Bull. Chem. Soc. Jpn. 1980, 53, 2334-2339. doi:10.1246/bcsj.53.2334

252.Sato, M.; Fujino, H.; Ebine, S.; Tsunetsugu, J. Tetrahedron Lett. 1978, 19, 143-146. doi:10.1016/S0040-4039(01)85067-X

253.Sato, M.; Ebine, S.; Nishijima, K.; Tsunetsugu, J. Bull. Chem. Soc. Jpn. 1981, 54, 766-770. doi:10.1246/bcsj.54.766

254.Kawamata, A.; Kikuchi, E.; Hirama, M.; Fujise, Y.; Ito, S. Chem. Lett. 1979, 859-862. doi:10.1246/cl.1979.859

255. Hirama, M.; Koyama, Y.; Shoji, Y.; Itô, S. Tetrahedron Lett. 1978, 19, 2289-2292. doi:10.1016/S0040-4039(01)91515-1

256. Miloshev, M.; Aleksiev, B. C. R. Acad. Bulg. Sci. 1976, 29, 523-525.

257.Lucien, H. W.; Taurins, A. Can. J. Chem. 1952, 30, 208-223. doi:10.1139/v52-030

258. Minchev, S.; Stoyanov, N.; Aleksiev, B. C. R. Acad. Bulg. Sci. 1992, 45, 47-49.

259.Aleksiev, B.; Milošev, M. Monatsh. Chem. 1969, 100, 2024-2032. doi:10.1007/BF01151755

260. Rigaudy, J.; Nedelec, L. Bull. Soc. Chim. Fr. 1959, 4, 655-659.

261.Cheung, K. Y.; Xu, X.; Miao, Q. J. Am. Chem. Soc. 2015, 137, 3910-3914. doi:10.1021/jacs.5b00403

\section{License and Terms}

This is an Open Access article under the terms of the Creative Commons Attribution License (http://creativecommons.org/licenses/by/4.0), which permits unrestricted use, distribution, and reproduction in any medium, provided the original work is properly cited.

The license is subject to the Beilstein Journal of Organic Chemistry terms and conditions:

(https://www.beilstein-journals.org/bjoc)

The definitive version of this article is the electronic one which can be found at: $\underline{\text { doi: } 10.3762 / \text { bjoc. } 14.98}$ 